\title{
SARS-CoV-2 infects and replicates in cells of the human endocrine and exocrine pancreas
}

\author{
Janis A. Müller ${ }^{1,20}$, Rüdiger Groß ${ }^{1,20}$, Carina Conzelmann ${ }^{1,20}$, Jana Krüger ${ }^{2,20}$, Uta Merle ${ }^{3}$,

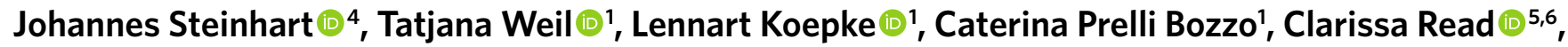 \\ Giorgio Fois $\mathbb{D}^{7}$, Tim Eiseler ${ }^{2}$, Julia Gehrmann ${ }^{10}{ }^{8}$, Joanne van Vuuren ${ }^{9,10,11,12}$, Isabel M. Wessbecher (1) ${ }^{13}$, \\ Manfred Frick $\mathbb{1}^{7}$, Ivan G. Costa $\mathbb{1}^{8}$, Markus Breunig ${ }^{(12}{ }^{2}$, Beate Grüner ${ }^{14}$, Lynn Peters ${ }^{14}$, \\ Michael Schuster ${ }^{15}{ }^{15}$, Stefan Liebau ${ }^{16}$, Thomas Seufferlein ${ }^{2}$, Steffen Stenger ${ }^{17}$, Albrecht Stenzinger ${ }^{18}$, \\ Patrick E. MacDonald ${ }^{19}$, Frank Kirchhoff', Konstantin M. J. Sparrer (D) ', Paul Walther ${ }^{5}$,

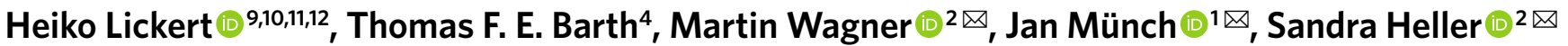 \\ and Alexander Kleger $\mathbb{B D}^{2} \otimes$
}

Infection-related diabetes can arise as a result of virus-associated $\beta$-cell destruction. Clinical data suggest that the severe acute respiratory syndrome coronavirus 2 (SARS-CoV-2), causing the coronavirus disease 2019 (COVID-19), impairs glucose homoeostasis, but experimental evidence that SARS-CoV-2 can infect pancreatic tissue has been lacking. In the present study, we show that SARS-CoV-2 infects cells of the human exocrine and endocrine pancreas ex vivo and in vivo. We demonstrate that human $\beta$-cells express viral entry proteins, and SARS-CoV-2 infects and replicates in cultured human islets. Infection is associated with morphological, transcriptional and functional changes, including reduced numbers of insulin-secretory granules in $\beta$-cells and impaired glucose-stimulated insulin secretion. In COVID-19 full-body postmortem examinations, we detected SARS-CoV-2 nucleocapsid protein in pancreatic exocrine cells, and in cells that stain positive for the $\beta$-cell marker NKX6.1 and are in close proximity to the islets of Langerhans in all four patients investigated. Our data identify the human pancreas as a target of SARS-CoV-2 infection and suggest that $\beta$-cell infection could contribute to the metabolic dysregulation observed in patients with COVID-19.

\begin{abstract}
nitially, the pandemic COVID-19, caused by SARS-CoV-2, was considered to be an exclusive lung disease, eventually leading to serious respiratory symptoms ${ }^{1}$. In the meantime, accumulating experimental and clinical studies have suggested that SARS-CoV-2 may also cause lesions in the kidneys, heart, brain, and gastrointestinal and endocrine organs ${ }^{2-7}$. SARS-CoV-2 tropism towards distinct tissues is governed by cellular factors expressed on target cells such as the viral entry receptor angiotensin-converting enzyme 2 (ACE2) ${ }^{8}$ and the transmembrane serine protease 2 (TMPRSS2) ${ }^{8}$. ACE2 messenger $\mathrm{RNA}^{9-13}$ and protein ${ }^{12-14}$ expression within the islets of Langerhans has been reported, but not yet been shown, to allow SARS-CoV-2 entry ${ }^{9,12,15}$. Diabetes mellitus presents Janus like in COVID-19 (refs. ${ }^{3,16}$ ): first, pre-existing diabetes is a highly prevalent comorbidity observed in $11-22 \%$ of patients and as such increases the risk of a severe disease, requiring more intense interventions
\end{abstract}

and increasing mortality ${ }^{17-22}$. Second, SARS-CoV-2 infection seems to affect the exocrine pancreas, manifesting as pancreatitis in $32.5 \%$ of critically ill patients ${ }^{23}$, and pancreatic enlargement and abnormal amylase or lipase levels in $7.5-17 \%$ of patients ${ }^{9,22}$. Third, metabolic dysregulation has been observed in patients with COVID-19 as: (1) increased hyperglycaemia in patients with type 2 diabetes $^{24}$; (2) ketoacidosis in $2-6.4 \%$ of diabetic and non-diabetic patients ${ }^{18,25}$; and (3), in case studies reporting ketoacidosis on SARS-CoV-2 infection, accompanied by (4) new-onset type 1 diabetes mellitus (T1DM) in the absence of autoantibodies ${ }^{26-28}$. In a cohort study of patients with diabetes, hyperglycaemia was reported in more than $50 \%$ of all cases, and almost a third experienced diabetic ketoacidosis $^{29}$. Finally, a multicentre study found an $80 \%$ increase of new-onset T1DM in children during the COVID-19 pandemic ${ }^{30}$. In accordance, a recent meta-analysis summarizes that severe

'Institute of Molecular Virology, Ulm University Medical Center, Ulm, Germany. ${ }^{2}$ Department of Internal Medicine 1, Ulm University Hospital, Ulm, Germany. ${ }^{3}$ Department of Internal Medicine 4, University of Heidelberg, Heidelberg, Germany. ${ }^{4}$ Department of Pathology, Ulm University Hospital, Ulm, Germany. ${ }^{5}$ Central Facility for Electron Microscopy, Ulm University, Ulm, Germany. ${ }^{6}$ Institute of Virology, Ulm University Medical Center, Ulm, Germany. ${ }^{7}$ Institute of General Physiology, Ulm University, Ulm, Germany. ${ }^{8}$ Institute for Computational Genomics, RWTH Aachen University, Aachen, Germany. ${ }^{9}$ Institute of Diabetes and Regeneration Research, Helmholtz Zentrum München, Neuherberg, Germany. ${ }^{10}$ Institute of Stem Cell Research, Helmholtz Zentrum München, Neuherberg, Germany. "'German Center for Diabetes Research (DZD), Neuherberg, Germany. ${ }^{12}$ School of Medicine, Technical University of Munich, Munich, Germany. ${ }^{13}$ Tissue Bank of the German Center for Infection Research, Institute of Pathology, Heidelberg University Hospital, Heidelberg, Germany. ${ }^{14}$ Department of Internal Medicine 3, Ulm University Hospital, Ulm, Germany. ${ }^{15}$ CeMM Research Center for Molecular Medicine of the Austrian Academy of Sciences, Vienna, Austria. ${ }^{16}$ Institute of Neuroanatomy \& Developmental Biology, Eberhard Karls University Tübingen, Tübingen, Germany. ${ }^{17}$ Institute for Microbiology and Hygiene, Ulm University Medical Center, Ulm, Germany. ${ }^{18}$ Institute of Pathology, University Hospital Heidelberg, Heidelberg, Germany. ${ }^{19}$ Alberta Diabetes Institute and Department of Pharmacology, University of Alberta, Edmonton, Canada. ${ }^{20}$ These authors contributed equally: Janis A. Müller, Rüdiger Groß, Carina Conzelmann, Jana Krüger. ${ }^{凶}$-mail: martin.wagner@uniklinik-ulm.de; jan.muench@uni-ulm.de; sandra.heller@uni-ulm.de; alexander.kleger@uni-ulm.de 
COVID-19 is associated with increased blood glucose levels ${ }^{31}$. However, the formal proof of SARS-CoV- 2 as a $\beta$-cell tropic virus, potentially leading to diabetes, is still missing, and the only correlative evidence stands in the light of conflicting experimental and clinical findings ${ }^{13,22,32-34}$. Prospectively collected acute and long-term outcomes on new-onset diabetes cases, together with thoughtful interpretations of emerging data up to final clarification of this debate, are warranted ${ }^{33}$.

Accordingly, it is unclear whether and how SARS-CoV-2 might trigger $\beta$-cell injury, but it may occur via either immune-mediated $\beta$-cell ablation or direct perturbation of $\beta$-cell function, both eventually leading to so-called infection-related diabetes according to the current World Health Organization (WHO) classification ${ }^{35}$. Recent evidence suggests that SARS-CoV-2 can infect human endocrine cells in vitro ${ }^{12,36}$. However, this finding was obtained with stem-cell-derived, immature human $\beta$-cells that express ACE2 and TMPRSS2, and viral replication or impact on $\beta$-cell function has not been analysed in detail ${ }^{36}$. ACE2 or TMPRSS2 expression was also detected in exocrine and endocrine cells in human pancreatic tissue; however, varying expression patterns across distinct pancreatic cell types were reported ${ }^{9,10,12-15,34,36-38}$. Thus, it is imperative to clarify whether human pancreatic endocrine cells organized within an islet of Langerhans are permissive for and affected by SARS-CoV-2 infection, and to elucidate the mechanisms underlying a potential endocrine dysfunction associated with COVID-19 (refs. ${ }^{16,21,22,36}$ ).

In the present study, we (1) defined ACE2 and TMPRSS2 expression patterns in human pancreatic endocrine and exocrine cell types, (2) employed human pancreatic islet cultures to demonstrate susceptibility to SARS-CoV-2 infection and viral replication in $\beta$-cells and (3) showed that SARS-CoV-2 infection affects glucose-stimulated insulin secretion (GSIS). In addition, we (4) visualized viral particles replicating in endocrine pancreatic cells and defined their subcellular localization patterns and finally (5) presented examples of multiorgan infection patterns including the pancreata of patients who died from COVID-19.

\section{Results}

ACE2 and TMPRSS2 expression in endocrine cells and a ductal subpopulation. As pancreatic ACE2 and TMPRSS2 expression is currently under debate $e^{12,13,34,37}$, we initiated our validation analysis with two reference antibodies (ab15348 and ab92323, Abcam; Extended Data Fig. 1), which have been previously extensively characterized in immunofluorescence and immunohistochemistry studies (ACE2 (refs. ${ }^{12,36,39-42}$ ) and TMPRSS2 (refs. ${ }^{43-47}$ )). First, quantitative PCR (qPCR) analysis of ACE2 and TMPRSS2 in human lung Calu- 3 cells and EndoC- $\beta \mathrm{H} 1$ cells, a model of human $\beta$-cells ${ }^{48}$, was performed and revealed detectable RNA levels of both viral entry proteins (Extended Data Fig. 2a). Immunoblotting confirmed detection of the correct molecular mass of $\sim 110 / 120 \mathrm{kDa}$ and recently reported ${ }^{12,49}$ short $50-\mathrm{kDa}$ isoforms of endogenous ACE2 in both cell types (Extended Data Fig. 2b). We found all isoforms of ACE2 to be expressed in fresh-frozen human pancreatic tissue comprising exocrine and endocrine cell types (Extended Data Fig. 2b). Similarly, the TMPRSS2 antibody detected proteins of $54 \mathrm{kDa}$ and $26 \mathrm{kDa}$, consistent with glycosylated forms of full-length TMPRSS2 and the cleaved serine protease domain, as previously reported ${ }^{50}$ (Extended Data Fig. 2c). Notably, ACE2 and TMPRSS2 expression of the different isoforms varied across participants (Extended Data Fig. 2b,c), in line with previous findings ${ }^{12}$. Immunofluorescence imaging revealed similar staining patterns for ACE2 or TMPRSS2 expression in differentiated air-liquid interface cultures of primary human airway epithelial cells (HAECs) ${ }^{51}$ as well as in EndoC- $\beta \mathrm{H} 1$ cells (Extended Data Fig. 2 d,e). Preincubation of the employed anti-ACE2 antibody with an epitope-matching blocking peptide abrogated ACE2 detection in EndoC- $\beta \mathrm{H} 1$ cells (Extended Data Fig. 2e).
After validation of antibody specificity, we imaged ACE2 and TMPRSS2 expression in tissue sections derived from five histologically healthy human pancreata. Fluorescence staining of both SARS-CoV-2 entry factors was observed in the islets of Langerhans in all samples (Fig. 1a,c, and Extended Data Figs. 3 and 4). Strong ACE2 expression was detected in endothelial cells (Extended Data Fig. 3a-c, white arrowheads) and in a subpopulation of cytokeratin 19 (CK19)-positive ductal cells (Extended Data Fig. 3d). Moderate ACE2 signals were observed in endocrine cells (Fig. 1a and Extended Data Fig. 3a-c) and detection was prevented by the ACE2-blocking peptide during immunostaining (Extended Data Fig. 3e). ACE2 was only faintly expressed in GATA-binding protein 4-positive acinar cells (Extended Data Fig. 3f). Similarly, TMPRSS2 was detected in the endocrine compartment (Fig. 1c and Extended Data Fig. 4a-c) and in some ducts (Extended Data Fig. 4d). TMPRSS2 expression in acinar cells was barely detectable (Extended Data Fig. 4e). Co-staining for endocrine cell types and viral entry proteins revealed a heterogeneous staining pattern across the five donors with varying coefficients (Fig. 1b,d). The highest coefficients were found for C-peptide (C-pep)-positive $\beta$-cells co-stained for ACE2 (mean: 0.40 (minimum-maximum: 0.22-0.78) and TMPRSS2 (mean: 0.73 (minimum-maximum: $0.59-0.86)$ ) (Fig. 1b,d). The $\alpha$ - and $\delta$-cells expressing either glucagon (GCG) or somatostatin (SST), respectively, revealed a smaller ACE2 (mean: 0.15 (minimum-maximum: 0.07-0.23); mean: 0.18 (minimum-maximum: 0.04-0.35)) or TMPRSS2 (mean: 0.12 (minimum-maximum: 0.01-0.28); mean: 0.17 (minimum-maximum: 0.03-0.42)) double-positive fraction with less variance across the five patients (Fig. 1b,d). Thus, pancreatic exocrine and endocrine cells express SARS-CoV-2 entry factors.

SARS-CoV-2 replicates in human pancreatic islets. To determine the susceptibility to ex vivo infection, human pancreatic islets isolated from four human donors were exposed to SARS-CoV-2, and expression of viral spike $(\mathrm{S})$ and nucleocapsid $(\mathrm{N})$ protein, as well as endocrine cell markers, was analysed. $\mathrm{S}$ and $\mathrm{N}$ proteins were not detected at day 1 (not shown), but became readily detectable at days 3 (Fig. 2a) and 5 (Fig. 2b) post-infection (Extended Data Fig. 5). Pancreatic islets treated with $5 \mu \mathrm{M}$ remdesivir, a polymerase inhibitor with potent in vitro anti-SARS-CoV-2 activity ${ }^{52}$, did not stain positive for $\mathrm{S}$ or $\mathrm{N}$ proteins, indicating suppression of SARS-CoV-2 replication. Quantification of viral N-protein expression in infected islets confirmed robust infection ranging between $20 \% \mathrm{~N}$-positive cells at day 3 and $34 \%$ at day 5 per infected islet (Fig. 2c). Only a few cells stained positive for cleaved caspase 3 (CASP3) across all conditions, suggesting no increased apoptosis at this stage (Fig. 2a,b). Although some cells exhibited double positivity for the pancreatic hormones C-pep/chromogranin A and the viral N/S proteins, which was not observed for GCG and SST, most of the SARS-CoV-2-infected cells appeared to lack hormone expression (Fig. 2a,b,d and Extended Data Fig. 5). Staining with non-endocrine markers such as the endothelial marker platelet endothelial cell adhesion molecule (PECAM-1, CD31), the ductal marker CK19 or the acinar marker chymotrypsin revealed only scattered positive cells in pancreatic islet preparations, thus making the bias of the results due to preparation impurities unlikely (Extended Data Fig. 6). To probe lineage identity of infected cells, we stained for pancreatic and duodenal homoeobox 1 (PDX1) and NKX6.1, both markers mostly labelling endocrine cells in the adult pancreas ${ }^{53-55}$, and found that infected hormone-negative cells were still positive for PDX1 or NKX6.1, suggesting that they are endocrine cells that lose hormones upon infection (Fig. 2d). Quantification of N/NKX6.1 double-positive cells per infected islet of donor 3 at day 5 post-infection revealed that approximately $21 \%$ of putative $\beta$-cells were infected (Extended Data Fig. 6d,e). A more definite quantification was impeded by the amount of analysable material 
a
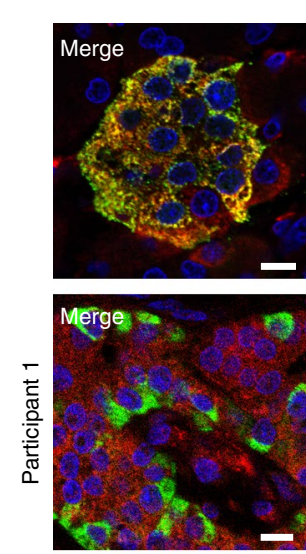

Pancreatic tissue (healthy)
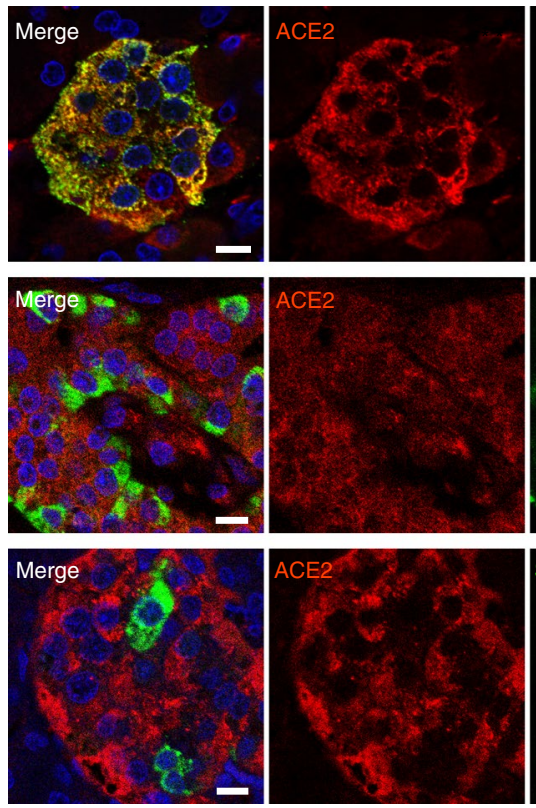

C

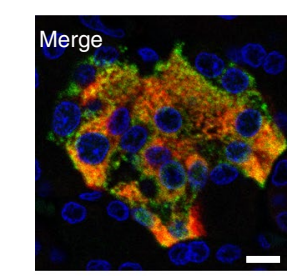

Pancreatic tissue (healthy)
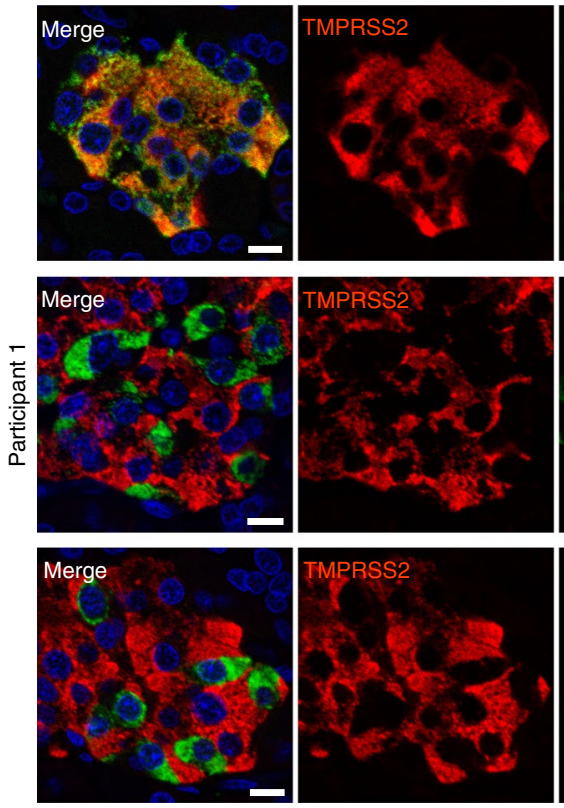
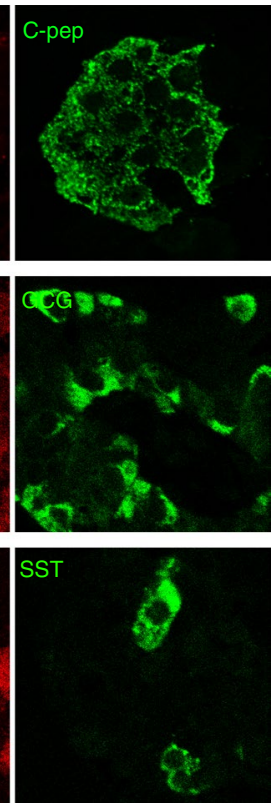

\section{b}

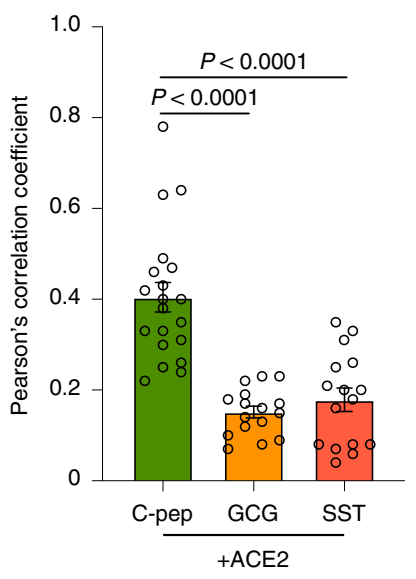

d
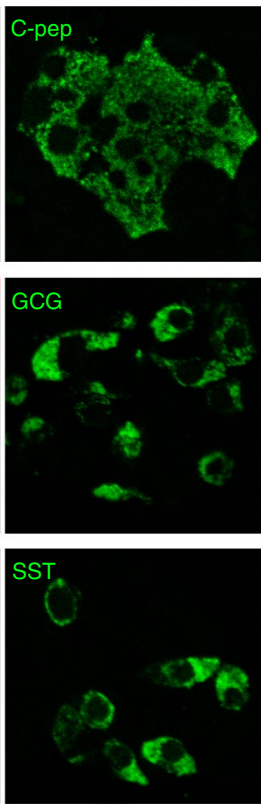

Fig. 1 | Pancreatic $\boldsymbol{\beta}$-cells express SARS-CoV-2 entry factors ACE2 and TMPRSS2. a,c, Adult pancreatic tissue sections from five healthy participants, stained with antibodies against ACE2 (a; red) or TMPRSS2 (c; red), and C-pep (green), GCG (green) or SST (green). Cell nuclei were visualized using DAPI (blue). Representative confocal sections of participant 1 are shown; for participants 2-5, see Extended Data Figs. 3 and 4 . Scale bars, 10 $\mu$ m. b,d, Colocalization of cell-specific markers C-pep, GCG or SST with ACE2 (b) or TMPRSS2 (d) was analysed using Pearson's correlation coefficients and Fiji. Numbers of investigated healthy human pancreata were as follows: ACE2/C-pep: $n=5$; TMPRSS2/C-pep: $n=4$; ACE2/SST or GCG: $n=4$; TMPRSS2/SST or GCG: $n=4$. Four different islets of Langerhans were analysed per patient. Data are presented as mean \pm s.e.m. quantified for each participant and staining combination. Ordinary one-way analysis of variance (ANOVA) with Tukey's post-test was used.

and the fact that N/S-positive cells of the endocrine lineage appear to be insulin negative on infection. However, increasing intra- and extracellular viral RNA levels of the islets in the absence of remdesivir indicate progressive viral replication (Fig. 2e,f). Productive viral replication in islets of all donors was confirmed by increasing infectious viral titres in the respective supernatants (Fig. 2g). On remdesivir treatment, almost no infectious virus was detected in the supernatants of islets (Fig. 2g), indicating efficient inhibition.
This is in line with low viral RNA levels (Fig. 2e,f) and the absence of $\mathrm{N}$ or $\mathrm{S}$ protein in confocal microscopy analyses (Fig. 2a,b and Extended Data Fig. 5) in the presence of remdesivir. Thus, pancreatic islets are susceptible to SARS-CoV-2 infection, which can be inhibited by remdesivir.

SARS-CoV-2-infected endocrine cells show subcellular and functional changes. Infection of endocrine cells by SARS-CoV-2 
was further analysed using transmission electron microscopy (TEM). Pancreatic islets from human organ donors 2 and 3 were infected with SARS-CoV-2 and analysed after 3 and $5 \mathrm{~d}$ ex vivo culture (Fig. 3a and Extended Data Fig. 7). Infection of islet cells with SARS-CoV-2 resulted in dilatation and vacuolization of the endoplasmic reticulum (ER)-Golgi apparatus complex, a finding suggestive of ER stress and Golgi body swelling ${ }^{56-58}$. These vacuoles contained viral particles showing coronavirus morphology ${ }^{56-58}$, indicating productively infected endocrine cells. The virion-containing vesicles were formed in the perinuclear region and processed to the cell surface. Furthermore, infection occurred in cells containing secretory vesicles that seemed to be enlarged and maintained in the perinuclear region (Fig. 3a). Granule numbers per cell in infected islets were decreased by 2.2 -fold on day 3 (Fig. 3 b) and 2.4-fold on day 5 (Fig. 3 c) post-infection. In contrast, we did not detect intracellular viral particles and observed fewer morphological alterations in remdesivir-treated islet cells (Fig. 3a and Extended Data Fig. 7a). Thus, SARS-CoV-2 behaved in human endocrine cells similar to previously reported TEM phenotypes of infected lungand gut-derived cells ${ }^{5-58}$. To analyse whether SARS-CoV-2 infection and associated subcellular changes of the islets affect function, we assessed the islet response towards a high glucose pulse. We found that GSIS was induced in all conditions, but the magnitude of induction from low to high glucose was reduced in infected islets (Fig. 3d,e). Of note, overall glucose responsiveness was lower in two-islet preparations, and varied between preparations, most probably due to the limitations of prolonged ex vivo culture. These data corroborate that SARS-CoV-2 replicates in endocrine cells and suggest that infection may affect glucose-dependent insulin secretion in pancreatic islets. However, to obtain more definite conclusions more islet preparations will be necessary.

Transcriptional changes in human islets after SARS-CoV-2 infection. To assess potential transcriptional changes induced by SARS-CoV-2, we performed bulk RNA-sequencing (Smart-Seq2) of uninfected and infected (with or without remdesivir), cultured human islets from two donors in an explorative analysis. First, respective transcriptomes obtained $5 \mathrm{~d}$ post-infection were clustered. Most of the sample variance was determined by the two islet preparations differing also in the donor sex (Fig. 4a). However, transcriptomes from SARS-CoV-2-infected cells clearly separated from uninfected counterparts, whereas remdesivir treatment resulted in intermediate clustering (Fig. 4a). Among the top upregulated genes in SARS-CoV-2-infected islets were several interferon (IFN)-stimulated genes (ISGs) such as IFITMs ${ }^{59}$, OAS2, IFI27 and ISG15, whereas genes linked to $\beta$-cell physiology or diabetes ${ }^{59-65}$, such as SYT4, PASK, PEX6 and PLCXD3, were significantly downregulated (Fig. 4b). Of note, ISGs were upregulated not only after SARS-CoV-2 infection, as compared with uninfected cases, but also in remdesivir-treated islets (Fig. 4c). Gene ontology (GO) term analysis confirmed an initiation of a transcriptional cellular defence reaction in response to SARS-CoV-2 infection. Terms such as 'defence response to virus' and 'regulation of viral genome replication' were strongly upregulated after SARS-CoV-2 infection (Fig. 4d). Comparing SARS-CoV-2 infection with remdesivir-treated infected cultures revealed a similar but less pronounced enrichment of INF-related terms such as 'IFN $\alpha / \beta$ signaling' and 'type I IFN signaling pathway', indicating a partial reversion of transcriptional changes (Fig. 4f). A similar pattern was observed when focusing on COVID-19-related disease terms (Fig. 4e,g). Gene set enrichment analysis (GSEA) further confirmed the enrichment of IFN signaling in SARS-CoV-2-infected islets against uninfected and remdesivir-treated infected islets (Fig. $4 \mathrm{~h}-\mathrm{k}$ ). In addition, a trend indicating loss of $\beta$-cell identity, as revealed by several gene sets ${ }^{66}$, as well as defects in protein secretion in virally infected islets, could be detected (Fig. $4 \mathrm{~h}-\mathrm{k}$ ). Vice versa, these defects were attenuated on remdesivir treatment, indicating that the observed changes are caused by SARS-CoV-2 infection, which is in accordance with our functional ex vivo experiments (Fig. 3). Thus, on a transcriptional level, infected islets show innate defence reactions and transcriptional changes indicative of loss of $\beta$-cell identity. Of note, viral infection and IFN type I response have been shown to trigger development of T1DM in individuals with genetic predisposition ${ }^{67-69}$. However, more studies with higher sample sizes will be necessary to confirm these conclusions.

Cross-organ and pancreatic infection during severe COVID-19. To examine whether the ex vivo observed infection of islets also naturally occurs in pancreatic tissue, we performed postmortem studies on four individuals who died from COVID-19 (Table 1). One patient was SARS-CoV-2 negative on admittance to the hospital but developed respiratory symptoms $4 \mathrm{~d}$ later, and consecutive SARS-CoV-2 tests revealed increasing viral RNA levels in analysed nasopharyngeal swabs (Fig. 5a). A past medical history included metformin-controlled type 2 diabetes, arterial hypertension and coronary artery disease (Table 1). Under conservative therapy, the patient rapidly deteriorated, accompanied by a progressive oxygen demand, and died due to respiratory failure $3 \mathrm{~d}$ after the onset of clinical symptoms (Fig. 5a). The other three patients had longer disease courses, ranging from 9 to $28 \mathrm{~d}$ of hospitalization and 6 to $24 \mathrm{~d}$ of ventilation before death (Table 1 ). One patient had diabetes and was taking oral medication and one had exocrine pancreatic insufficiency. These three patients developed acute kidney injury at various stages. In total, two patients died from respiratory failure, one from gastrointestinal bleeding and one from multiorgan failure (Table 1).

At the postmortem examination, we systematically stained different organs for viral SARS-CoV-2 $\mathrm{N}$ protein using two independent anti- $\mathrm{N}$ antibodies, validated for immunohistochemistry in a SARS-CoV-2 gut organoid model ${ }^{70}$ (Extended Data Fig. 8a). In patient 1 , we observed massive $\mathrm{N}$-protein staining in pneumocytes lining the alveolar space, as well as alveolar macrophages

Fig. 2 | SARS-CoV-2 productively infects human pancreatic islets. Human pancreatic islets were mock treated with medium or infected with SARS-CoV-2 and cultivated in the presence or absence of remdesivir $(5 \mu \mathrm{M})$. Displayed images represent three donors. $\mathbf{a}, \mathbf{b}$, Islets of donor 2 fixed $3 \mathrm{~d}$ (a) or $5 \mathrm{~d}$ (b) post-infection were stained for SARS-CoV-2 N protein (SARS-CoV-2 N, red), C-pep (green), cleaved CASP3 (white) and nuclei (DAPI, blue). Representative images are shown. Scale bars, $10 \mu \mathrm{m}$. c, Quantification of fraction of SARS-CoV-2 N-protein-positive cells in infected islets of donors 2 and 3 (see Extended Data Fig. 5 for donor 3 stainings). Data are presented as mean \pm s.e.m. from seven (day 3 ) and six (day 5) individual infected islets and from four uninfected islets (unpaired, two-sided, Student's $t$-test). d, Islets from donor 3 were infected and SARS-CoV-2-infected cells (SARS-CoV-2 N, red), $\beta$-cells (C-pep, green) and endocrine lineage cells (PDX1, blue) were visualized. Nuclei stained with DAPI are pseudo-coloured in white. Scale bar, $5 \mu \mathrm{m}$. SARS-CoV-2-infected cells frequently became hormone (C-pep) negative but remained lineage positive (PDX1). Uninfected cells remained double positive for C-pep and PDX1. e, Supernatants of islets (donors 1-4) were harvested over 5 d and SARS-CoV-2 ORF1b-nsp14 was quantified by qPCR. Data are presented as the mean values of two replicates. For each donor (Do), changes relative to day 0 (viral input RNA) are visualized. f, SARS-CoV-2 $\mathrm{N}$ was quantified in cellular RNA isolates of donors 2 and 3 at days 3 and 5 post-infection and normalized to GAPDH RNA. Data are presented as mean values of two replicates. $\mathbf{g}$, Supernatants of all four donors from e were assessed for infectivity by TCID $_{50}$ endpoint titration. Data are presented as the mean values of two replicates and the dotted line indicates the lower limit of quantification. 
resembling acute pneumonia with diffuse alveolar damage (Fig. 5b and Extended Data Fig. 8b), explaining the rapid death of this patient due to acute respiratory failure ${ }^{66}$. In addition, some epithelial cells of the kidney tubules and a few hepatocytes and chol- angiocytes stained $\mathrm{N}$-protein positive, whereas heart muscle, lymph nodes and the spleen showed no signs of SARS-CoV-2 infection (Fig. 5b and Extended Data Fig. 8b). No clear viral N-protein signal was detected in the lung tissues of the other three patients (Fig. $5 \mathrm{c}$

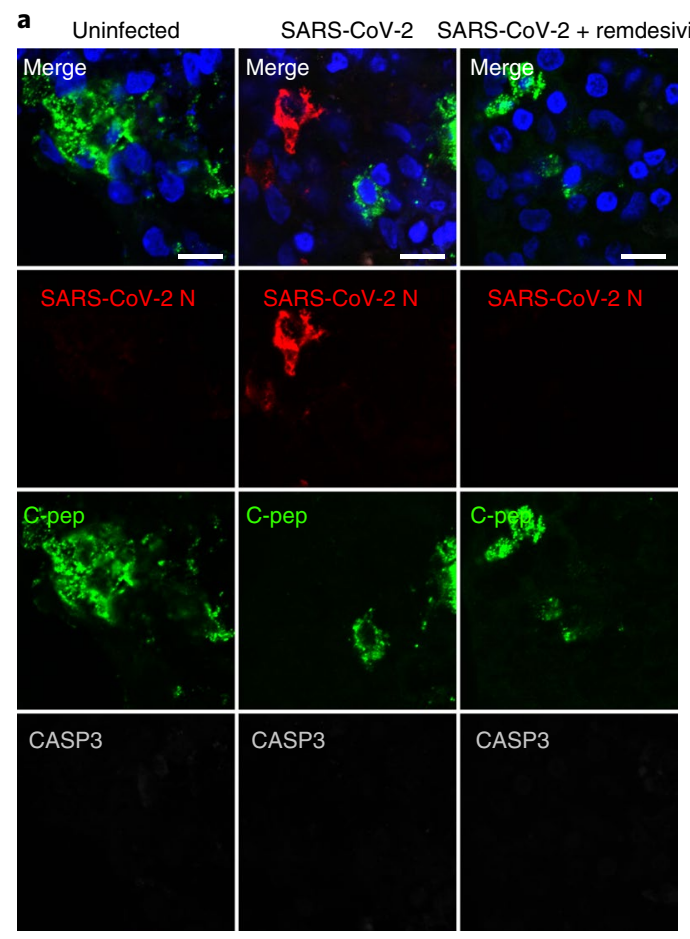

Day 3

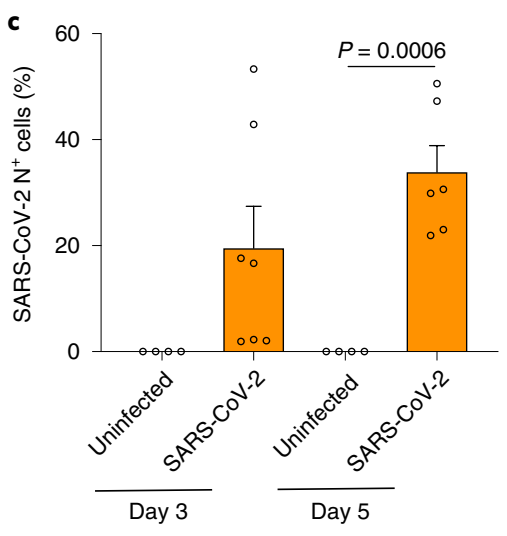

e

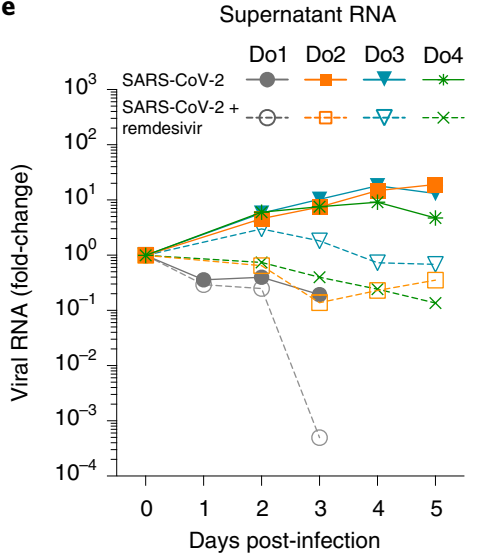

d

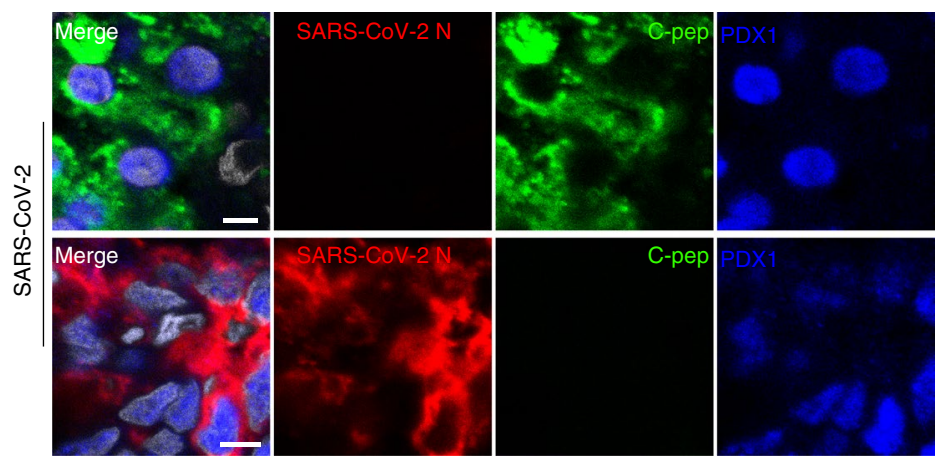

g

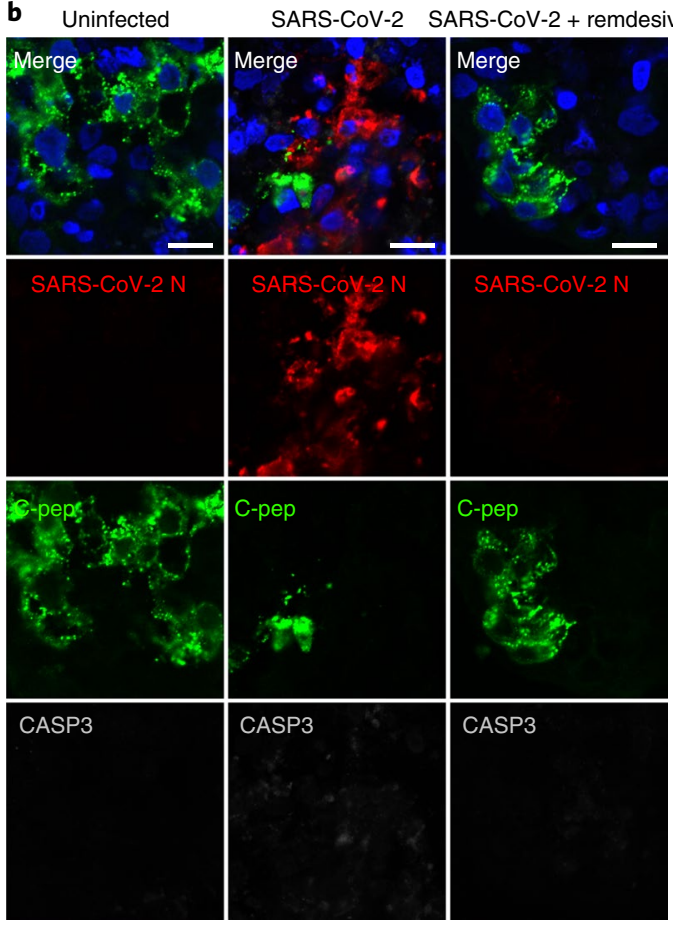

Day 5
Cellular RNA

$\mathbf{f}$

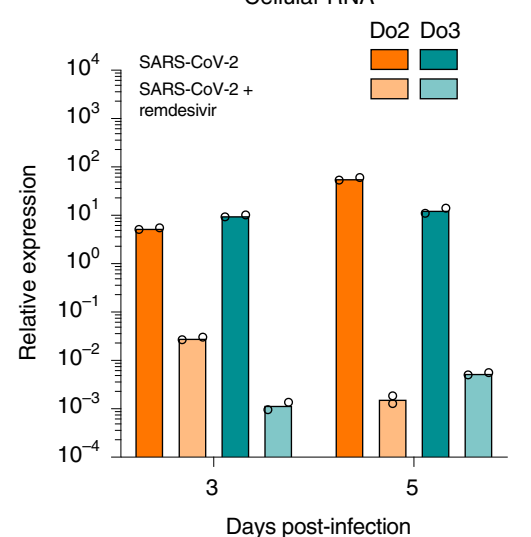

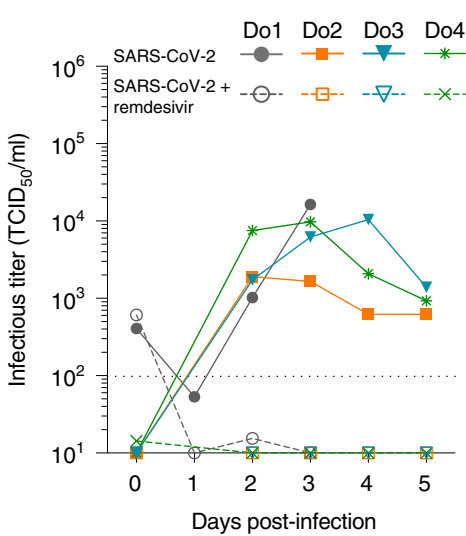



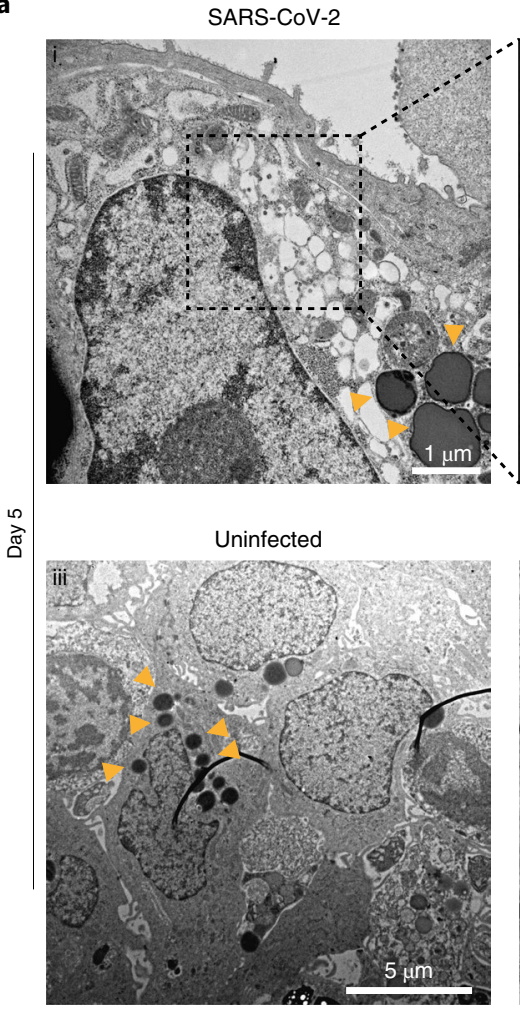

b
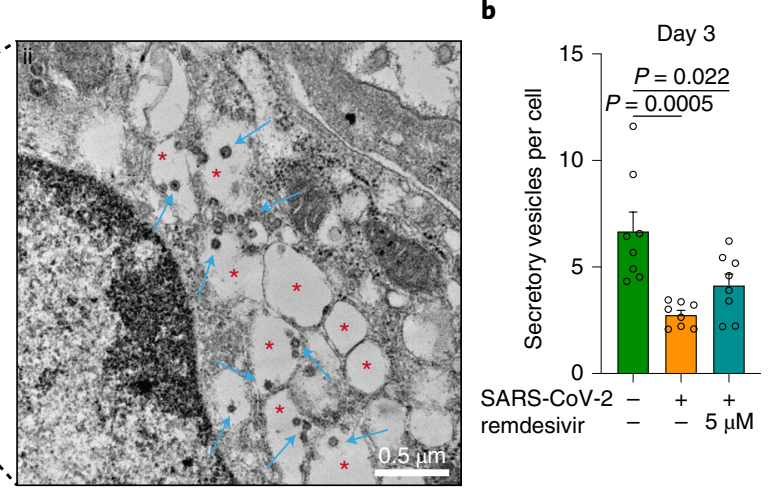
$\begin{array}{lll}\text { SARS-CoV-2 } & + & + \\ \text { remdesivir } & - & + \\ \mu\end{array}$
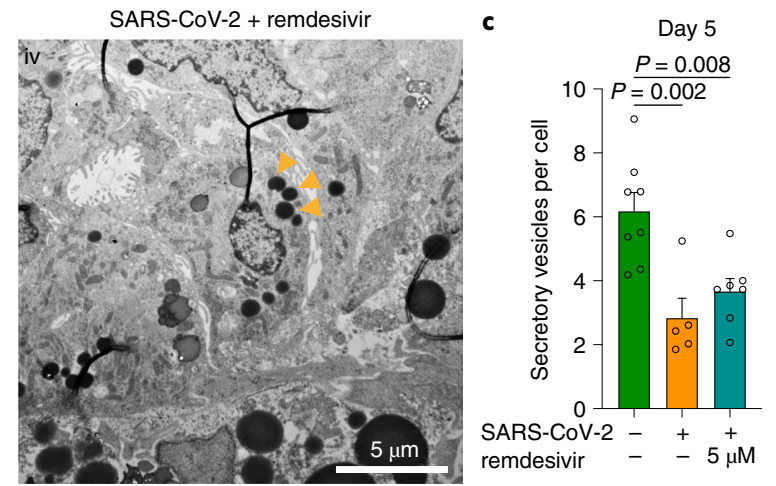

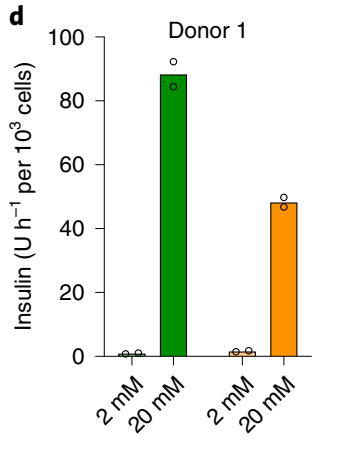

Uninfected SARS-CoV-2

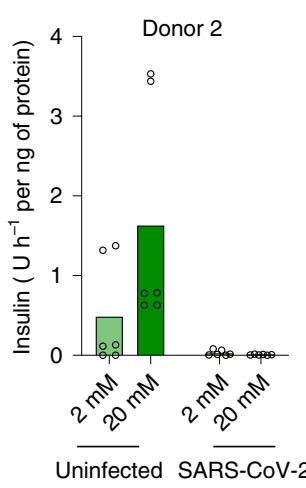

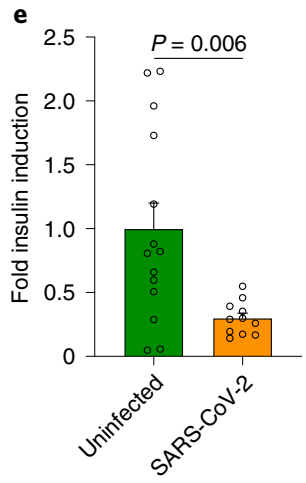

Fig. 3 SARS-CoV-2 infects and replicates in pancreatic islets, thus resulting in impairment of $\boldsymbol{\beta}$-cell function. Human pancreatic islets of donor 3 were infected with SARS-CoV-2 and cultivated with or without $5 \mu \mathrm{M}$ remdesivir, or left uninfected. $\mathbf{a}$, At day 5 , islets were fixed and sectioned for TEM analysis. Electron micrograph (i) and magnified inlet (ii) of the infected preparation show cells with endocrine secretory vesicles (orange arrowheads) and dilated Golgi vacuoles (red asterisks) containing virus particles (blue arrows). Vacuoles and viral particles were absent in the uninfected (iii) and remdesivir-treated ( $5 \mu \mathrm{M}$ ) (iv) samples (see Extended Data Fig. 7a for further micrographs at equal magnifications as in i and ii). b,c, Endocrine secretory vesicles from donor 3 were manually identified by two independent individuals at day 3 (b) or 5 (c) post-infection and quantified blinded using Fiji. Data are presented as mean \pm s.e.m. of 8 TEM images (day 3) and 8, 5 and 7 TEM images for uninfected, infected and remdesivir-treated islets (day 5), respectively, containing on average 19 nuclei. Statistical significance was calculated by ordinary one-way ANOVA with Tukey's post-test. d,e, At day 3 post-infection, islet functionality of donors 1,2 and 4 was analysed by static GSIS. Islets were exposed first to $2 \mathrm{mM}$ and then to $20 \mathrm{mM}$ glucose for $1 \mathrm{~h}$ each, and insulin secretion into the buffer was determined by ultrasensitive insulin ELISA. Calculated insulin secretion indicated in the corresponding bars (d) and averaged as fold inductions (e) is shown. Data are presented as mean \pm s.e.m. of two technical replicates (donor 1 ) and six replicates (donors 2 and 4). Statistical significance of fold insulin induction was calculated using an unpaired, two-sided Student's $t$-test.

and Extended Data Fig. 8b) with a longer disease course, but rather we observed macrothrombi (the asterisk in Fig. 5c), which is in line with previous observations during later stages of COVID-19 (refs. ${ }^{4,71}$ ). Similar to patient 1 (Fig. 5 b and Extended Data Fig. 8 b), we found viral $\mathrm{N}$ protein in all analysed kidneys, supporting previous findings of a renal tropism of SARS-CoV-2 (refs. ${ }^{3,4,6,71-77}$ ) (Fig. $5 \mathrm{c}$ and Extended Data Fig. 8b). Human kidney obtained from a non-COVID-19 postmortem examination served as a negative control to ensure valid staining (Extended Data Fig. 8c). In the spleens, just patients 2 and 4 showed some scattered infected cells without gross abnormalities (Fig. $5 \mathrm{c}$ and Extended Data Fig. 8b).

We then analysed pancreatic involvement of the four patients. During COVID-19 treatment we observed hyperglycaemia in patients 1, 2 and 3, accompanied by a progressive insulin demand in patients 2 and 3. Pancreatic histopathology revealed the presence of SARS-CoV-2 N protein, with varying numbers of positive 
cells in all four patients, indicating a persistent infection during severe COVID-19 independent of early (patient 1) or late (patient 2-4) COVID-19 disease stage (Fig. 6a and Extended Data Fig. 8b). Specifically, N protein was detected in some small ducts (CK19) and in single or grouped acinar cells, but was negative in an uninfected control specimen (Fig. 6a and Extended Data Fig. 9), in agreement with the viral entry protein expression pattern (Fig. 1, and Extended Data Figs. 3 and 4). Of note, one patient had elevated lipase levels, indicating a certain degree of exocrine damage due to SARS-CoV-2 infection (Table 1). N-protein-positive cells were not randomly scattered across the human pancreas, but instead occurred in clusters of infected cells, suggesting localized viral spread (Fig. 6a,b). To probe infection of human $\beta$-cells, we performed immunohistochemical double staining for the viral $\mathrm{N}$ protein and insulin, but observed only a few double-positive cells (Fig. 6a, close-ups marked with a hash). Nevertheless, N-protein-positive cell clusters were located close to the islets of Langerhans, indicating a certain degree of association between SARS-CoV-2 infection and the endocrine compartment. This was quantified by a vicinity score based on the distance between $\mathrm{N}$-protein- and insulin-positive cell clusters, and classified in cells with a distance $<100 \mu \mathrm{m}$ or $\geq 100 \mu \mathrm{m}$ against a randomly calculated reference distance. On average, $51 \%$ of SARS-CoV2 -infected cell clusters were located close to human islets, with a significant maximum of $60 \%$ and $83 \%$ in patients 1 and 2 , as well as similar trends with $40 \%$ and $31 \%$ in patients 3 and 4 , respectively (Fig. 6b,c). Again, some insulin-positive cells revealed a faint red $\mathrm{N}$-protein signal pointing towards spreading infection (Fig. $6 \mathrm{~d}$, arrowheads). The morphology of some of the clearly infected cells did not resemble ductal, acinar or endocrine morphology, indicating a certain degree of plasticity occurring after infection. This is in line with the observed loss of hormones and endocrine granules as suggested by immunostaining and TEM images of infected islet explants (Figs. 2 and 3). Indeed, high $\mathrm{N}$-protein signals appeared to go along with low insulin-staining intensity (Fig. 6d, close-up). To further address this, we co-stained for $\mathrm{N}$ protein and NKX6.1, which is exclusively expressed by $\beta$-cells within the adult pancreas ${ }^{55}$. Indeed, we detected N-/NKX6.1-double-positive cells in four out of four patients, in close proximity to the islets of Langerhans and SARS-CoV-2-infected cell clusters (Fig. 6e,f and Extended Data Fig. 10). Under the assumption that clusters of NKX6.1-positive cells represent or are derived from the endocrine compartment, we estimated the percentage of infected endocrine cells on average at 46\% (range 23-65\%) (Extended Data Fig. 10). This indicates that infection of $\beta$-cells might result in hormone loss, an observation matched by our ex vivo analyses (Fig. 2 and Extended Data Fig. 5). To conclude, pancreatic SARS-CoV-2 infection can occur in severe cases of COVID-19, including the exocrine and endocrine compartment. Nevertheless, the still low sample size, suboptimal tissue quality due to autolytic necrosis and limited clinical data precluded a correlation with the individual endocrine function and outcome in patients.

\section{Discussion}

The disease course in patients with COVID-19 can be perturbed by diabetes mellitus in two ways. On the one hand, diabetes is a risk factor for severe disease $e^{3,16-22}$ and, on the other, SARS-CoV-2 infection has been associated with altered glucose metabolism ${ }^{3,16,24,29}$. Specifically, ketosis and ketoacidosis were observed during and after SARS-CoV-2 infection, both being at least indirect clinical indicators of a lack of insulin due to $\beta$-cell loss or malfunction ${ }^{18,25-30}$. In the present study, we: (1) dissected pancreatic expression patterns of SARS-CoV-2 viral entry proteins, and (2) demonstrated permissiveness of $\beta$-cells to SARS-CoV-2 infection and replication, which affects (3) subcellular morphology and glucose responsiveness. Moreover, we (4) demonstrated the presence of SARS-CoV-2 viral antigen in pancreata and, most importantly, in NKX6.1-positive $\beta$-cells from COVID-19 deceased patients, some of whom had prediagnosed diabetes.

We analysed human pancreatic islets for SARS-CoV-2 entry factor expression and consistently observed ACE2 positivity of intra-islet endothelial cells as previously reported ${ }^{12,13,34,37}$. We also demonstrated that the endocrine cells of human pancreatic islets express TMPRSS2 as well as the long and short isoforms of ACE2, in line with recent findings ${ }^{12,36}$. However, partially conflicting data have been reported about the expression of the long ACE2 isoform in human $\beta$-cells ${ }^{13,34}$. These different experimental outcomes might be attributed to intra- and interindividual variations in the investigated donor tissue, or utilization of antibodies that have various affinities to the respective isoforms $s^{12,13,34,36}$. In the present study, we used established antibodies in our immunohistochemistry analysis that detect the short and long isoforms and, in addition, performed an extensive in-house characterization of these antibodies and the applied methodology ${ }^{12,36,49}$. Fignani et al. ${ }^{12}$ provide a comprehensive analysis on ACE2 expression in $\beta$-cells, including mass-spectrometry-based detection. Briefly, this study showed that the short ACE2 isoform is expressed in human pancreatic islets, where it is preferentially expressed in subsets of insulin-producing $\beta$-cells ${ }^{12,49}$. It is interesting also that Kusmartseva et al. reported detectable mRNA levels of ACE2 in a proportion of endocrine cells ${ }^{13}$. Of note, other viral entry factors might potentiate low ACE2 expression levels in $\beta$-cells. Specifically, neuropilin-1, a factor expressed in pancreatic $\beta$-cells ${ }^{80}$, and the high-density-lipoprotein scavenger receptor B type 1 , also expressed in human endocrine cells ${ }^{81,82}$, have been shown to facilitate SARS-CoV-2 infectivity ${ }^{83,84}$. However, according to the current state of knowledge, ACE2 expression remains the major determinant of SARS-CoV-2 entry and thus organ tropism. Several proteases can prime the coronavirus $S$ protein of which pancreatic TMPRSS2 expression also matched our infection pattern of COVID19 deceased patients $s^{6,8,37,85,86}$. We found that ACE2 and TMPRSS2 colocalize less with markers of $\delta$ - and $\alpha$-cells. However, this lower frequency does not preclude infection as suggested by previous data $^{36}$. We acknowledge that further studies are necessary to reveal the exact entry mechanisms of SARS-CoV-2 into $\beta$-cells and to

Fig. 4 | Transcriptional changes in human islets after SARS-CoV-2 infection. Human pancreatic islets of donors 2 and 3 were infected with SARS-CoV-2 and cultivated with or without $5 \mu \mathrm{M}$ remdesivir, or left uninfected, and prepared for RNA-seq. a, Smart-seq2 expression heatmap illustrating proximity between different treatment conditions and experiments ( $n=2$ islet donors). b,c, Volcano plots with depicted genes of interest for comparison of islets infected with SARS-CoV-2 and uninfected (b) or remdesivir-treated (c) islets. Significant genes were highlighted in blue (adjusted $P<0.1$ ) and significant genes with a $\log _{2}$ (fold-change) $>|1|$ in red. Statistical significance was tested using DESeq2 (ref. ${ }^{104}$ ). d,f, Selection of significantly enriched gene sets comparing differentially expressed genes in islets infected with SARS-CoV-2 versus uninfected (d) or versus remdesivir-treated (f) islets in overrepresentation analyses against common databases; the enrichment test for significance was performed using g:Profiler ${ }^{105}$. e,g, Selection of significantly enriched gene sets in overrepresentation analyses against COVID-19-related disease terms comparing differentially expressed genes in islets infected with SARS-CoV-2 versus uninfected (e) or versus remdesivir-treated ( $\mathbf{g}$ ) islets; the enrichment test for significance was performed using EnrichR ${ }^{106}$ ( ${ }^{\star \star \star}$ adjusted $P<0.001,{ }^{\star \star}$ adjusted $P<0.01$, ${ }^{\star}$ adjusted $P<0.05$ ). $\mathbf{h}, \mathbf{j}$, Normalized enrichment scores for a selection of gene sets in GSEA of islets infected with SARS-CoV-2 compared to uninfected (h) or to remdesivir-treated (j) islets (FDR; $\left.{ }^{\star \star \star} P<0.001,{ }^{\star \star} P<0.01,{ }^{\star} P<0.05\right)$. ROS, reactive oxygen species. i,k, GSEA plots for selected gene sets of islets infected with SARS-CoV-2 compared to uninfected (i) or to remdesivir-treated (k) islets. The false discovery rate (FDR) was determined using the GSEA (Broad Institute) desktop tool ${ }^{107}$ as detailed in Methods. 
assess infection patterns of other endocrine cells in more detail. However, independent of a potential debate on viral entry protein expression, we observed productive SARS-CoV-2 infection of ex vivo cultured islets using state-of-the-art, molecular virologybased assays, providing evidence for the presence of functional entry factors. a

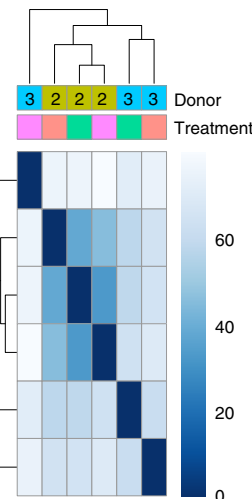

b

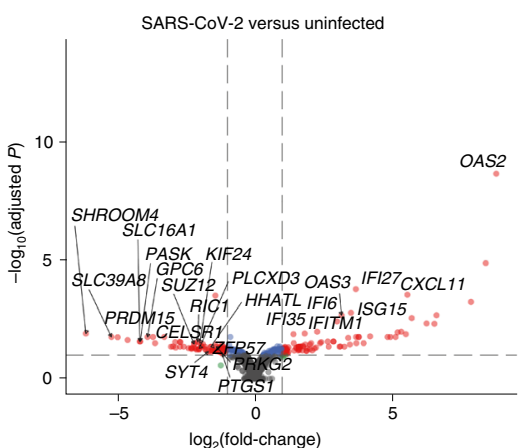

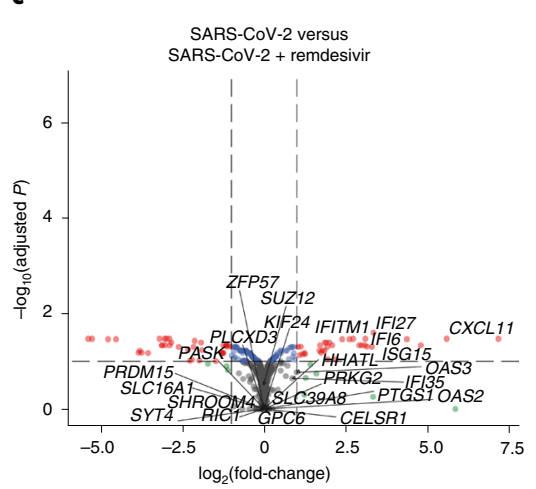

$\square$ Uninfected $\square$ SARS-CoV-2 $\square$ SARS-CoV-2 + remdesivir

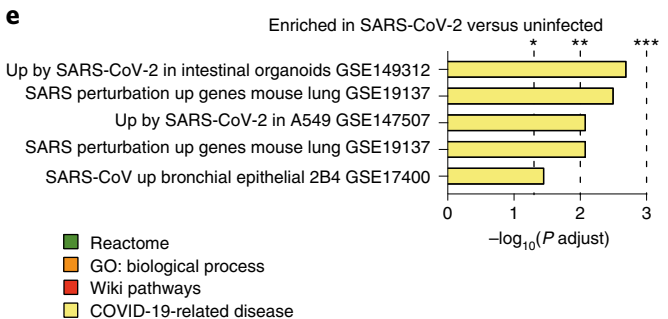

g

Enriched in SARS-CoV-2 versus SARS-CoV-2 + remdesivir

SARS-CoV up bronchial epithelial 2B4 GSE17400 p by SARS-CoV-2 in intestinal organoids GSE149312 COVID-19 up in lung series 15 GSE147507 Up by SARS-CoV-2 in Calu-3 GSE148729 Up by SARS-CoV-2 in lung tissue GSE147507

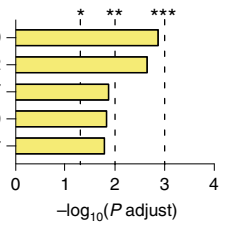

i
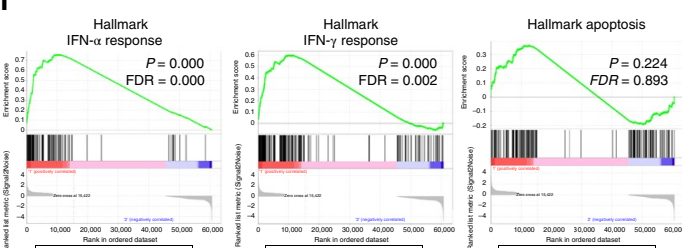

|| |||||||||||||||||||||||
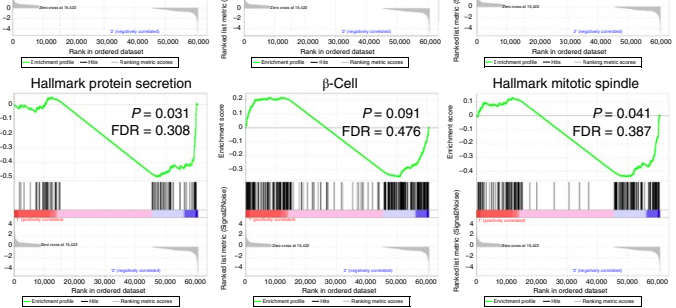

$\mathbf{k}$

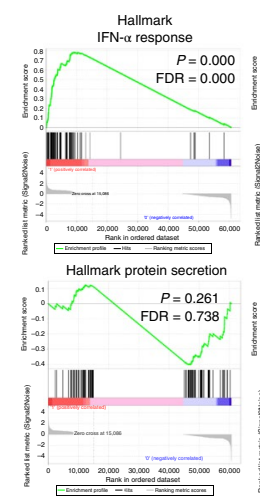

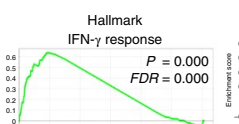
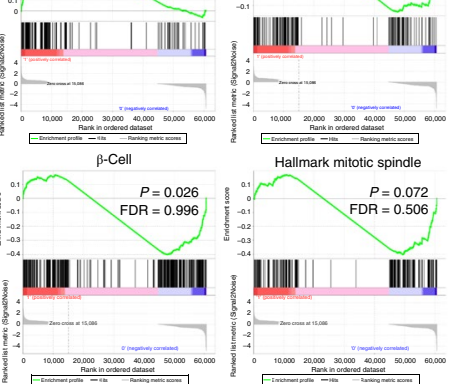
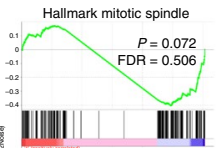


\section{Table 1 | Patient data of COVID-19 deceased patients}

Patient data

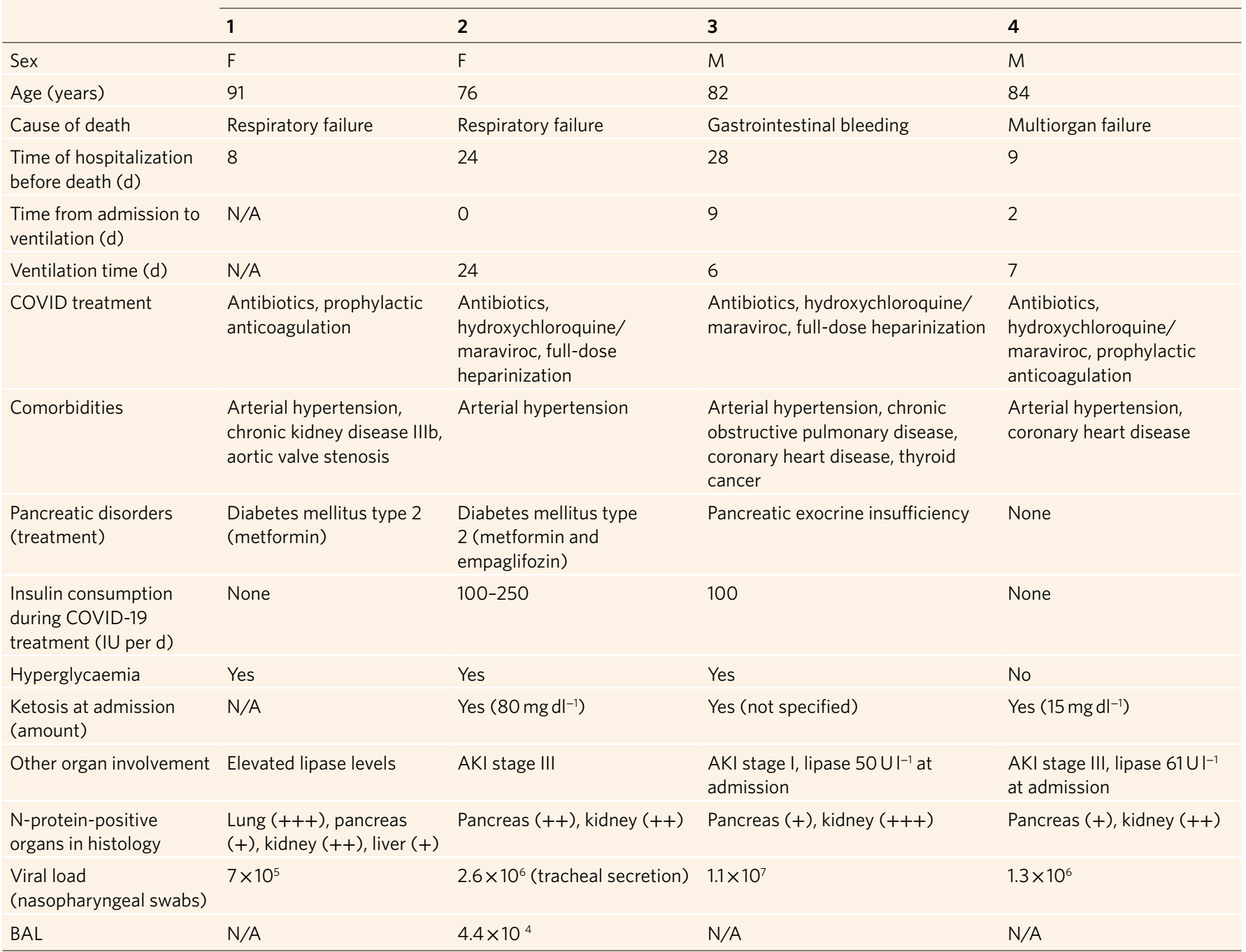

Patient no.

+++> 70\%; ++ 30-70\%; +<30\%. AKI, acute kidney injury; N/A, not applicable.

Human pluripotent, stem-cell-derived $\beta$-cells can be infected by SARS-CoV-2 (ref. ${ }^{87}$ ). In endocrine cells of human ex vivo cultured Islets of Langerhans, we detected viral proteins, viral RNA and increasing infectious viral titres, and we also visualized SARS-CoV-2 particles inside vacuoles in the perinuclear region ${ }^{56}$ by TEM. The most striking observation was an enlarged and vacuolized ER-Golgi intermediate compartment, similar to observations in SARS-CoV2 -infected intestinal, kidney and airway epithelial cells ${ }^{56-58}$. The hallmarks of endocrine differentiation, namely secretory granules, are displaced and significantly reduced. However, a more comprehensive TEM-based analysis across a complete viral replication cycle in human islets, as well as more samples from infected patients, is required to draw definite conclusions. Nevertheless, the TEM observations are in line with the affected insulin secretion observed in our study, even though we faced experimental variations across the four investigated islet preparations. Of note, $\beta$-cells infected by enterovirus display decreased GSIS and loss of Golgi body structure $^{88}$. Furthermore, dedifferentiation of $\beta$-cells mimicking reversal to a progenitor state accompanied by decreased $\beta$-cell-specific gene transcription may occur after viral $^{89}$ but also chemical ${ }^{90}$ injury. Our RNA-seq, confocal microscopy analysis and TEM data would be in line with both hypotheses, namely ER stress followed by $\beta$-cell degranulation and dedifferentiation. However, pancreatic virus-induced injury can also be a self-potentiating damage driver due to inflammation, recruitment of bystander immune cells and potentially development of autoimmunity, which is specific to $\beta$-cells ${ }^{67}$. In fact, SARS-CoV-2 infection provoked a broad signature of cytokines and ISGs attributed to type I and II IFN responses in human islets. We recently showed that IFN-induced transmembrane (IFITM) proteins promote SARS-CoV-2 infection of human lung cells ${ }^{91}$. Of note, IFITM1-3 ranged top among upregulated transcripts in SARS-CoV-2-infected human islets. Similar GO terms have been reported in gut-derived organoids after SARS-CoV-2 infection $^{58}$, identifying such intrinsically triggered immune responses as a general feature across distinct organs during COVID-19. These global studies of islet transcriptomes are, however, limited by the bulk design, preventing access to cell-type-specific, single-cell-resolved transcriptomes ${ }^{92}$. Finally, our results show that viral replication in ex vivo infected islets was efficiently inhibited by remdesivir used as a control to prevent SARS-CoV-2 replication. This inhibition of viral replication was associated with neither an entire rescue in $\beta$-cell function nor full restoration of transcriptomes. This is most probably due to a delay in full $\beta$-cell recovery, which cannot be reached in the present experimental setting due to 
the deterioration of islets on prolonged ex vivo culture. However, the effects of remdesivir suggest that observed changes are specific to SARS-CoV-2 infection.

Investigation of pancreata of COVID-19 deceased patients revealed a scattered distribution of infected cell clusters across the pancreas in all four patients, most visible in the exocrine compartment, but with a closeness to the islets of Langerhans. Such a pattern could indicate spread to neighbouring pancreatic cells originating from a few infected cells, potentially reached by viral particles directly via the bloodstream during temporary viraemia, typically occurring in severe COVID-19 (refs. ${ }^{93,94}$ ). Kusmartseva et al. also investigated $\mathrm{N}$-protein expression in COVID-19 deceased patients, but could not detect co-expression with insulin ${ }^{13}$. In our study, detection of $\mathrm{N}$-/insulin-double-positive cells was technically challenging and rare in frequency. However, building on our observations in ex vivo cultured islets, co-staining of viral $\mathrm{N}$ protein with the $\beta$-cell lineage label NKX6.1 confirmed SARS-CoV-2 infection in cell clusters expressing NKX6.1 in all investigated patients with COVID-19. Notably, pancreatic NKX6.1 expression is unique because no other transcription factor is restricted exclusively to $\beta$-cells within the adult pancreas ${ }^{55}$. As we also observed those hormone-negative cells in the human islet preparations, this suggests that SARS-CoV-2 infection might perturb hormone positivity by cytokine and/or ER stress, followed by $\beta$-cell degranulation and dedifferentiation. Further analysis is necessary to fully understand the underlying mechanism and it is important to note that hormone loss on infection complicates these experimental evaluations. Specifically, insulin might not be a suitable marker to show colocalization with viral proteins. Thus, estimating infection rates of the respective cells, within islets or pancreatic tissues, remains a challenge. The precise SARS-CoV-2 infection pattern in human islet subpopulations is still warranted, and whether the number of SARS-CoV-2-infected cells and associated identity loss of $\beta$-cells suffice to affect endocrine function in healthy and diseased islets remain to be determined. Accordingly, our results prompt the question of whether SARS-CoV-2 directly perturbs $\beta$-cell integrity and potentially leads to endocrine dysregulation and causes autoantibody-negative T1DM, as reported in recent clinical studies after SARS-CoV-2 infection ${ }^{9,17-30}$. Alternatively, SARS-CoV-2 infection might be a precipitating factor of autoimmune-mediated diabetes mellitus arising even years after recovery ${ }^{1,22}$, underpinning the necessity for long-term follow-up of patients with COVID-1933. Although, for example, Coxsackie B4 or congenital rubella virus infections as such can trigger development of $\mathrm{T}^{\mathrm{D}} \mathrm{DM}^{67,95,96}$, the virus-mediated $\beta$-cell insult presents heterogeneously across different viruses, for instance, enterovirus infection of $\beta$-cells can lead to: (1) cell death accompanied by increased proliferation in neighbouring non-infected $\beta$-cells, (2) impaired insulin production and secretion, or (3) $\beta$-cell dedifferentiation ${ }^{89,97}$. Collectively, whether SARS-CoV-2 infection triggers a detrimental immune response or directly reduces $\beta$-cell function, thus affecting the endocrine system, needs to be evaluated in future studies.

Infection of pancreatic ducts and acinar cells further raises the question of whether there is a correlation with observed lipase level elevations and acute oedematous pancreatitis in patients with COVID-19 with SARS-CoV-2-associated pneumonia. Acute pancreatitis has also been reported to occur in COVID-19 (refs. ${ }^{5,22,23,98}$ ). Recent studies reported acute pancreatitis in $12.6 \%$ of the entire cohort and $32.5 \%$ in critical patients ${ }^{23}$. However, it remains unclear whether acute pancreatitis, a potentially fatal disease because it in particular causes deterioration in critically ill patients, occurs as a side effect or a direct consequence of pancreatic SARS-CoV-2 infection.

Analysis of other organs of COVID-19 deceased patients revealed robust staining of the kidneys, whereas the spleen was not consistently infected. Lung tissue showed different infection patterns, which might correspond to differences in temporal and spatial disease presentation ${ }^{71,99}$. We cannot exclude infection in other lung or spleen regions due to the sampling bias during the postmortem examination and the low sample size. In particular, the question of renal tropism remains under discussion. Of note, there are reports that kidneys are highly susceptible to SARS-CoV-2 infection ${ }^{3,6,71,73-79}$, whereas others failed to detect viral elements in kidneys ${ }^{78,100-103}$. These discrepancies reveal that our knowledge about (1) the frequencies and (2) the association with pre-existing diseases, and (3) the clinical impact of extrapulmonary infections by SARS-CoV-2 remains incomplete. There are several explanations for these conflicting findings such as spatial and temporal heterogeneity of viral spread, technical constraints such as sample preservation and the detection assays used. Time-resolved, ultrasound-guided tissue biopsies might circumvent the limitations of endpoint analysis in postmortem studies.

Collectively, we demonstrate that the exocrine and endocrine compartments of the pancreas are susceptible to productive SARSCoV-2 infection, which can perturb $\beta$-cell integrity. The mechanism of virus-induced damage and whether infection has a direct consequence for glucose homoeostasis or might even trigger diabetes mellitus remain under discussion and deserve future studies.

\section{Methods}

Drugs. Remdesivir was obtained from Selleck Chemicals (catalogue no. S8932).

Cell culture. Vero E6 (Cercopithecus aethiops-derived epithelial kidney, American Type Culture Collection (ATCC)) cells were grown in Dulbecco's modified Eagle's medium (DMEM, Gibco) which was supplemented with $2.5 \%$ heat-inactivated fetal calf serum (FCS), $100 \mathrm{U} \mathrm{ml}^{-1}$ of penicillin, $100 \mu \mathrm{g} \mathrm{ml}^{-1}$ of streptomycin, 2 $\mathrm{mM}$ L-glutamine and $1 \mathrm{mM}$ sodium pyruvate. Calu-3 (human epithelial lung adenocarcinoma, kindly provided by Professor Frick, Ulm University) cells were cultured in minimum essential medium Eagle (MEM, Sigma-Aldrich, catalogue no. M4655) supplemented with $10 \% \mathrm{FCS}, 100 \mathrm{U} \mathrm{ml}^{-1}$ of penicillin, $100 \mu \mathrm{g} \mathrm{ml}^{-1}$ of streptomycin, $1 \mathrm{mM}$ sodium pyruvate and $1 \times$ non-essential amino acids. EndoC- $\beta \mathrm{H} 1$ cells (Univercell Biosolutions) were cultured on coated culture wells

Fig. 5 | Multiorgan infection in COVID-19 deceased patients. a, Timeline of disease course of patient 1, hospitalized due to a planned transcatheter aortic valve implantation (TAVI) procedure, including blood glucose levels throughout hospitalization and thoracic $\mathrm{X}$-ray at day 5 of hospitalization. $\mathbf{b}$, Multiple organs of patient 1 were stained for viral $\mathrm{N}$ protein (red). Sections of the lung showed strong staining of shed alveolar macrophages as well as of alveolar lining cells. In the kidney, epithelial cells of the tubulus (arrows) are N-protein positive, as well as some cells within the glomerulus (arrowhead). The spleen shows no positive cells. In the liver, N protein is detected in some cells of the bile duct as well-isolated hepatocytes, whereas lymph nodes and heart muscle appear negative. Representative images from four biopsy sections of the lung and one biopsy section of other organs were selected. c, Lungs, kidneys and spleens of patients 2-4 were stained for viral N protein. For patient 2, the lung tissue appeared negative, whereas oedema (hash) and thrombus in a small vessel (asterisk) were seen. In the kidney, some tubulus cells were $\mathrm{N}$-protein positive whereas in the spleen only very few cells showed weak staining. Patient 3: the lung tissue was negative for SARS-CoV-2 N, showing some initial oedema and thrombus in a small pulmonary artery (asterisk). In the kidney, cells of the proximal tubulus were positive (arrow), as were some cells in Bowman's capsule of the glomerulus (arrowhead). No $\mathrm{N}$ protein was seen in the spleen. Patient 4: lung tissue appeared negative except for one positive cell in the interstitial space. A thrombus is marked by an asterisk; the hash marks the alveolar space. In the kidney some tubular cells were N-protein positive, whereas the glomerulus appeared negative. In the spleen one single positive cell cluster was detected. Inset shows a high magnification to illustrate this observation. A representative image from one biopsy section was selected. Scale bar, $100 \mu \mathrm{m}$. 
( $2 \mu \mathrm{g} \mathrm{ml}^{-1}$ of fibronectin, $1 \%$ extracellular matrix) in OPTI $\beta 1$ medium (Univercell Biosolutions) according to the manufacturer's protocol. Human umbilical vein endothelial cells were cultivated in endothelial cell growth medium (Merck).
Cells were grown at $37^{\circ} \mathrm{C}$ in a $5 \% \mathrm{CO}_{2}$ humidified incubator. For differentiation of stem-cell-derived intestinal organoids, human embryonic stem cell (hESC) line HUES8 (Harvard University) was used with permission from the Robert Koch

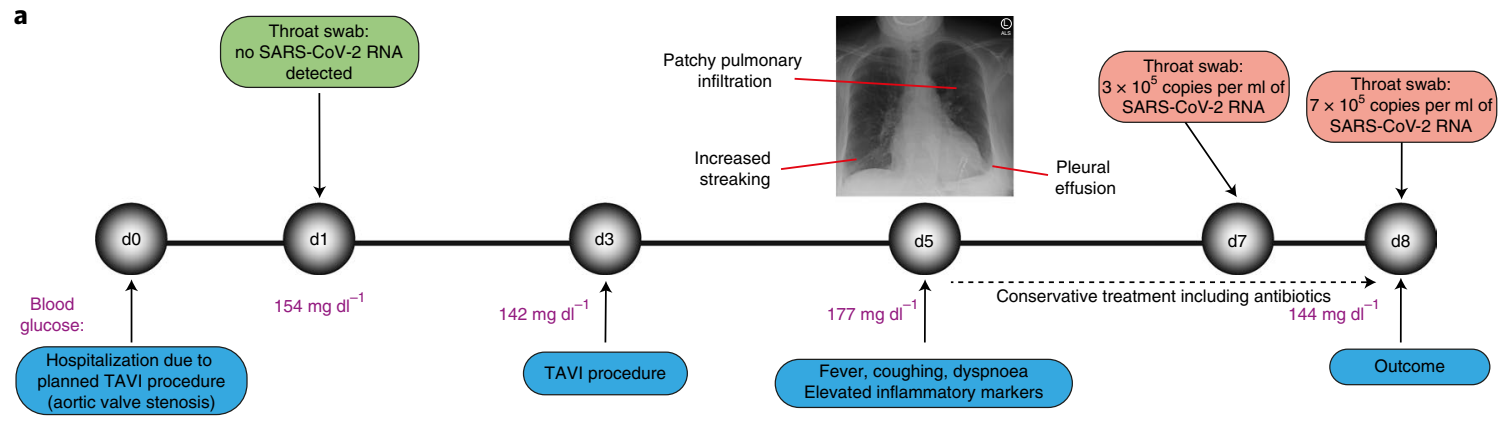

b
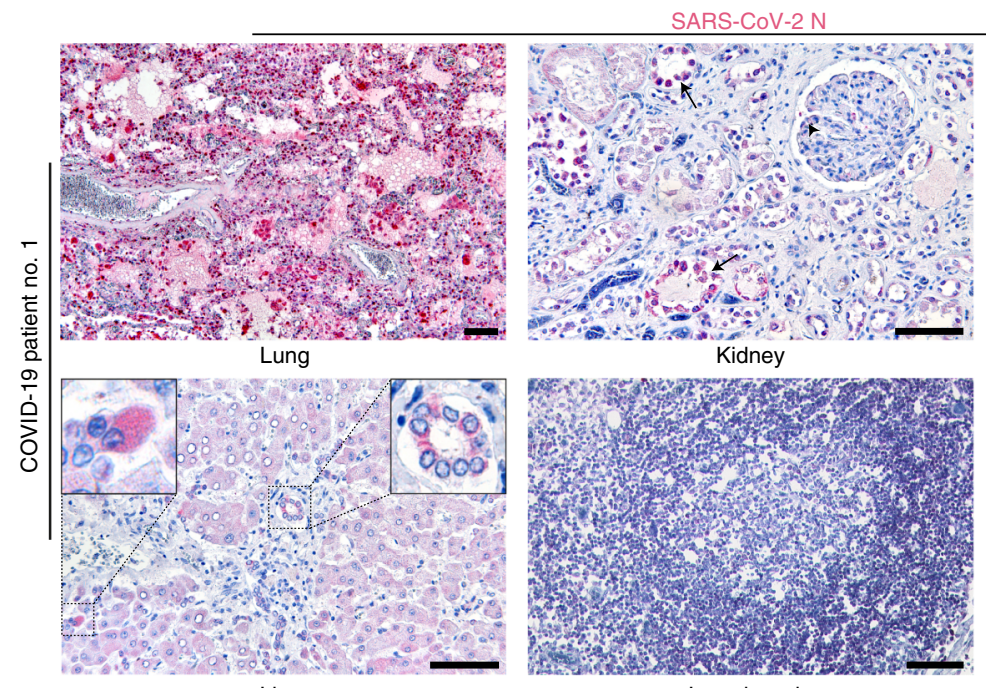

Lymph node

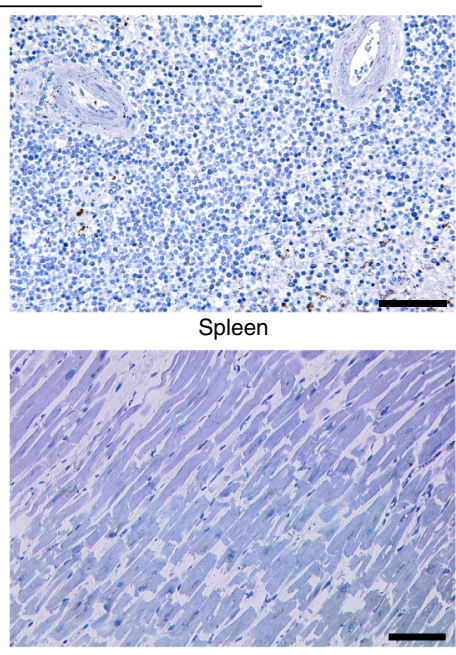

Heart muscle

c

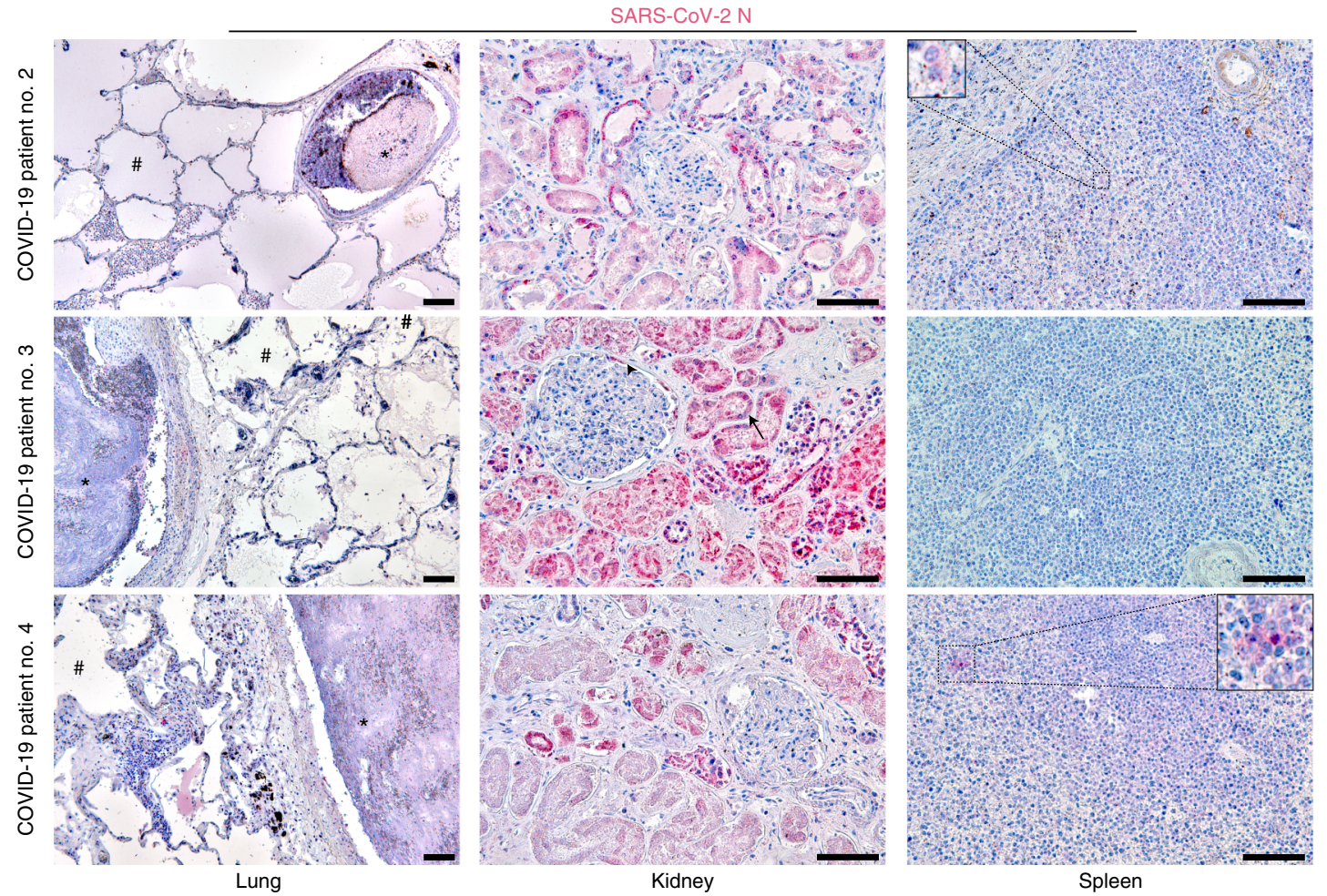




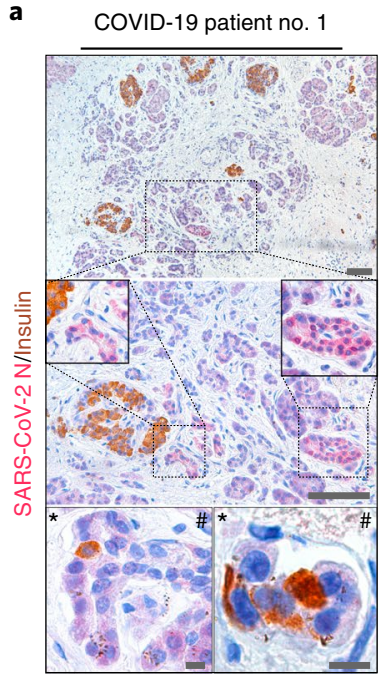

COVID-19 patient no. 2

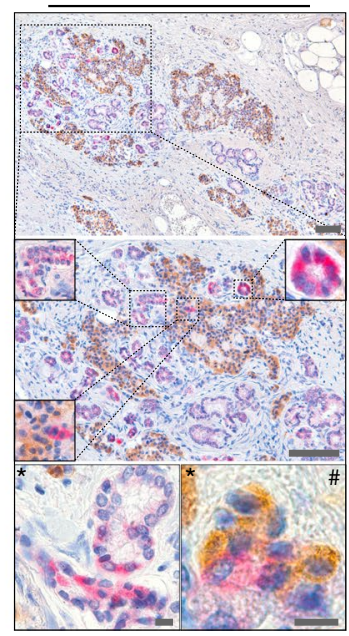

COVID-19 patient no. 3

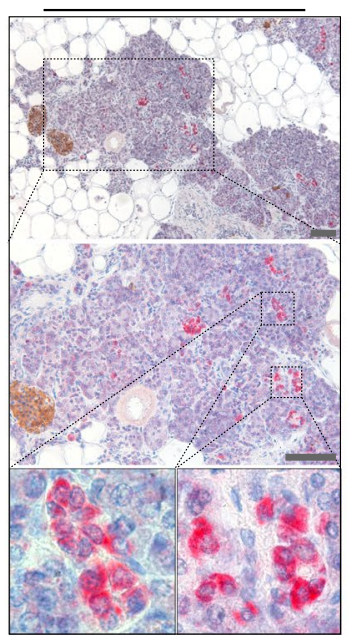

COVID-19 patient no. 4

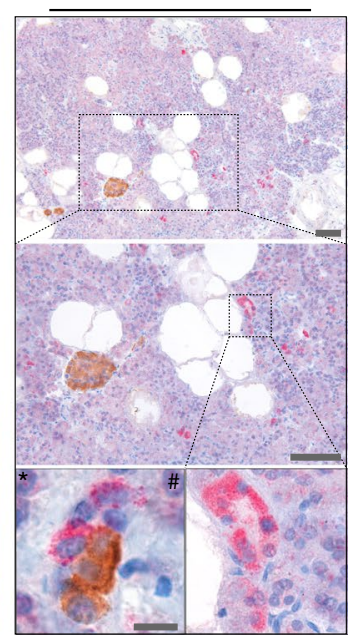

b

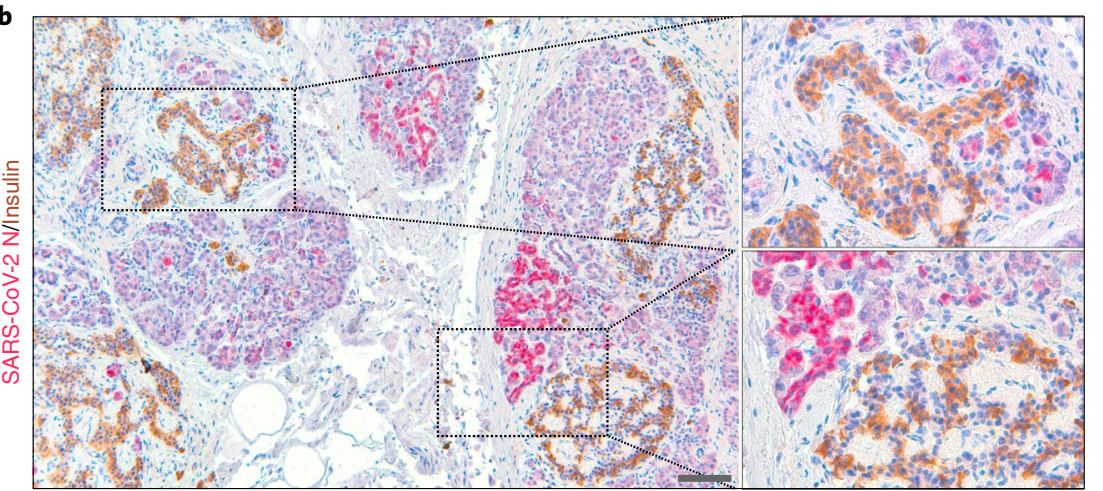

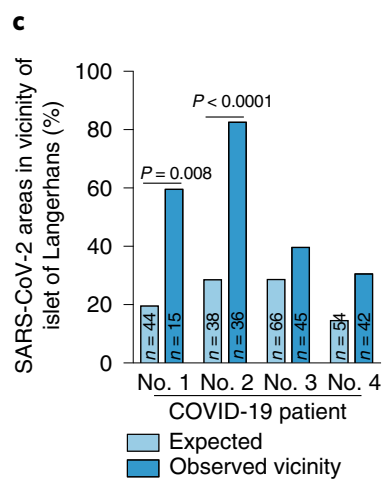

SARS-CoV-2 N/Insulin

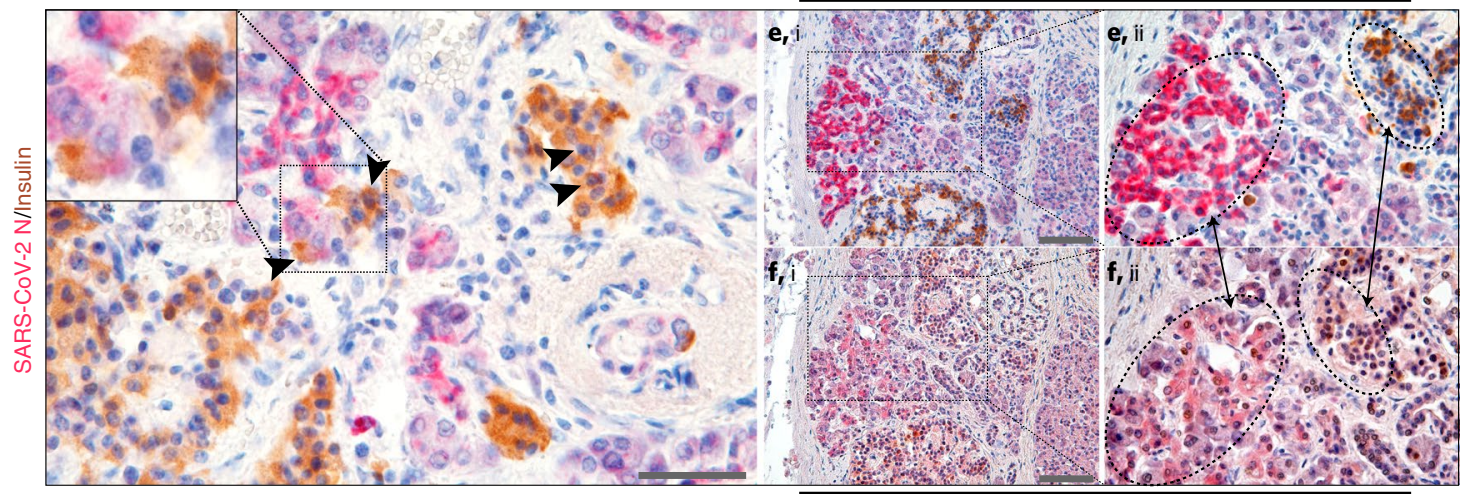

SARS-COV-2 N/NKX6.1

Fig. 6 | Pancreatic infection pattern in COVID-19 deceased patients. a, Pancreatic tissue sections from four different COVID-19 deceased patients stained for SARS-CoV-2 N protein (red) and insulin (brown). Rectangles mark areas of higher magnification in the next row. Insets show further high magnification to illustrate specific patterns. Asterisks mark the magnification of stained areas outside the illustrated regions but corresponding to the patients from the respective column. Infection occurred as N-positive clusters in all four patients with positivity of some ductal cells and a few acinar cells. Insulin and $\mathrm{N}$-protein double-positive cells were observed in three out of four patients (marked with a hash). A representative image from one biopsy section of each patient is displayed. b, N-positive cells are often located in close vicinity to the islets of Langerhans or even mixed in islet-like structures together with insulin-positive cells. The morphology of $\mathrm{N}$-positive cells frequently resembled non-acinar/non-ductal morphology. A representative image is derived from one biopsy section of patient 1. c, Vicinity ratio of $\mathrm{N}$-positive regions ( $>5$ positive cells) located near insulin-positive endocrine cells $(<100$ - $\mu \mathrm{m}$ distance to endocrine cell) divided by all $\mathrm{N}$-positive regions ( $>5$ positive cells) reveals that SARS-CoV-2 is not randomly distributed across the pancreas, but rather located close to endocrine structures. On average, $51 \%$ of $\mathrm{N}$-positive regions are located close to endocrine cells or islets. For statistical testing, two-sided Fisher's exact test was applied to the absolute numbers $\left({ }^{\star} P<0.05,{ }^{\star \star} P<0.01,{ }^{\star \star \star} P<0.001,{ }^{\star \star * \star} P<0.0001\right.$ ). $\mathbf{d}$, Viral $\mathrm{N}$ - and insulin-double-positive cells are rare (arrowheads) but interlaced into the islets of Langerhans. The highest $\mathrm{N}$-protein signal in a cell cluster or even in individual cells correlates with the lowest insulin signal (close-up). e,f, Consecutive sections were stained for either insulin (e) or NKX6.1 (f), together with N protein. Rectangles in (i) mark areas of higher magnification (ii). Dashed areas connected with double-headed arrows mark corresponding regions that are highly N positive, insulin negative and NKX6.1 positive (left) or N negative, insulin positive and NKX6.1 positive (right). Representative images are derived from one biopsy section of patient 2 . Scale bars, $100 \mu \mathrm{m}$; insets, $10 \mu \mathrm{m}$. 
Institute according to the 79 . Genehmigung nach dem Stammzellgesetz, AZ 3.04.02/0084'. For differentiation, 300,000 cells per well were seeded on 24-well plates coated with growth-factor-reduced Matrigel (Corning) in mTeSR1 with $10 \mu \mathrm{M}$ ROCK inhibitor. The next day differentiation was started by washing with phosphate-buffered saline (PBS) and adding d0 differentiation medium (BE1 medium (MCDB131 (Invitrogen), $2 \mathrm{mM}$ L-glutamine (Gibco), $1.174 \mathrm{gl}^{-1}$ of sodium bicarbonate (Sigma-Aldrich), $0.8 \mathrm{gl}^{-1}$ of glucose (Sigma-Aldrich), $0.1 \%$ fatty-acid-free bovine serum albumin (BSA, Proliant)) with $100 \mathrm{ng} \mathrm{ml}^{-1}$ of Activin A (R\&D/ PeproTech) and $2 \mu \mathrm{M}$ CHIR99021 (Axon MedChem). After $24 \mathrm{~h}$ and $48 \mathrm{~h}$ the medium was changed to $\mathrm{d} 1 / \mathrm{d} 2$ medium (BE1 with $100 \mathrm{ng} \mathrm{ml}^{-1}$ of Activin A). From day 3 on, the medium was changed daily to fresh mid-hindgut formation medium (RPMI-1640 (Gibco), 2\% FCS (Biochrom), 2 mM L-glutamine (Gibco), 1\% penicillin-streptomycin (Sigma-Aldrich), $10 \mathrm{ng} \mathrm{ml}^{-1}$ of BMP4 (Peprotech), $100 \mathrm{ng} \mathrm{ml}^{-1}$ of basic fibroblast growth factor (Novoprotein), $3 \mu \mathrm{M}$ CHIR99021 (Cayman Chemical Co.)). From day 7 structures started floating in the medium and were collected and plated on 48 -well Nunclon plates (Sigma-Aldrich) in Matrigel domes (20-40 $\mu$ l of Matrigel per dome). Then, $350 \mu \mathrm{l}$ of intestinal growth medium (DMEM F12 (Gibco), $1 \times$ B27 supplement (Thermo Fisher Scientific), $2 \mathrm{mM}$ L-glutamine, 1\% penicillin-streptomycin (Sigma-Aldrich), 40 mM 4-(2-hydroxyethyl)-1-piperazine-ethanesulfonic acid

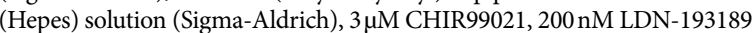
(Sigma-Aldrich) and $100 \mathrm{ng} \mathrm{ml}^{-1}$ of human epithelial growth factor (Novoprotein)) was added per well. The medium was changed twice a week.

Virus strains and virus propagation. Viral isolate BetaCoV/Netherlands/01/ NL/2020 (catalogue no. 010V-03903) of the pandemic D614G variant was obtained from the European Virus Archive global and propagated on Vero E6 cells. To this end, $70 \%$ confluent cells in $75-\mathrm{cm}^{2}$ cell culture flasks were inoculated with $100 \mu \mathrm{l}$ of SARS-CoV-2 isolate in 3.5-ml serum-free medium containing $1 \mu \mathrm{g} \mathrm{ml}^{-1}$ of trypsin. Cells were incubated for $2 \mathrm{~h}$ at $37^{\circ} \mathrm{C}$, before adding $20 \mathrm{ml}$ of medium containing $15 \mathrm{mM}$ Hepes. Cells were incubated at $37^{\circ} \mathrm{C}$ and supernatant harvested when a strong cytopathic effect was visible. Supernatants were centrifuged for $5 \mathrm{~min}$ at $1,000 \mathrm{~g}$ to remove cellular debris, and then aliquoted and stored at $-80^{\circ} \mathrm{C}$ as virus stocks. The infectious virus titre was determined as plaque-forming units on Vero E6 cells, which was used to calculate the multiplicity of infection (MOI).

Isolation of RNA and RT-qPCR. Viral RNA from cells was isolated using the QIAGEN RNeasy Plus Mini Kit (catalogue no. 74136) and RNA from supernatants using the QIAGEN Viral RNA Mini Kit (catalogue no. 52906) as described by the manufacturer. Cells were lysed in $600 \mu$ RLT Plus buffer containing $1 \%$ $\beta$-mercaptoethanol, vortexed for $30 \mathrm{~s}$ and then frozen at $-20^{\circ} \mathrm{C}$ until further isolation. For supernatants, $140 \mu \mathrm{l}$ was mixed with $560 \mu \mathrm{l}$ of AVL buffer, vortexed and frozen as above. Reverse transcription (RT)-qPCR from cells or supernatants was performed with primer sets targeting SARS-CoV-2 $N$ (nucleocapsid) or ORF1b-nsp14 (refs. ${ }^{108,109}$ ) using TaqMan Fast Virus 1-Step Master Mix (Thermo Fisher Scientific, catalogue no. 4444436) and a StepOnePlus Real-Time PCR System (96-well format, fast mode). Expression of ACE2 and TMPRSS2 was evaluated using TaqMan assays (Thermo Fisher Scientific, catalogue nos. Hs01085333_m1 and Hs01122322_m1, respectively). Synthetic SARS-CoV-2-RNA (Twist Bioscience, catalogue no. 102024 or ATCC, catalogue no. VR-3276SD) was used as a standard to obtain viral copy numbers for quantification of viral RNA in supernatants. For RNA isolated from cells, glyceraldehyde 3-phosphate dehydrogenase (GAPDH) was used as an endogenous control (Applied Biosystems, catalogue no. 4310884E) to calculate relative expression. The threshold for detection was set at threshold cycle, $C_{t}$, of 35 . All reactions were run in duplicate. Primer sets:

Target N:

Forward primer (HKU-NF): 5' -TAATCAGACAAGGAACTGATTA-3

Reverse primer (HKU-NR): 5' -CGAAGGTGTGACTTCCATG-3'

Probe (HKU-NP): 5'-FAM-GCAAATTGTGCAATTTGCGG-TAMRA-3

Target ORF1b-nsp14:

Forward primer (HKU-ORF1b-nsp14F): 5' -TGGGGYTTTACRGGTAACCT-3'

Reverse primer (HKU- ORF1b-nsp14R)

$5^{\prime}$-AACRCGCTTAACAAAGCACTC-3'

Probe (HKU-ORF1b-nsp141P):

5'-FAM-TAGTTGTGATGCWATCATGACTAG-TAMRA-3'.

TCID $_{50}$ endpoint titration. To determine the tissue culture infectious dose $50\left(\mathrm{TCID}_{50}\right)$, supernatant samples were serially diluted and used to inoculate Vero E6 cells. To this end, 20,000 Vero E6 cells were seeded per well in 96-well, flat-bottomed plates in $100 \mu$ of medium and incubated overnight before $62 \mu \mathrm{l}$ of fresh medium was added. Next, $18 \mu \mathrm{l}$ of five- or tenfold titrated sample was used for inoculation in triplicate. Cells were then incubated for 4-6 d and monitored for cytopathic effect. The $\mathrm{TCID}_{50}$ per $\mathrm{ml}$ was calculated according to Reed and Muench $^{110}$.

Islet culture. Four preparations of human pancreatic islets were obtained from the Alberta Diabetes Institute IsletCore at the University of Alberta, headed by P. E. MacDonald. Islet material was derived from excess donor organs used for clinical transplantation and with the written informed consent for research (approval no. Pro00013094). The first donor (95\% purity), female, aged 31 years, had a body mass index (BMI) of 20.3 and no history of diabetes (glycated haemoglobin (HbAlc): 4.8\%). The second donor (50\% purity), female, aged 55 years, had a BMI of 29.1 and no history of diabetes (HbAlc: not given). The third donor (40\% purity), male, aged 58 years, had a BMI of 31 and no history of diabetes (HbAlc: 5.6\%). The fourth donor (90\% purity), female, aged 53 years, had a BMI of 33.2 and no history of diabetes (HbAlc: $6.1 \%$ ). This study was also approved by 'Ethikkommission TUM' no. 394/20S. After shipping, islets were washed in culture medium and seeded into ultra-low attachment, 12-well plates (Corning) at a density of 400 islets per well. Infection experiments were started $48 \mathrm{~h}$ after recovery. Pancreatic islets were cultivated in CMRL1066 (Gibco) supplemented with $10 \%$ human serum (Sigma-Aldrich), 2 mM L-glutamine (Sigma-Aldrich), $1 \%$ penicillin-streptomycin (Sigma-Aldrich) and $25 \mathrm{mM}$ Hepes buffer (Sigma-Aldrich). The medium was replaced every second day.

Islet infection. Pancreatic islets of donor 1 in $800 \mu \mathrm{l}$ of medium were infected by adding $200 \mu \mathrm{l}$ of virus inoculum, resulting in an MOI of $\sim 1$. To achieve higher infection rates, islets of donors 2-4 were pre-incubated with TrypLE for $5 \mathrm{~min}$, the reaction stopped by adding BSA-containing DMEM/F12, the supernatant discarded and the islets infected with an MOI of $\sim 2.5$. After $3 \mathrm{~h}$ of incubation, islets were washed three times and cultured in $1 \mathrm{ml}$ of medium per 24 wells or $4 \mathrm{ml}$ per 6 wells, which was in one setting supplemented with $5 \mu \mathrm{M}$ remdesivir. At indicated time points, 0.5 or $2 \mathrm{ml}$ of medium supernatant was collected for RT-qPCR and $\mathrm{TCID}_{50}$ analysis and medium was refilled respectively.

Static GSIS. Static GSIS was performed $3 \mathrm{~d}$ post-infection. Pancreatic islets were washed in Krebs-Ringer bicarbonate buffer (KRBH) containing 0.1\% BSA and incubated for $1 \mathrm{~h}$ in $\mathrm{KRBH}$ with $2 \mathrm{mM}$ glucose. After $1 \mathrm{~h}$, islets were washed in $\mathrm{KRBH} / \mathrm{BSA}$ and resuspended in a buffer containing $2 \mathrm{mM}$ glucose. After $1 \mathrm{~h}$ of incubation, the supernatant was taken and stored for insulin quantification; the islets were washed in $\mathrm{KRBH}$ and incubated in $\mathrm{KRBH}$ with $20 \mathrm{mM}$ glucose for another hour. The supernatant was taken and stored for insulin quantification. The GSIS procedure was performed for one-islet sample (donor 1) and three-islet samples (donors 2 and 4). The supernatants from static GSIS were analysed in duplicate with the ultrasensitive insulin ELISA Kit (Alpco), according to the manufacturer's instructions. Of note, stimulation of one uninfected islet sample (donor 2) with $2 \mathrm{mM}$ glucose did not result in detectable insulin secretion. Values were normalized to cell numbers or protein content (quantified by BCA assay, Thermo Fisher Scientific, catalogue no. A53227) and the fold induction of insulin secretion ( $20 \mathrm{mM}$ glucose stimulation compared with $2 \mathrm{mM}$ glucose) was calculated for each sample.

TEM of islets. Sample preparation for TEM was done as described previously ${ }^{111}$ To this end, pancreatic islets were washed once with PBS and fixed with $2.5 \%$ glutaraldehyde containing $1 \%$ saccharose in phosphate buffer, $\mathrm{pH}$ 7.3. Samples were washed with PBS and post-fixed in $2 \%$ aqueous osmium tetroxide. After dehydrating the samples in a graded series of 1-propanol, they were stained in $2 \%$ uranyl acetate and embedded in Epon. Ultra-thin sections $(80 \mathrm{~nm})$ were collected on copper TEM grids, contrasted with $0.3 \%$ lead citrate for $1 \mathrm{~min}$ and imaged in a Jeol TEM 1400 at $120 \mathrm{kV}$.

\section{Histology of healthy pancreatic tissue sections and ex vivo culture human} islets. Sections of human pancreas were provided by the pathology department of Ulm University. Non-neoplastic pancreatic tissue integrity was approved by a board-certified pathologist (T.F.E.B.). Experiments were conducted in accordance with the guidelines of the Ethics Committee of the Federal General Medical Council and approved by the Ethics Committee of the University of Ulm (vote for usage of archived human material 03/2014). Sections were deparaffinized, rehydrated and subjected to heat-mediated antigen retrieval in Tris buffer, $\mathrm{pH} 9$, or citrate buffer, $\mathrm{pH} 6$. Tissue was permeabilized with $0.5 \%$ Triton X-100 for $30 \mathrm{~min}$ at room temperature, and stained overnight with primary antibodies (Extended Data Fig. 1) in antibody diluent (Zytomed) in a wet chamber at $4{ }^{\circ} \mathrm{C}$. After washing with PBS-Tween $0.05 \%$ (PBS-T), slides were incubated with secondary antibodies (Alexa Fluor IgG $\mathrm{H}+\mathrm{L}$, Invitrogen, 1:500) and $500 \mathrm{ng} \mathrm{ml}^{-1}$ of $4^{\prime}$,6-diamidino2-phenylindole (DAPI) in antibody diluent for $90 \mathrm{~min}$ in a wet chamber at room temperature. After washing with PBS-T and water, slides were mounted with Fluoromount-G (Southern Biotech). For antibody-blocking experiments, ACE2 primary antibody with blocking peptide (Extended Data Fig. 1) at sevenfold excess protein amount was incubated for $30 \mathrm{~min}$ at room temperature in antibody diluent before staining.

For histological examination, pancreatic islets were fixed in $4 \%$ paraformaldehyde (PFA) overnight. Then, they were incubated in $1 \mathrm{M}$ sucrose in PBS overnight and embedded in O.C.T. freezing compound (Tissue-Tek). Cryoblocks were sectioned at $7 \mu \mathrm{m}$ and slides stored at $-80^{\circ} \mathrm{C}$. Immunofluorescence staining was performed similarly to paraffin sections, except for the deparaffinization, rehydration and antigen retrieval steps, which were omitted. Washing in between staining steps was performed with $0.1 \%$ Triton X-100 in PBS.

Negative controls were performed using immunoglobulin (Ig)G controls or irrelevant polyclonal serum (anti-Mycobacterium tuberculosis) for polyclonal 
antibodies, respectively. The absence of background staining confirmed the specificity of the primary antibodies. Laser scanning confocal images were acquired using the Zeiss LSM710. Alternatively, some images shown in Figs. 1 and 2 were acquired using a Leica TCS SP8 equipped with a HC PL APO CS2 63×/1.2 WATER immersion objective. Images were acquired in sequential scan mode as single confocal airy sections using HyD-detectors and the following detection range: Ex: $405 \mathrm{~nm}, \mathrm{Em}$ : 430-470 nm; Ex: $488 \mathrm{~nm}$, Em: 500-535 nm; Ex: 561, Em: $571-620 \mathrm{~nm}$. Colocalization was quantified using the Coloc2 quantification tool of Fiji and standard settings. The fraction of SARS-CoV-2 N-protein-positive cells (Fig. 2c) was quantified in infected islets of donors 2 and 3 (days 3 and 5), stained for SARS-CoV-2 N protein. N-protein-positive cells were counted in seven (day 3 ) and six (day 5 ) islet clusters positive for $\mathrm{N}$ protein and the fraction of the total cell population is shown in Fig. 2c. Uninfected islets from each donor $(n=4)$ served as a control.

Images of SARS-CoV-2-infected islets of donor 3 (day 5) stained for NKX6.1 and SARS-CoV-2 N protein (Extended Data Fig. 6d) were acquired using a Zeiss ApoTome. NKX6.1-positive cells and N-protein-positive cells were quantified in 11 islet clusters positive for N protein and the fraction of NKX6.1 and N-protein double-positive cells of the total NKX6.1-positive cell population is shown in Extended Data Fig. 6e.

Immunohistology of tissue sections of SARS-CoV-2-infected patients. Tissue samples were provided by the tissue bank of the German Center for Infection Research (DZIF, Heidelberg, Germany, approval S242/2020) and of the Institute of Pathology, Ulm University. The characteristics of the patients are reported in Table 1. Immunohistochemical double stainings were performed by sequential incubation with antibodies from different species against nucleocapsid (N protein) of SARS-CoV-2 (mouse, 1:50 in situ, 1:100 in vitro) and against insulin as a marker for endocrine $\beta$-cells (rabbit, 1:10,000 in situ, 1:5,000 in vitro), NKX6.1 (mouse, 1:75 in situ) and CK19 (mouse, 1:100 in situ) as ductal markers. Antigen retrieval was carried out by treatment of the slides in citrate buffer, $\mathrm{pH} 6.1$ in a steamer for $25 \mathrm{~min}$. Specific antigen binding was ensured by incubation of all used antibodies for $30 \mathrm{~min}$ at room temperature. Detection of antibodies was by alkaline phosphatase/RED Detection system (Dako REAL Detection System) for N protein and DAB Chromogen System (Dako EnVision HRP DAB System) for insulin and NKX6.1. For imaging, pictures were taken in a bright field using a Zeiss Axiophot microscope with an included CCD-camera (JVC Digital Camera KY-F75U) connected to Diskus Viewer software (v.5.0)

The distance from N-protein-positive cell clusters to insulin-positive cells (vicinity score) was quantified using Leica LAS-X imaging software and classified in cells with a distance $<100 \mu \mathrm{m}$ or $\geq 100 \mu \mathrm{m}$. To allow statistical testing, a reference distance was generated (expected numbers of cells in islet proximity). For this, cells were randomly selected using LAS-X imaging software and the respective distance of such reference cells to islets was quantified. For statistical testing, Fisher's exact test was applied to the absolute numbers in the contingency tables. For illustration only the fraction of cells, not the absolute numbers of cells, with a proximity $<100 \mu \mathrm{m}$ to C-pep-positive islets is displayed $\left({ }^{\star} P<0.05,{ }^{* *} P<0.01,{ }^{* *} P<0.001\right.$, $* * * * P<0.0001)$

Under the assumption that clusters of NKX6.1-positive cells ( $>10$ positive nuclei in close proximity, with both preserved and disturbed islet morphology) represent or are derived from the endocrine compartment, we estimated the number of infected clusters in non-necrotic areas of the specimens (defined as preserved acinar morphology). To this end, 20 randomly assigned clusters were evaluated for $\mathrm{N}$-protein expression and clusters harbouring more than five double-positive cells were assumed to be infected by SARS-CoV-2. A more detailed analysis and quantification were hindered by large areas of necrotic tissue in postmortem pancreatic tissue (percentage of necrotic area given in Extended Data Fig. 10b).

RNA-seq. NGS library preparation. For the preparation of next-generation sequencing (NGS) libraries from low-input samples of cellular RNA isolates, we followed the Smart-seq 2 protocol ${ }^{112}$. Library concentrations were quantified with the Qubit 2.0 Fluorometric Quantitation system (Life Technologies) and the size distribution was assessed using the Experion Automated Electrophoresis System (Bio-Rad). For sequencing, samples were diluted and pooled into NGS libraries in equimolar amounts.

Sequencing and raw data processing. Expression profiling libraries were sequenced on a HiSeq 4000 instrument (Illumina) in 50-bp, single-end mode. Base calls, provided by the real-time analysis (RTA, v.2.7.7) software (Illumina), were subsequently converted into multiplexed, unaligned BAM format before demultiplexing into sample-specific, unaligned BAM files. For raw data processing off the instruments, customized programs, based on Picard tools (v.2.19.2) ${ }^{113}$, were used.

Transcriptome analysis. NGS reads were mapped to the Genome Reference Consortium GRCh38 assembly via 'Spliced Transcripts Alignment to a Reference' (STAR, v.2.7.5a) ${ }^{114}$ using the 'basic' Ensembl transcript annotation from v.e100 (April 2020) as reference transcriptome. As the hg38 assembly flavour of the University of California, Santa Cruz (UCSC) Genome Browser was preferred for downstream data processing with Bioconductor packages for entirely technical reasons, Ensembl transcript annotation had to be adjusted to UCSC Genome Browser sequence region names. STAR was run with options suggested by the ENCODE project. Aligned NGS reads overlapping Ensembl transcript features were counted with the Bioconductor (3.11) GenomicAlignments::summarizeOv erlaps() function (1.24.0) ${ }^{115}$, taking into account that the Smart-seq2 protocol is not strand specific. Transcript-level counts were aggregated to gene-level counts and the Bioconductor DESeq2 package (v.1.28.1) ${ }^{104}$ was used to test for differential expression based on a model using the negative binomial distribution.

An initial exploratory analysis included principal component analysis, multidimensional scaling, sample distance and expression heatmap plots, all annotated with variables used in the expression modelling (CRAN ggplot2 v.3.3.2 (ref. ${ }^{116}$ ), Bioconductor ComplexHeatmap v.2.4.3 (ref. ${ }^{117}$ )) as well as volcano plots (Bioconductor EnhancedVolcano v.1.6.0 (ref. ${ }^{118}$ )). Sample distance heatmaps were obtained via the CRAN pheatmap package ${ }^{119}$ by calculating the Euclidean distance matrix (via R stats::dist()) of DESeq2 normalized count values after variance-stabilizing transformation in model-aware mode (via DESeq2::varian ceStabilizingTransformation) and subsequent hierarchical clustering with the complete linkage method (via R stats::hclust()). Biologically meaningful results were extracted from the model, $\log _{2}$ (fold-change) $\left(\log _{2}(\mathrm{FC})\right)$ values were shrunk with the CRAN ashr package (v.2.2-47) ${ }^{120}$ and $P$ values were adjusted using the Bioconductor Independent Hypothesis Weighting (IHW, v.1.16.0) package p $^{121}$. The resulting gene lists were annotated, filtered for significantly differentially up- and downregulated genes (adjusted $P<0.1$ and $\log _{2}(\mathrm{FC})>|1|$ ), and were independently subjected to overrepresentation analyses. While g:Profiler [v.: e100 eg47_p14_7733820 $]^{105}$ was applied to test enrichment of significantly differentiated genes against gene sets in common databases, EnrichR allowed expansion to COVID-19-related disease terms (Enrichr) ${ }^{106,122}$. For GSEA, the gsea desktop tool ${ }^{107}$ was used (GSEA v.4.0.3) with setting 'Permutation Type' to 'gene_set' and 'Metric for ranking genes' to 'Signal2Noise.' Enrichment was tested against hallmark gene sets from MSigDB 7.2 (ref. ${ }^{123}$ ) and an additional $\beta$-cell gene cluster derived from Ackermann et al. ${ }^{66}$. Enrichment scores were cross-checked with GSEA Preranked tool using $\log _{2}(\mathrm{FC})$ as ranking parameter, yielding highly similar results.

Whole cell and tissue lysates. To determine expression of cellular proteins, frozen pancreatic tissue was pulverized with a liquid nitrogen-cooled mortar and pestle, and directly transferred into a tube on dry ice to reduce protein degradation. Pulverized tissue samples as well as cell pellets were washed in PBS and lysed in western blot lysis buffer $(150 \mathrm{mM} \mathrm{NaCl}, 50 \mathrm{mM}$ Hepes, $5 \mathrm{mM}$ ethylenediaminetetraacetic acid, $0.1 \% \mathrm{NP}-40,500 \mu \mathrm{M} \mathrm{Na}_{3} \mathrm{VO}_{4}$ and $500 \mu \mathrm{M} \mathrm{NaF}$, $\mathrm{pH}$ 7.5) supplemented with protease inhibitor (Roche). After $5 \mathrm{~min}$ (cell lysate) or $20 \mathrm{~min}$ (tissue lysate) of incubation on ice, the samples were centrifuged $\left(4^{\circ} \mathrm{C}\right.$, $20 \mathrm{~min}, 14,000$ r.p.m.) to remove cell debris. The supernatant was transferred to a fresh tube, the protein concentration was measured using the BCA assay (Thermo Fisher Scientific, catalogue no. A53227) and the concentration was adjusted using western blot lysis buffer.

\section{Sodium dodecylsulfate-polyacrylamide gel electrophoresis and} immunoblotting. For western blotting, whole cell lysates were mixed with $4 \times$ protein sample-loading buffer (LI-COR, at a final dilution of $1 \times$ ) supplemented with $10 \% \beta$-mercaptoethanol (Sigma-Aldrich), heated at $95^{\circ} \mathrm{C}$ for $10 \mathrm{~min}$, separated on NuPAGE 4-12\% Bis-Tris Gels (Invitrogen) for $90 \mathrm{~min}$ at $110 \mathrm{~V}$ and blotted on to Immobilon-FL poly(vinylidene fluoride) membranes (Merck Millipore). The transfer was performed at a constant voltage of $30 \mathrm{~V}$ for $30 \mathrm{~min}$ After the transfer, the membrane was blocked with $1 \%$ casein in PBS (Thermo Fisher Scientific, catalogue no. 37528). Proteins were stained using primary antibodies (Extended Data Fig. 1) against ACE2 (1:1,000, Abcam), TMPRSS2 (1:1,000, Abcam) and GAPDH (1:5,000, Abcam, Bio-Rad), and infrared dye-labelled secondary antibodies (LI-COR IRDye; Bio-Rad StarBright) Uncropped and unprocessed western blots are provided with Source data.

Immunofluorescence of EndoC- $\beta$ H1 cells. EndoC- $\beta$ H1 cells were seeded in an 8- $\mu \mathrm{m}$ IBIDI slide. After $48 \mathrm{~h}$, cells were fixed with $1 \%$ PFA for $15 \mathrm{~min}$ at room temperature. Cells were treated with $0.1 \mathrm{M}$ glycine for $10 \mathrm{~min}$ at room temperature, followed by permeabilization with $0.25 \%$ Triton X-100 in PBS for $10 \mathrm{~min}$ and subsequent blocking with $3 \%$ BSA in $0.1 \%$ Triton X-100 for $30 \mathrm{~min}$ at room temperature. After blocking, primary antibodies were added, diluted in 5\% normal donkey serum in $0.1 \%$ Triton X-100 in PBS and incubated for $2 \mathrm{~h}$ at room temperature. Cells were washed twice and incubated with secondary antibodies and DAPI in 5\% normal donkey serum in $0.1 \%$ Triton X-100 in PBS for $1 \mathrm{~h}$ at room temperature in the dark. For ACE2-blocking experiments, ACE2 primary antibody with and without blocking peptide (Extended Data Fig. 1) at sevenfold excess protein amount was incubated for $30 \mathrm{~min}$ at room temperature in the respective buffer.

Cell culture and immunofluorescence staining of HAECs. Differentiated HAECs were generated as described by Winkelmann et al. ${ }^{124}$. All experiments were performed with approval of the ethics committee of the Medical School Hannover (project no. 2701-2015). Briefly, $3.5 \times 10^{4}$ basal epithelial cells obtained 
from several donors were seeded on collagen-coated 6.5-mm Transwell filters (Corning Costar). On reaching confluency $(\sim 48 \mathrm{~h})$, the apical side medium was removed (air lifting) and the basolateral side replaced with air-liquid interface differentiation medium (DMEM-H and LHC Basal (1:1), Thermo Fisher Scientific, supplemented with Airway Epithelial Cell Growth Medium Supplement Pack, Promocell). To avoid mucus accumulation, cells were washed with PBS every $3 \mathrm{~d}$ from day 14 . Then $25-30 \mathrm{~d}$ after air lifting, cells were fixed with $4 \%$ PFA in PBS for $30 \mathrm{~min}$ and permeabilized for $10 \mathrm{~min}$ with $0.2 \%$ saponin and $10 \%$ FCS (Thermo Fisher Scientific) in PBS. Cells were stained with anti-ACE2 (1:750, Abcam) or anti-TMPRSS2 (1:250, Abcam), and anti- $\alpha$-tubulin antibody (1:500, Thermo Fisher Scientific; Extended Data Fig. 1) diluted in PBS, 0.2\% saponin and $10 \%$ FCS overnight at $4{ }^{\circ} \mathrm{C}$. Subsequently, cells were washed twice with PBS and incubated for $1 \mathrm{~h}$ at room temperature in PBS, $0.2 \%$ saponin and $10 \%$ FCS containing Alexa Fluor-488-labelled anti-rabbit secondary antibody, Alexa Fluor647-labelled anti-rat secondary antibody (1:500; Thermo Fisher Scientific) and DAPI (1:5,000; Thermo Fisher Scientific). Images were acquired on an inverted confocal microscope (Leica TCS SP5) using a 40× lens (Leica HC PL APO CS2 $40 \times 1.30$ OIL). Images for the blue (DAPI), green (Alexa Fluor-488) and red (Alexa Fluor-647) channels were taken in sequential mode using appropriate excitation and emission settings.

Reporting Summary. Further information on research design is available in the Nature Research Reporting Summary linked to this paper.

\section{Data availability}

RNA-seq data have been deposited in the National Center for Biotechnology Information's Gene Expression Omnibus under GEO series accession no. GSE159717. Additional data that support the findings of the present study are available from the corresponding authors on request. Source data are provided with this paper.

\section{Code availability}

For raw data processing off the instruments, code for two customized programs based on Picard tools (v.2.19.2) is available at https://github.com/DanieleBarreca/ picard and https://broadinstitute.github.io/picard. Further programs used for transcriptome analysis are described in Methods.

Received: 15 July 2020; Accepted: 14 January 2021; Published online: 3 February 2021

\section{References}

1. Zhu, N. et al. A novel coronavirus from patients with pneumonia in China, 2019. N. Engl. J. Med. 382, 727-733 (2020).

2. Lai, C.-C., Ko, W.-C., Lee, P.-I., Jean, S.-S. \& Hsueh, P.-R. Extra-respiratory manifestations of COVID-19. Int. J. Antimicrob. Agents 56, 106024 (2020).

3. Gupta, A. et al. Extrapulmonary manifestations of COVID-19. Nat. Med. 26, 1017-1032 (2020).

4. Wichmann, D. et al. Autopsy findings and venous thromboembolism in patients with COVID-19: a prospective cohort study. Ann. Intern. Med. 173, 268-277 (2020).

5. Xiao, F. et al. Evidence for gastrointestinal infection of SARS-CoV-2. Gastroenterology 158, 1831-1833 e1833 (2020).

6. Puelles, V. G. et al. Multiorgan and renal tropism of SARS-CoV-2. N. Engl. J. Med. 383, 590-592 (2020).

7. Song, E. et al. Neuroinvasion of SARS-CoV-2 in human and mouse brain. J. Exp. Med. 218, e20202135 (2021).

8. Hoffmann, M. et al. SARS-CoV-2 cell entry depends on ACE2 and TMPRSS2 and is blocked by a clinically proven protease inhibitor. Cell 181, 271-280.e8 (2020)

9. Liu, F. et al. ACE2 expression in pancreas may cause pancreatic damage after SARS-CoV-2 infection. Clin. Gastroenterol. Hepatol. 18, 2128-2130.e2 (2020).

10. Taneera, J. et al. Expression profile of SARS-CoV-2 host receptors in human pancreatic islets revealed upregulation of ACE2 in diabetic donors. Biology 9, 215 (2020).

11. Blodgett, D. M. et al. Novel observations from next-generation RNA sequencing of highly purified human adult and fetal islet cell subsets. Diabetes 64, 3172-3181 (2015).

12. Fignani, D. et al. SARS-CoV-2 receptor angiotensin I-converting enzyme type 2 (ACE2) is expressed in human pancreatic $\beta$-cells and in the human pancreas microvasculature. Front. Endocrinol. 11, 596898 (2020).

13. Kusmartseva, I. et al. Expression of SARS-CoV-2 entry factors in the pancreas of normal organ donors and individuals with COVID-19. Cell Metab. 32, 1041-1051.e6 (2020).

14. Yang, J. K., Lin, S. S., Ji, X. J. \& Guo, L. M. Binding of SARS coronavirus to its receptor damages islets and causes acute diabetes. Acta Diabetol. 47, 193-199 (2010).
15. Muniangi-Muhitu, H. et al. Covid-19 and diabetes: a complex bidirectional relationship. Front. Endocrinol. 11, 758 (2020).

16. Rubino, F. et al. New-onset diabetes in Covid-19. N. Engl. J. Med. 383, 789-790 (2020).

17. Guan, W. J. et al. Clinical characteristics of coronavirus disease 2019 in China. N. Engl. J. Med. 382, 1708-1720 (2020).

18. Li, J. et al. COVID-19 infection may cause ketosis and ketoacidosis. Diabetes Obes. Metab. 22, 1935-1941 (2020).

19. Chow, N. et al. Preliminary estimates of the prevalence of selected underlying health conditions among patients with coronavirus disease 2019-United States, February 12-March 28, 2020. MMWR Morb. Mortal. Wkly Rep. 69, 382-386 (2020).

20. Holman, N. et al. Risk factors for COVID-19-related mortality in people with type 1 and type 2 diabetes in England: a population-based cohort study. Lancet Diabetes Endocrinol. 8, 823-833 (2020).

21. Williamson, E. J. et al. Factors associated with COVID-19-related death using OpenSAFELY. Nature 584, 430-436 (2020).

22. Zhu, L. et al. Association of blood glucose control and outcomes in patients with COVID-19 and pre-existing type 2 diabetes. Cell Metab. 31, 1068-1077.e3 (2020).

23. Akarsu, C. et al. Association between acute pancreatitis and COVID-19: could pancreatitis be the missing piece of the puzzle about increased mortality rates? J. Invest. Surg. https://doi.org/10.1080/08941939.2020.18332 63 (2020).

24. Xue, T. et al. Blood glucose levels in elderly subjects with type 2 diabetes during COVID-19 outbreak: a retrospective study in a single center. Preprint at medRxiv https://doi.org/10.1101/2020.03.31.20048579 (2020).

25. Goldman, N., Fink, D., Cai, J., Lee, Y. N. \& Davies, Z. High prevalence of COVID-19-associated diabetic ketoacidosis in UK secondary care. Diabetes Res. Clin. Pr. 166, 108291 (2020).

26. Chee, Y. J., Ng, S. J. H. \& Yeoh, E. Diabetic ketoacidosis precipitated by Covid-19 in a patient with newly diagnosed diabetes mellitus. Diabetes Res. Clin. Pr. 164, 108166 (2020).

27. Marchand, L., Pecquet, M. \& Luyton, C. Type 1 diabetes onset triggered by COVID-19. Acta Diabetol. 57, 1265-1266 (2020).

28. Hollstein, T. et al. Autoantibody-negative insulin-dependent diabetes mellitus after SARS-CoV-2 infection: a case report. Nat. Metab. 2, 1021-1024 (2020).

29. Ebekozien, O. A., Noor, N., Gallagher, M. P. \& Alonso, G. T. Type 1 diabetes and COVID-19: preliminary findings from a multicenter surveillance study in the U.S. Diabetes Care 43, e83-e85 (2020).

30. Unsworth, R. et al. New-onset type 1 diabetes in children during COVID-19: multicenter regional findings in the U.K. Diabetes Care 43, e170-e171 (2020).

31. Chen, J., Wu, C., Wang, X., Yu, J. \& Sun, Z. The impact of COVID-19 on blood glucose: a systematic review and meta-analysis. Front. Endocrinol. 11, $574541(2020)$

32. Tittel, S. R. et al. Did the COVID-19 lockdown affect the incidence of pediatric type 1 diabetes in Germany? Diabetes Care 43, e172-e173 (2020).

33. DiMeglio, L. A., Albanese-O’Neill, A., Munoz, C. E. \& Maahs, D. M. COVID-19 and children with diabetes-updates, unknowns, and next steps: first, do no extrapolation. Diabetes Care 43, 2631-2634 (2020).

34. Coate, K. C. et al. SARS-CoV-2 cell entry factors ACE2 and TMPRSS2 are expressed in the microvasculature and ducts of human pancreas but are not enriched in $\beta$ cells. Cell Metab. 32, 1028-1040.e4 (2020).

35. Classification of Diabetes Mellitus (WHO, 2019); https://www.who.int/ publications/i/item/classification-of-diabetes-mellitus

36. Pan, L. et al. Clinical characteristics of COVID-19 patients with digestive symptoms in Hubei, China: a descriptive, cross-sectional, multicenter study. Am. J. Gastroenterol. 115, 766-773 (2020).

37. Hikmet, F. et al. The protein expression profile of ACE2 in human tissues. Mol. Syst. Biol. 16, e9610 (2020).

38. Lee, J. J. et al. Relative abundance of SARS-CoV-2 entry genes in the enterocytes of the lower gastrointestinal tract. Genes 11, 645 (2020).

39. Nicin, L. et al. Cell type-specific expression of the putative SARS-CoV-2 receptor ACE2 in human hearts. Eur. Heart J. 41, 1804-1806 (2020).

40. Chen, Y. et al. Rhesus angiotensin converting enzyme 2 supports entry of severe acute respiratory syndrome coronavirus in Chinese macaques. Virology 381, 89-97 (2008).

41. Marques, F. Z. et al. Molecular characterization of renin-angiotensin system components in human intrauterine tissues and fetal membranes from vaginal delivery and cesarean section. Placenta 32, 214-221 (2011).

42. Smits, S. L. et al. Distinct severe acute respiratory syndrome coronavirus-induced acute lung injury pathways in two different nonhuman primate species. J. Virol. 85, 4234-4245 (2011).

43. Esumi, M. et al. Transmembrane serine protease TMPRSS2 activates hepatitis C virus infection. Hepatology 61, 437-446 (2015). 
44. Collin, J. et al. Co-expression of SARS-CoV-2 entry genes in the superficial adult human conjunctival, limbal and corneal epithelium suggests an additional route of entry via the ocular surface. Ocul. Surf. https://doi. org/10.1016/j.jtos.2020.05.013 (2020).

45. Ubuka, T., Moriya, S., Soga, T. \& Parhar, I. Identification of transmembrane protease serine 2 and forkhead Box Al as the potential bisphenol A responsive genes in the neonatal male rat brain. Front. Endocrinol. 9, 139 (2018).

46. Zmora, P. et al. Non-human primate orthologues of TMPRSS2 cleave and activate the influenza virus hemagglutinin. PLoS ONE 12, e0176597 (2017).

47. Sakaguchi, W. et al. Existence of SARS-CoV-2 entry molecules in the oral cavity. Int. J. Mol. Sci. 21, 6000 (2020).

48. Tsonkova, V. G. et al. The EndoC-betaH1 cell line is a valid model of human beta cells and applicable for screenings to identify novel drug target candidates. Mol. Metab. 8, 144-157 (2018).

49. Blume, C. et al. A novel isoform of ACE2 is expressed in human nasal and bronchial respiratory epithelia and is upregulated in response to RNA respiratory virus infection. Nat Genet. https://doi.org/10.1038/s41588-02000759-x (2021)

50. Lucas, J. M. et al. The androgen-regulated type II serine protease TMPRSS2 is differentially expressed and mislocalized in prostate adenocarcinoma. J. Pathol. 215, 118-125 (2008).

51. Leung, J. M. et al. ACE-2 expression in the small airway epithelia of smokers and COPD patients: implications for COVID-19. Eur. Respir. J. 55, https://doi.org/10.1183/13993003.00688-2020 (2020).

52. Wang, M. et al. Remdesivir and chloroquine effectively inhibit the recently emerged novel coronavirus $(2019-\mathrm{nCoV})$ in vitro. Cell Res. 30, 269-271 (2020).

53. Holland, A. M., Hale, M. A., Kagami, H., Hammer, R. E. \& MacDonald, R. J. Experimental control of pancreatic development and maintenance. Proc. Natl Acad. Sci. USA 99, 12236-12241 (2002).

54. Wu, K. L. et al. Hepatocyte nuclear factor 3 beta is involved in pancreatic beta-cell-specific transcription of the pdx-1 gene. Mol. Cell. Biol. 17, 6002-6013 (1997).

55. Sander, M. et al. Homeobox gene Nkx6.1 lies downstream of Nkx2.2 in the major pathway of beta-cell formation in the pancreas. Development 127, 5533-5540 (2000).

56. Brahim Belhaouari, D. et al. The strengths of scanning electron microscopy in deciphering SARS-CoV-2 infectious cycle. Front. Microbiol. 11, 2014 (2020)

57. Zhu, N. et al. Morphogenesis and cytopathic effect of SARS-CoV-2 infection in human airway epithelial cells. Nat. Commun. 11, 3910 (2020)

58. Lamers, M. M. et al. SARS-CoV-2 productively infects human gut enterocytes. Science 369, eabc1669 (2020).

59. Semplici, F. et al. Human mutation within Per-Arnt-Sim (PAS) domain-containing protein kinase (PASK) causes basal insulin hypersecretion. J. Biol. Chem. 286, 44005-44014 (2011).

60. Zhang, D. D. et al. Per-Arnt-Sim kinase (PASK): an emerging regulator of mammalian glucose and lipid metabolism. Nutrients 7, 7437-7450 (2015).

61. Boonen, S. E. et al. Transient neonatal diabetes, ZFP57, and hypomethylation of multiple imprinted loci: a detailed follow-up. Diabetes Care 36, 505-512 (2013).

62. Hoytema van Konijnenburg, E. M. M. et al. Hyperinsulinism in a patient with a Zellweger spectrum disorder and a 16p11.2 deletion syndrome. Mol. Genet Metab. Rep. 23, 100590 (2020).

63. Huang, C. et al. Synaptotagmin 4 regulates pancreatic beta cell maturation by modulating the $\mathrm{Ca}^{2+}$ sensitivity of insulin secretion vesicles. Dev. Cell $\mathbf{4 5}$ 347-361 e345 (2018).

64. Aljaibeji, $\mathrm{H}$. et al. Reduced expression of PLCXD3 associates with disruption of glucose sensing and insulin signaling in pancreatic $\beta$-cells. Front. Endocrinol. 10, 735 (2019).

65. Pae, E. K. \& Kim, G. Insulin production hampered by intermittent hypoxia via impaired zinc homeostasis. PLoS ONE 9, e90192 (2014).

66. Ackermann, A. M., Wang, Z., Schug, J., Naji, A. \& Kaestner, K. H. Integration of ATAC-seq and RNA-seq identifies human alpha cell and beta cell signature genes. Mol. Metab. 5, 233-244 (2016).

67. De Beeck, A. O. \& Eizirik, D. L. Viral infections in type 1 diabetes mellitus-why the $\beta$ cells? Nat. Rev. Endocrinol. 12, 263-273 (2016)

68. Ferreira, R. C. et al. A type I interferon transcriptional signature precedes autoimmunity in children genetically at risk for type 1 diabetes. Diabetes 63, 2538-2550 (2014).

69. Reynier, F. et al. Specific gene expression signature associated with development of autoimmune type-I diabetes using whole-blood microarray analysis. Genes Immun. 11, 269-278 (2010)

70. Kruger, J. et al. Drug inhibition of SARS-CoV-2 replication in human pluripotent stem cell-derived intestinal organoids. Cell Mol. Gastroenterol. Hepatol. https://doi.org/10.1016/j.jcmgh.2020.11.003 (2020).

71. Nienhold, R. et al. Two distinct immunopathological profiles in autopsy lungs of COVID-19. Nat. Commun. 11, 5086 (2020).
72. Menter, T. et al. Postmortem examination of COVID-19 patients reveals diffuse alveolar damage with severe capillary congestion and variegated findings in lungs and other organs suggesting vascular dysfunction. Histopathology 77, 198-209 (2020).

73. Braun, F. et al. SARS-CoV-2 renal tropism associates with acute kidney injury. Lancet 396, 597-598 (2020).

74. Farkash, E. A., Wilson, A. M. \& Jentzen, J. M. Ultrastructural evidence for direct renal infection with SARS-CoV-2. J. Am. Soc. Nephrol. 31, 1683-1687 (2020).

75. Hanley, B. et al. Histopathological findings and viral tropism in UK patients with severe fatal COVID-19: a post-mortem study. Lancet Microbe 1, e245-e253 (2020).

76. Khan, S. et al. Does SARS-CoV-2 infect the kidney? J. Am. Soc. Nephrol. 31, 2746-2748 (2020).

77. Kissling, S. et al. Collapsing glomerulopathy in a COVID-19 patient. Kidney Int. 98, 228-231 (2020).

78. Kudose, S. et al. Kidney biopsy findings in patients with COVID-19. J. Am. Soc. Nephrol. 31, 1959-1968 (2020).

79. Su, H. et al. Renal histopathological analysis of 26 postmortem findings of patients with COVID-19 in China. Kidney Int. 98, 219-227 (2020).

80. Hasan, N. M. et al. Genetic association of the neuropilin-1 gene with type 1 diabetes in children: neuropilin-1 expression in pancreatic islets. Diabetes Res. Clin. Pr. 87, e29-e32 (2010).

81. Segerstolpe, A. et al. Single-cell transcriptome profiling of human pancreatic islets in health and type 2 diabetes. Cell Metab. 24, 593-607 (2016).

82. Wang, Y. J. et al. Single-cell transcriptomics of the human endocrine pancreas. Diabetes 65, 3028-3038 (2016).

83. Cantuti-Castelvetri, L. et al. Neuropilin-1 facilitates SARS-CoV-2 cell entry and infectivity. Science 370, 856-886 (2020).

84. Wei, C. et al. HDL-scavenger receptor B type 1 facilitates SARS-CoV-2 entry. Nat. Metab. 2, 1391-1400 (2020).

85. Hoffmann, M., Kleine-Weber, H. \& Pöhlmann, S. A multibasic cleavage site in the spike protein of SARS-CoV-2 is essential for infection of human lung cells. Mol. Cell 78, 779-784.e775 (2020).

86. Millet, J. K. \& Whittaker, G. R. Host cell proteases: critical determinants of coronavirus tropism and pathogenesis. Virus Res. 202, 120-134 (2015).

87. Yang, L. et al. A human pluripotent stem cell-based platform to study SARS-CoV-2 tropism and model virus infection in human cells and organoids. Cell Stem Cell 27, 125-136.e7 (2020).

88. Hodik, M. et al. Enterovirus infection of human islets of Langerhans affects beta-cell function resulting in disintegrated islets, decreased glucose stimulated insulin secretion and loss of Golgi structure. BMJ Open Diabetes Res. Care 4, e000179 (2016).

89. Oshima, M. et al. Virus-like infection induces human beta cell dedifferentiation. JCI Insight 3, e97732 (2018).

90. Sachs, S. et al. Targeted pharmacological therapy restores $\beta$-cell function for diabetes remission. Nat. Metab. 2, 192-209 (2020).

91. Bozzo, C. P. et al. IFITM proteins promote SARS-CoV-2 infection and are targets for virus inhibition. Preprint at bioRxiv https://doi. org/10.1101/2020.08.18.255935 (2020).

92. Han, Y. et al. Identification of SARS-CoV-2 inhibitors using lung and colonic organoids. Nature 589, 270-275 (2021).

93. Morris, K. V. The improbability of the rapid development of a vaccine for SARS-CoV-2. Mol. Ther. 28, 1548-1549 (2020).

94. Bermejo-Martin, J. F. et al. SARS-CoV-2 RNA viremia is associated with a sepsis-like host response and critical illness in COVID-19. Preprint at medRxiv https://doi.org/10.1101/2020.08.25.20154252 (2020).

95. Fairweather, D. \& Rose, N. R. Type 1 diabetes: virus infection or autoimmune disease? Nat. Immunol. 3, 338-340 (2002).

96. Ruiz, P. L. et al. Pandemic influenza and subsequent risk of type 1 diabetes: a nationwide cohort study. Diabetologia 61, 1996-2004 (2018).

97. Petzold, A., Solimena, M. \& Knoch, K. P. Mechanisms of beta cell dysfunction associated with viral infection. Curr. Diab. Rep. 15, 73 (2015).

98. Schepis, T. et al. SARS-CoV2 RNA detection in a pancreatic pseudocyst sample. Pancreatology 20, 1011-1012 (2020).

99. Desai, N. et al. Temporal and spatial heterogeneity of host response to SARS-CoV-2 pulmonary infection. Nat. Commun. 11, 6319 (2020).

100. Brook, O. R. et al. Feasibility and safety of ultrasound-guided minimally invasive autopsy in COVID-19 patients. Abdom. Radiol. https://doi. org/10.1007/s00261-020-02753-7 (2020).

101. Massoth, L. R. et al. Comparison of RNA in situ hybridization and immunohistochemistry techniques for the detection and localization of SARS-CoV-2 in human tissues. Am. J. Surg. Pathol. 45, 14-24 (2021).

102. Best Rocha, A. et al. Detection of SARS-CoV-2 in formalin-fixed paraffin-embedded tissue sections using commercially available reagents. Lab. Invest. 100, 1485-1489 (2020).

103. Bradley, B. T. et al. Histopathology and ultrastructural findings of fatal COVID-19 infections in Washington State: a case series. Lancet 396, 320-332 (2020) 
104. Love, M. I., Huber, W. \& Anders, S. Moderated estimation of fold change and dispersion for RNA-seq data with DESeq2. Genome Biol. 15, 550 (2014).

105. Raudvere, U. et al. g:Profiler: a web server for functional enrichment analysis and conversions of gene lists (2019 update). Nucleic Acids Res. 47, W191-w198 (2019).

106. Kuleshov, M. V. et al. Enrichr: a comprehensive gene set enrichment analysis web server 2016 update. Nucleic Acids Res. 44, W90-W97 (2016).

107. Subramanian, A. et al. Gene set enrichment analysis: a knowledge-based approach for interpreting genome-wide expression profiles. Proc. Natl Acad. Sci. USA 102, 15545-15550 (2005).

108. Groß, R. et al. Detection of SARS-CoV-2 in human breastmilk. Lancet 395, 1757-1758 (2020).

109. Chu, D. K. et al. Molecular diagnosis of a novel coronavirus (2019-nCoV) causing an outbreak of pneumonia. Clin. Chem. 66, 549-555 (2020).

110. Reed, L. J. \& Muench, H. A simple method of estimating fifty per cent endpoints. Am. J. Epidemiol. 27, 493-497 (1938).

111. Groß, R. et al. A placenta derived C-terminal fragment of $\beta$-hemoglobin with combined antibacterial and antiviral activity. Front. Microbiol. 11, 508 (2020).

112. Picelli, S. et al. Full-length RNA-seq from single cells using Smart-seq2. Nat. Protoc. 9, 171-181 (2014).

113. Picard toolkit v.2.19.2 (Broad Institute, 2019); https://github.com/ DanieleBarreca/picard/

114. Dobin, A. et al. STAR: ultrafast universal RNA-seq aligner. Bioinformatics 29, 15-21 (2013).

115. Lawrence, $M$. et al. Software for computing and annotating genomic ranges. PLoS Comput. Biol. 9, e1003118 (2013).

116. Wickham, H. ggplot2: Elegant Graphics for Data Analysis (Springer, 2016).

117. Gu, Z., Eils, R. \& Schlesner, M. Complex heatmaps reveal patterns and correlations in multidimensional genomic data. Bioinformatics 32, 2847-2849 (2016).

118. Blighe, K. \& Sharmila Lewis, M. EnhancedVolcano: Publication-ready volcano plots with enhanced colouring and labeling. Bioconductor from within R. R version 1.8.0 (2020).

119. Kolde, R. pheatmap package v. 1.0.12 (CRAN, 2018).

120. Stephens, M. False discovery rates: a new deal. Biostatistics $\mathbf{1 8}$ 275-294 (2017).

121. Ignatiadis, N., Klaus, B., Zaugg, J. B. \& Huber, W. Data-driven hypothesis weighting increases detection power in genome-scale multiple testing. Nat. Methods 13, 577-580 (2016).

122. Chen, E. Y. et al. Enrichr: interactive and collaborative HTML5 gene list enrichment analysis tool. BMC Bioinf. 14, 128 (2013).

123. Liberzon, A. et al. The molecular signatures database (MSigDB) hallmark gene set collection. Cell Syst. 1, 417-425 (2015).

124. Winkelmann, V. E. et al. Inflammation-induced upregulation of P2X4 expression augments mucin secretion in airway epithelia. Am. J. Physiol. Lung Cell. Mol. Physiol. 316, L58-L70 (2019).

\section{Acknowledgements}

We thank A. Saed, R. Gowdru Bijegatte, K. Köhn, D. Krnavek, N. Schrott, R. Kunz and J. Nell for their excellent technical assistance. We also thank, in particular, L. Labriola, as well as M. Melzer, J. Merkle and M. Hohwieler, for helpful discussions. We thank J. Lyon, N. Smith and J. Manning Fox (Alberta Diabetes Institute IsletCore) for their work isolating human islets, and organ procurement organizations across Canada, particularly the Human Organ Procurement and Exchange (HOPE) programme in Edmonton and the Trillium Gift of Life Network (TGLN) in Ontario, for their work in obtaining human pancreata for research. We thank I. Wessbecher, coordinating the DZIF tissue bank in Heidelberg, for providing pancreatic tissue sections. We also thank S. Brandl for assistance with clinical data organization. We thank S. Schmidt for sharing the thoracic X-ray and clinical history of patient 1 with us. H.L. thanks R. Scharfmann for sharing the EndoC- $\beta \mathrm{H} 1$ cell line. Moreover, we thank K. Sato and M. Volcic for providing pLV-EF1a-human ACE2-IRES-puro and the ACE2-expressing HEK293T cells. The main funding was provided by the Deutsche Forschungsgemeinschaft (DFG) via 'focus funding on COVID-19' DFG KL 2544/8-1-AO 673221 to A.K. and J.M., as well as via 'Sachbeihilfe' KL 2544/7-1, 'Heisenberg-Programm' KL 2544/6-1 and the Baden-Württemberg-Foundation ExPoChip to A.K. This work was supported by grants from the MWK Baden-Württemberg (to J.A.M., T.F.E.B., J.S., F.K., J.M. and A.K.), the BMBF (restrict SARS-CoV-2 to F.K.), the EU's Horizon 2020 research and innovation program (Fight-nCoV, 101003555 to J.M.) and the DFG (grant nos. SPP1923 to K.M.J.S. and F.K., and CRC1279 to K.M.J.S., S.S., F.K. and J.M.). K.M.J.S. is supported by the Federal Ministry of Education and Research of Germany (BMBF Junior Research Group IMMUNOMOD, 01KI2014). A.K., M.W. and T.S. are principal investigators in the HEIST RTG funded by the DFG (GRK 2254/1). Additional funding came from the DFG (KL 2544/1-1 and 1-2 and 5-1), and the Else-Kröner-Fresenius Excellence funding (to A.K.). R.G., C.C., J.K., L.K. and T.W. are part of, and R.G. is funded by, a scholarship from the International Graduate School in Molecular Medicine, Ulm. J.A.M. is indebted to the Baden-Württemberg Stiftung for the financial support of this research project Eliteprogramme for Postdocs. S.H. received supportive funds from the Bausteinprogramm and is a designated Hertha-Nathorff-Programm fellow of Ulm University. T.E. acknowledges funding by the DFG (grant nos. 380319649 and 376202546). I.G.C. received funding from the Excellence Initiative of the German federal and state governments. This work was also funded in part by the German Center for Diabetes Research (DZD e.V.) and the Helmholtz Alliance Aging and Metabolic Programming, AMPro?

\section{Author contributions}

J.A.M., R.G., C.C., J.K., M.W., J.M., S.H. A.K., U.M. and T.W. acquired, analysed and interpreted data, and drafted and revised the manuscript. J.A.M, C.C. and T.W. performed and analysed infection experiments and functional islet assays. R.G. and T.W. performed qPCR. C.P.B. and R.G. performed western blots. L.K., S.H., T.E., M.W., J.K., R.G., K.M.J.S. and T.E. performed confocal imaging of stained organoids, and deconvolution and editing of microscopy pictures, and revised the manuscript. C.R., J.A.M., P.W. and M.W. prepared samples for and performed electron microscopy. G.F. and M.F. performed HAEC cultures and microscopy. A.S., I.W., U.M., B.G. and L.P. provided postmortem histopathological sections from patients with COVID-19. M.B., I.G.C., J.G. and M.S. performed bioinformatics analysis. J.v.V., P.E.M. and H.L. provided pancreatic islets and helped with the analysis. T.F.E.B., M.W. and J.S. provided sections of human pancreatic tissue for immunofluorescence, performed double immunohistochemistry staining and helped with analysis. S.S. supervised the BSL3 work. F.K. provided resources. T.S., S.L. and M.W. helped to interpret the data. S.H., M.W., A.K. and J.M. directed the work, interpreted the data and drafted the manuscript, with input from all authors.

\section{Competing interests}

The authors declare no competing interests.

\section{Additional information}

Extended data is available for this paper at https://doi.org/10.1038/s42255-021-00347-1.

Supplementary information The online version contains supplementary material available at https://doi.org/10.1038/s42255-021-00347-1.

Correspondence and requests for materials should be addressed to M.W., J.M., S.H. or A.K.

Peer review information Nature Metabolism thanks Michele Solimena and the other, anonymous, reviewer(s) for their contribution to the peer review of this work. Primary Handling Editor: Christoph Schmitt.

Reprints and permissions information is available at www.nature.com/reprints.

Publisher's note Springer Nature remains neutral with regard to jurisdictional claims in published maps and institutional affiliations.

(c) The Author(s), under exclusive licence to Springer Nature Limited 2021 
Used primary antibodies and their manufacturer.

\begin{tabular}{|c|c|c|c|c|}
\hline Antigen & Species & Cat. No. & Company & Dilution \\
\hline ACE2 & rabbit & ab15348 & Abcam & $\begin{array}{l}1: 1,500 \text { (IF-P); } \\
1: 1,000 \text { (WB); } \\
1: 500 \text { (IF) } \\
1: 750 \text { (HAECs) }\end{array}$ \\
\hline ACE2 blocking peptide & synthetic & ab15352 & Abcam & \\
\hline SARS-CoV-2 spike & rabbit & ab252690 & Abcam & $1: 500$ \\
\hline SARS-CoV-2 spike & mouse & GTX632604 & Biozol & $1: 500$ \\
\hline SARS-CoV-2 nucleocapsid & rabbit & NB100-56576 & Novus biologicals & $\begin{array}{l}1: 1,000 \text { (IF); } \\
1: 100 \text { (IHC) }\end{array}$ \\
\hline SARS-CoV-2 nucleocapsid & mouse & 40143-MM05 & Sinobiological & $\begin{array}{l}1: 500 \text { (IF); } \\
1: 100(\mathrm{IHC})\end{array}$ \\
\hline TMPRSS2 & rabbit & ab92323 & Abcam & $\begin{array}{l}1: 250 \text { (IF-P); } \\
1: 1,000 \text { (WB); } \\
1: 250 \text { (HAECS) }\end{array}$ \\
\hline Cleaved CASP3 & rabbit & 9664 & Cell Signaling & $1: 100$ \\
\hline CHGA & rabbit & $\mathrm{A} 0430$ & DAKO & $1: 200$ \\
\hline C-peptide & rabbit & 4593 & Cell Signaling & $1: 200$ \\
\hline C-peptide & guinea-pig & ab30477 & Abcam & $1: 150$ \\
\hline CK19 & mouse & RCK108 & DAKO & 1:100 \\
\hline CD31 & mouse & M0823 & DAKO & $1: 35$ \\
\hline Chymotrypsin & mouse & MAB1476 & Millipore & $1: 1000$ \\
\hline GATA4 & mouse & 560327 & BD Bioscience & $1: 50$ \\
\hline Glucagon & rabbit & 2760 & Cell Signaling & $1: 200$ \\
\hline Insulin & rabbit & ab181547 & Abcam & $1: 5,000$ \\
\hline NKX6.1 & mouse & F55A12 conc. & DSHB & $1: 125$ \\
\hline PDX1 & goat & AF2419 & $R \& D$ & $1: 500$ \\
\hline Somatostatin & mouse & sc-74556 & Santa Cruz & 1:100 \\
\hline$\alpha$-tubulin & rat & MA1-80017 & Thermo Fisher & 1:500 (HAECS) \\
\hline GAPDH & rat & 607902 & BioLegend & $1: 5,000$ \\
\hline GAPDH & human & 12004168 & Biorad & $1: 5,000$ \\
\hline
\end{tabular}

Extended Data Fig. 1 | Primary antibody list. Used primary antibodies, dilutions and their manufacturer. 
a

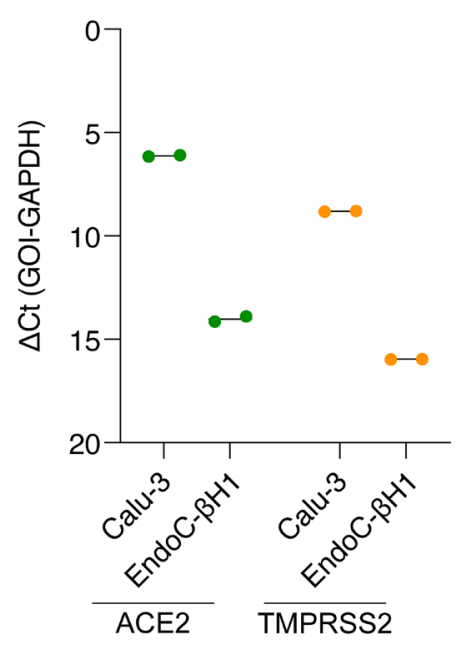

b

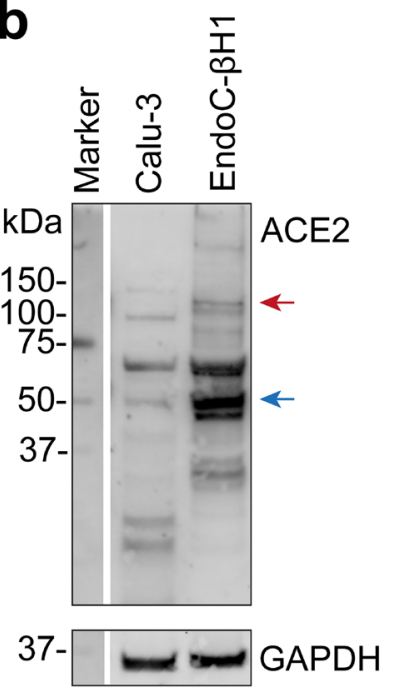

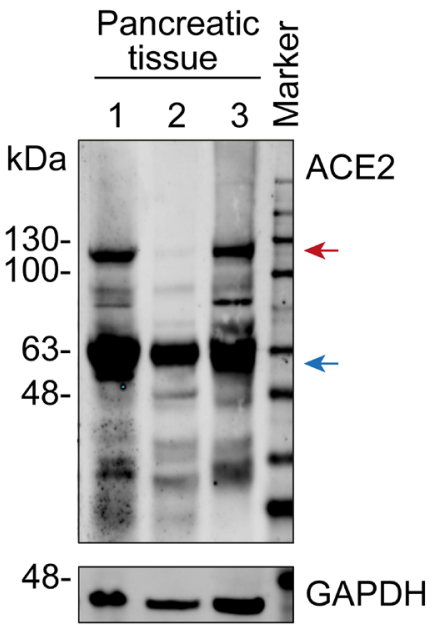
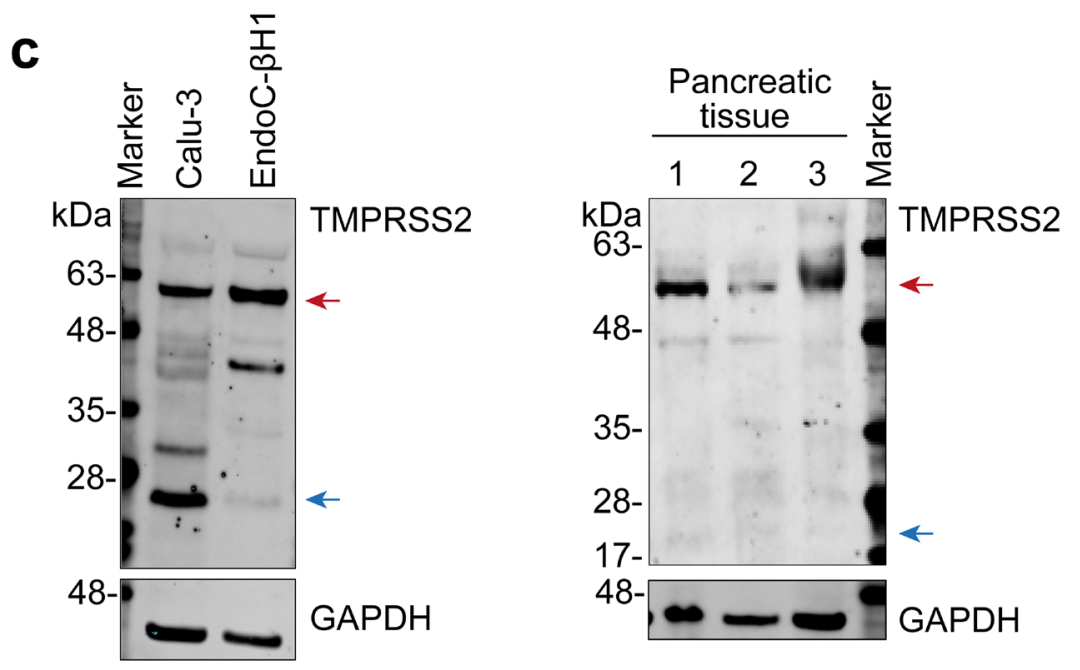

d

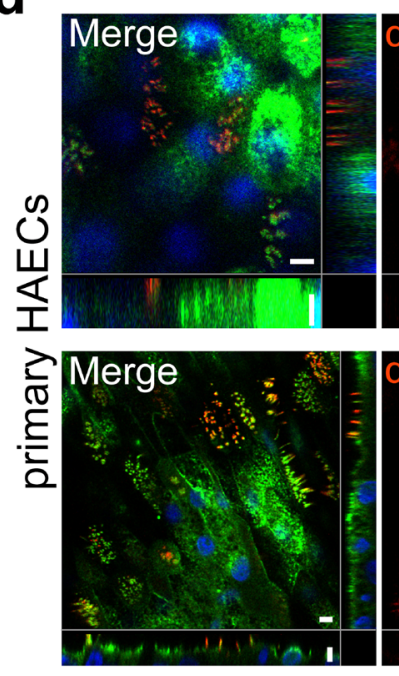

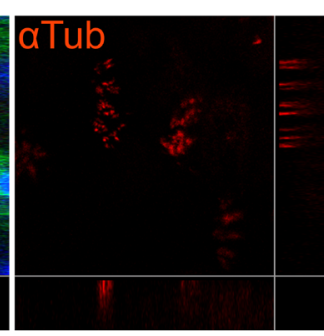

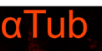

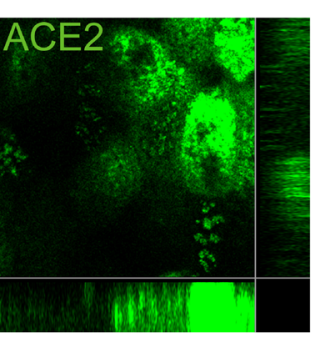

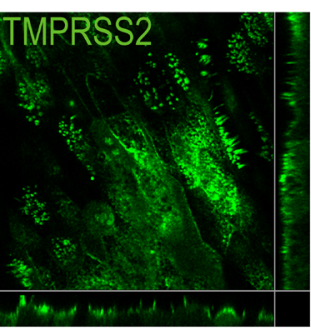

e

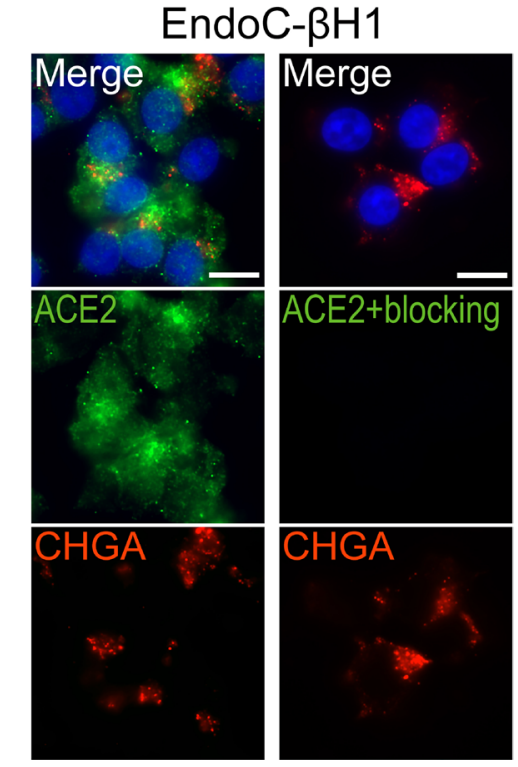

Extended Data Fig. 2 | See next page for caption. 
Extended Data Fig. 2 | Antibody validation and expression of ACE2 and TMPRSS2 in human lung Calu-3 cells, EndoC- $\beta$ H1 cells and human pancreatic tissue. (a) Expression of ACE2 and TMPRSS2 in Calu-3 and EndoC- $\beta \mathrm{H} 1$ cells was analyzed via RT-qPCR and normalized to GAPDH expression (technical duplicates). (b) Western blot analysis of ACE2 and GAPDH expression in Calu-3 cells, EndoC- $\beta \mathrm{H} 1$ cells and of frozen pancreatic tissue from three donors, representative blot of 3 technical replicates. Colored arrows indicate long (red, 110/120 kDa) and short (blue, $50 \mathrm{kDa}$ ) isoforms of $\mathrm{ACE} 2$. Of note, blots of ACE2 and GAPDH for pancreatic tissue samples derived from 3 donors were processed in parallel. (c) Western blot analysis of TMRPSS2 and GAPDH expression in Calu- 3 cells, EndoC- $\beta \mathrm{H} 1$ cells and of frozen pancreatic tissue from three donors $(n=1)$. Colored arrows indicate the glycosylated full-length (red, $54 \mathrm{kDa}$ ) and cleaved (blue, $26 \mathrm{kDa}$ ) form of TMRPSS2. Of note, blots of TMPRSS2 and GAPDH with samples derived from same experiment were processed in parallel. (d) Air-liquid interface (ALI) cultures of differentiated primary human airway epithelial cells (HAECs) were stained for $\alpha$-tubulin ( $\alpha$ Tub, red) and ACE2 or TMPRSS2 (green). Cell nuclei were visualized by DAPI (blue). Representative laser-scanning confocal images from one technical replicate are shown; scale bars indicate $5 \mu \mathrm{m}$. (e) EndoC- $\beta \mathrm{H} 1$ cells were stained for ACE2 (green) and endocrine marker chromogranin A (CHGA, red) in presence or absence of a synthetic ACE2 epitope-specific blocking peptide $(n=2)$. Scale bars indicate $10 \mu \mathrm{m}$. 
a
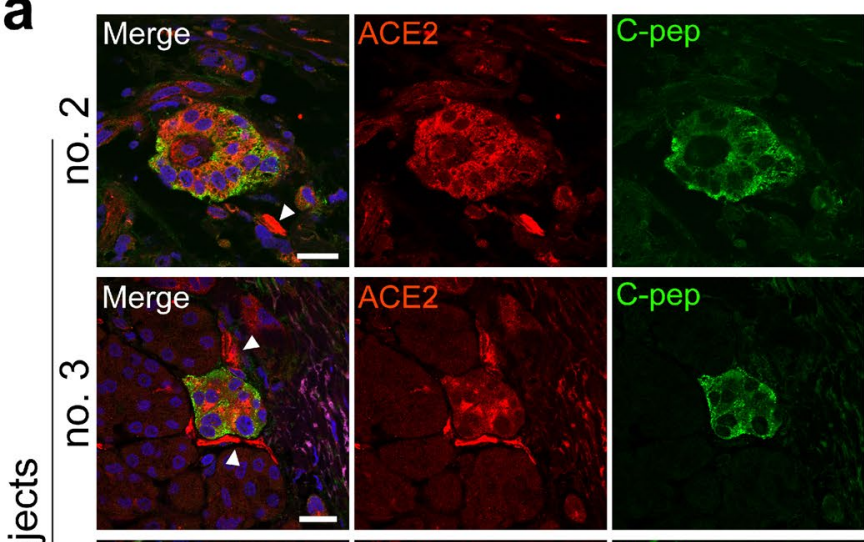

$\frac{2}{3}$
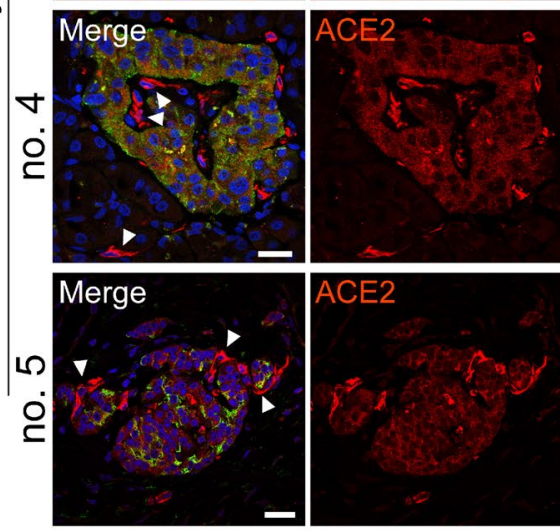

d
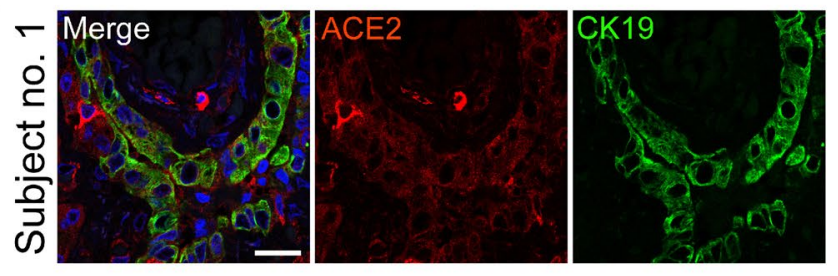

f
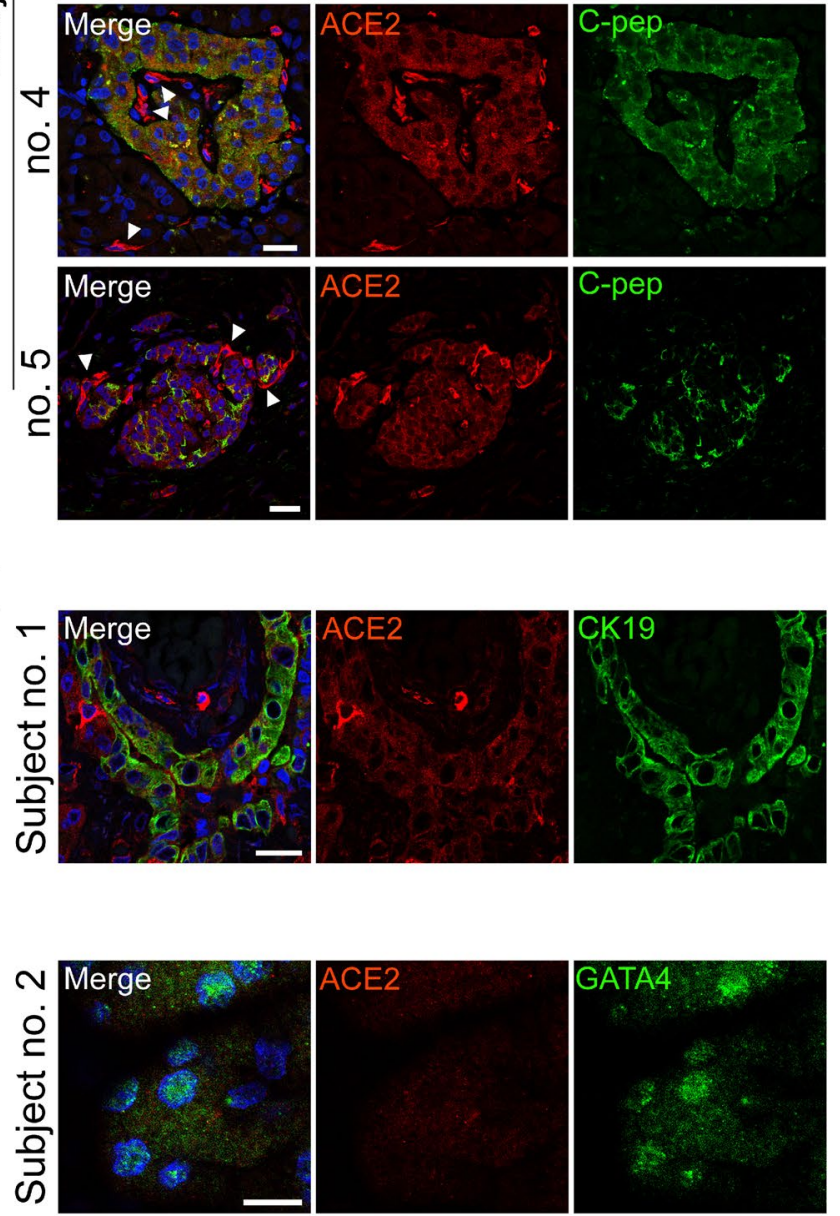

b
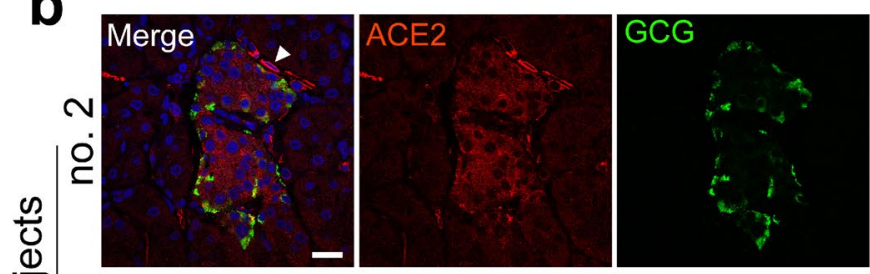

금
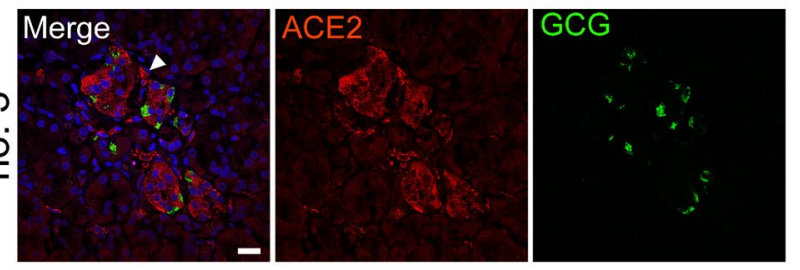

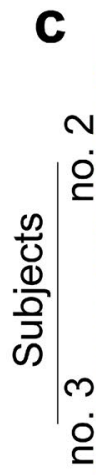
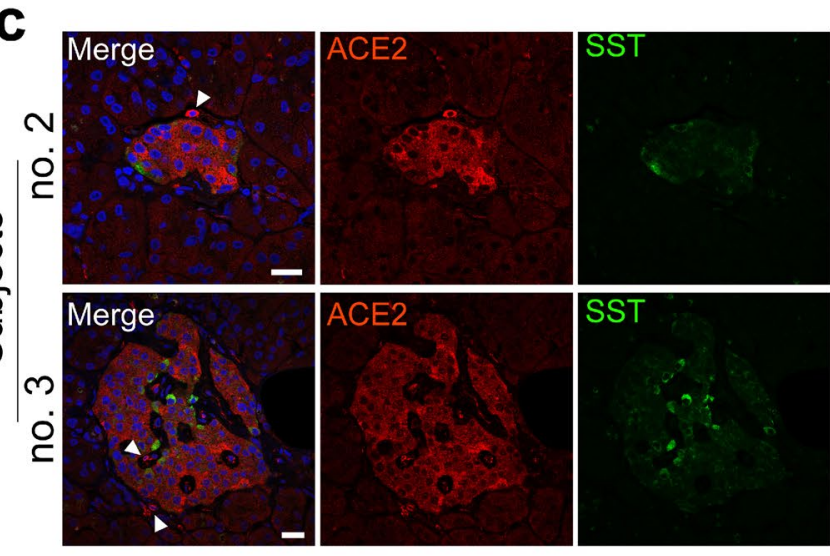

$\mathbf{e}$

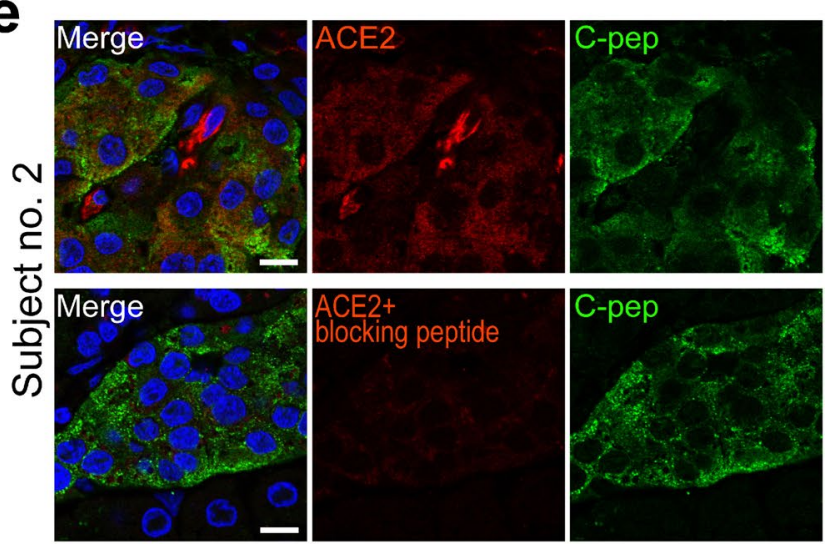

Extended Data Fig. 3 | Expression of SARS-CoV-2 entry protein ACE2 in healthy pancreatic exocrine and endocrine tissue. (a-c) Adult pancreatic tissue sections from subjects 2-5 were stained with antibodies against ACE2 (red), C-peptide (C-pep, green), glucagon (GCG, green), or somatostatin (SST, green) and specific secondary antibodies. Cell nuclei were visualized by DAPI (blue). Blood vessels are marked with white arrow heads. Representative image of stained pancreas section was selected from 4 islets. (d) Adult pancreatic tissue sections from subject 1 were stained with antibodies against ACE2 (red) and ductal marker cytokeratin 19 (CK19, green). Representative image was selected from one stained pancreas section. (e) Pancreatic tissue sections from subject 2 were stained with antibodies against ACE2 and C-peptide (C-pep, green) in the presence or absence of an ACE2 epitope-specific blocking peptide. Representative image of stained pancreas section was selected from 4 islets. (f) Pancreatic tissue sections from subject 2 were stained for ACE2 and acinar cell marker GATA binding protein 4 (GATA4, green) and specific secondary antibodies. Representative laser-scanning confocal images are shown, scale bars depict $20(\mathbf{a}-\mathbf{c})$ or $10 \mu \mathrm{m}(\mathbf{d}-\mathbf{f})$. 
a
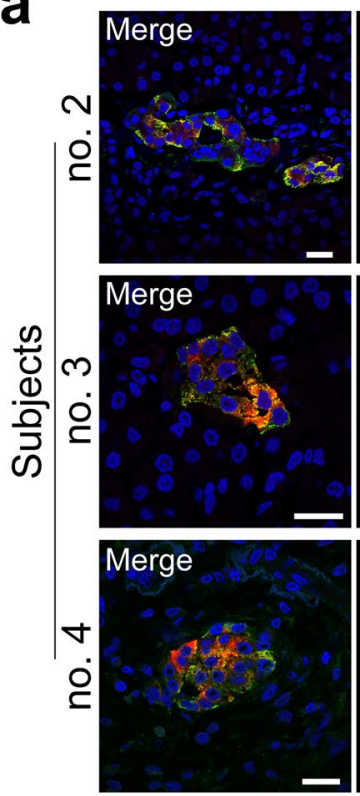

C

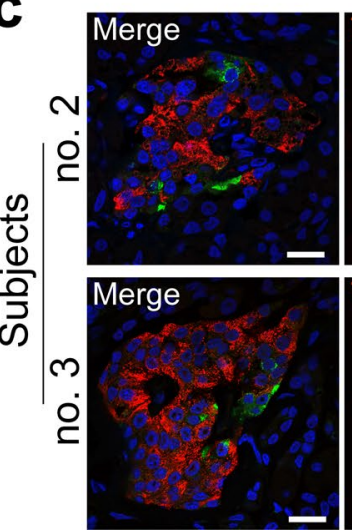

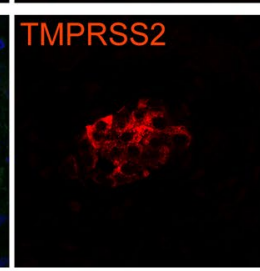
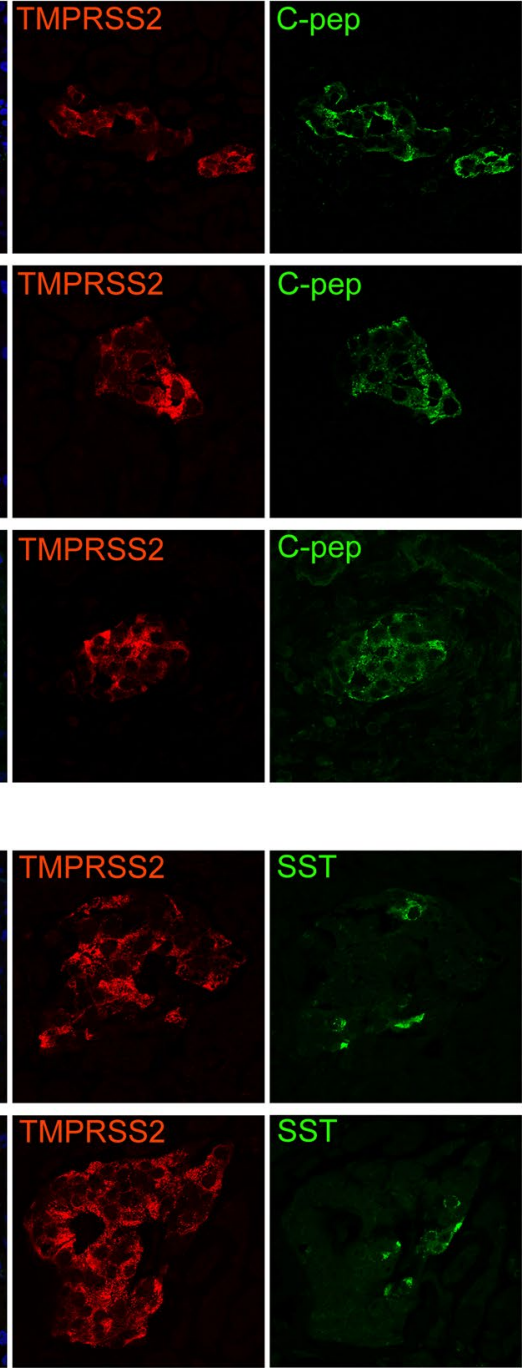

\section{b}

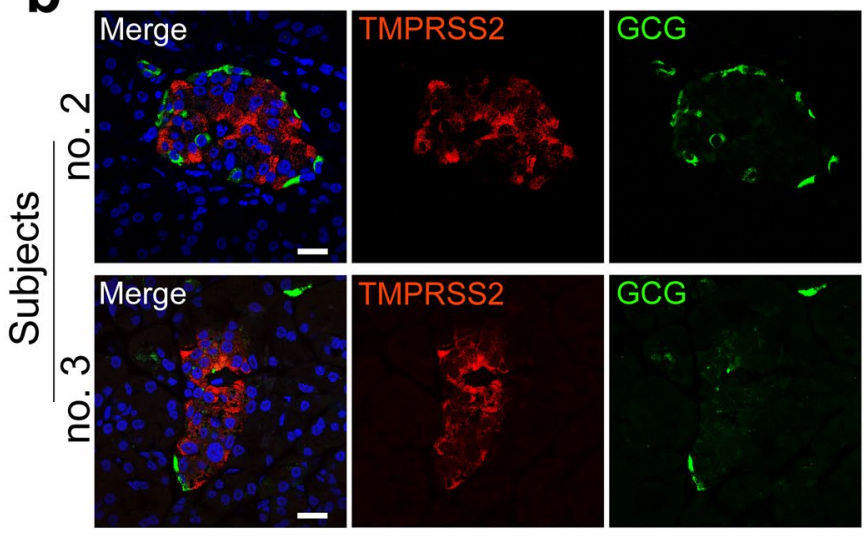

d
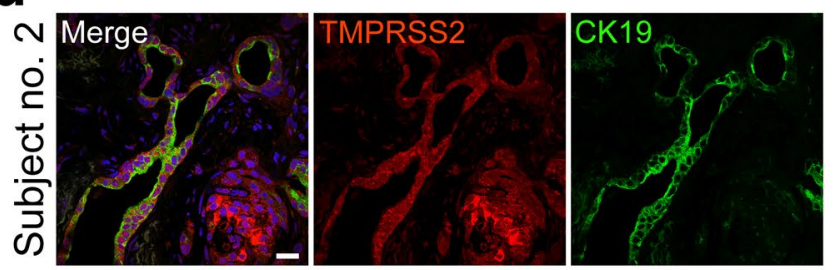

e
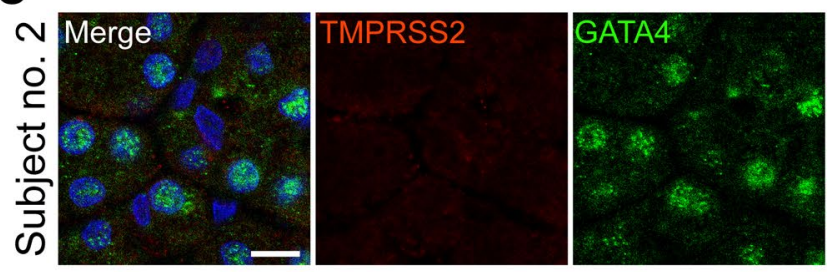

Extended Data Fig. 4 | Expression of SARS-CoV-2 entry protein TMPRSS2 in healthy pancreatic tissue. (a-c) Adult pancreatic tissue sections from subjects 2-4 were stained with antibodies against TMPRSS2 (red), C-peptide (C-pep, green), glucagon (GCG, green), or somatostatin (SST, green) and specific secondary antibodies. Cell nuclei were visualized by DAPI (blue). (d,e) Adult pancreatic tissue sections from subject 2 were stained with antibodies against TMPRSS2 (red) and ductal marker cytokeratin 19 (CK19, green) (d) or acinar cell marker GATA binding protein 4 (GATA4, green) (e) and specific secondary antibodies. Representative laser-scanning confocal images selected from 4 islets of stained pancreas section are shown, scale bars depict $20(\mathbf{a}-\mathbf{c})$ or $10 \mu \mathrm{m}(\mathbf{d}, \mathbf{e})$. 
a

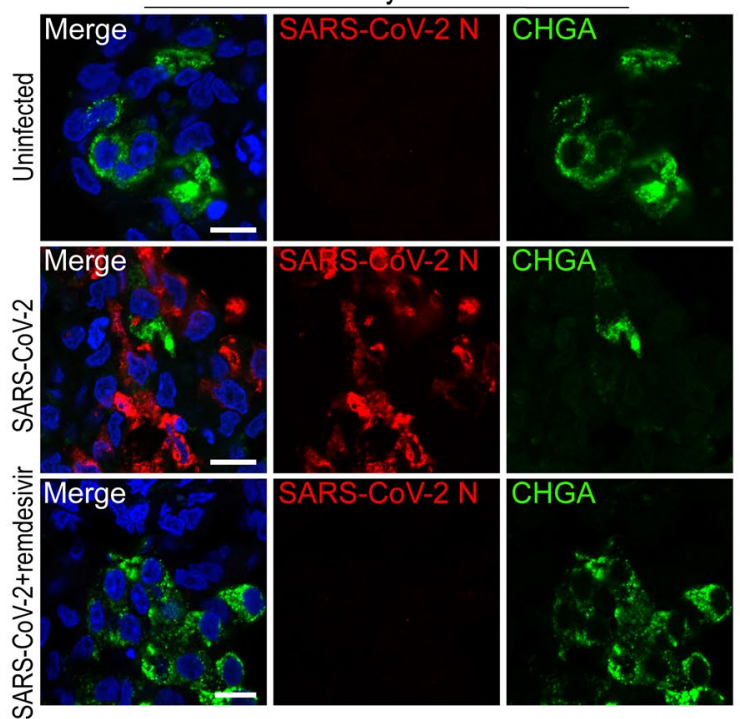

c

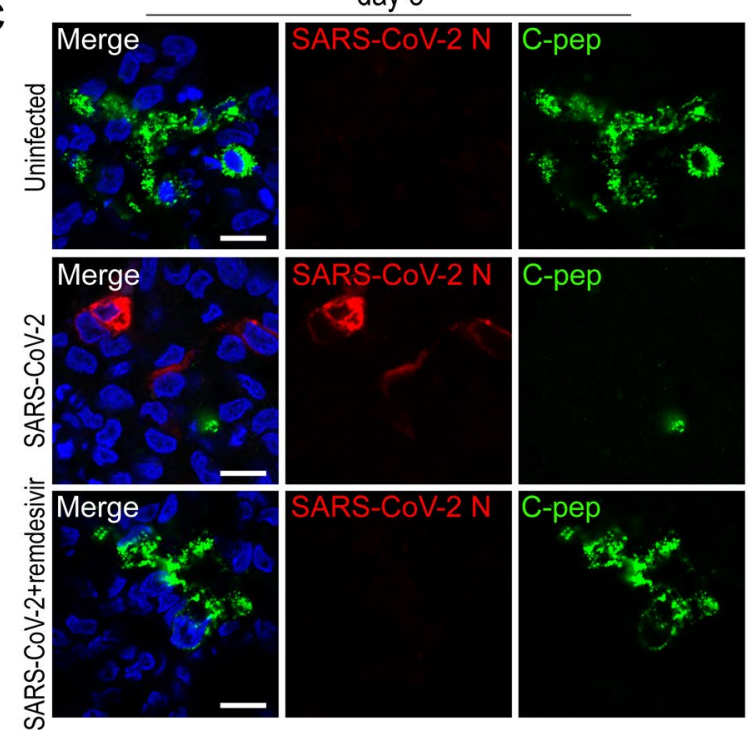

day 3

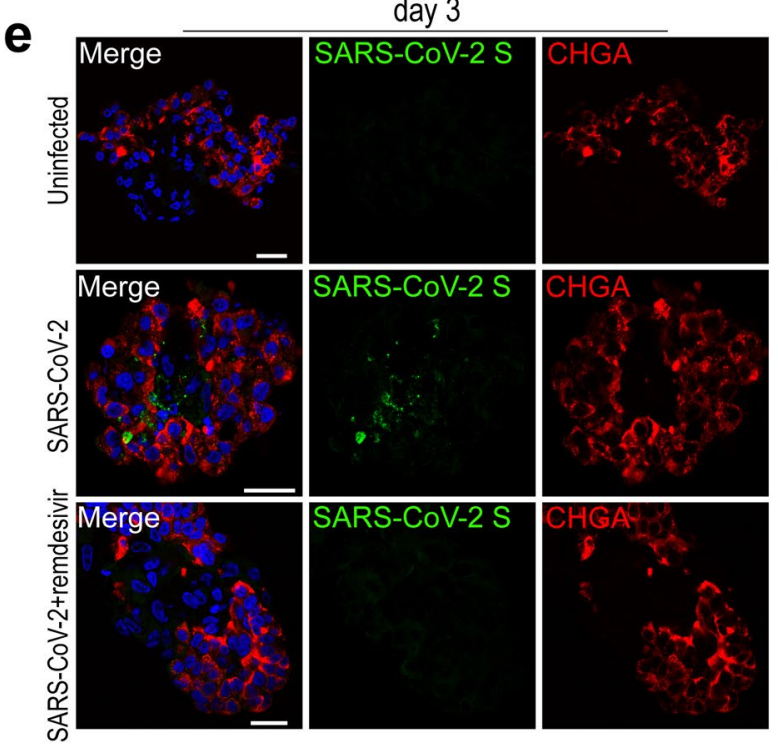

b

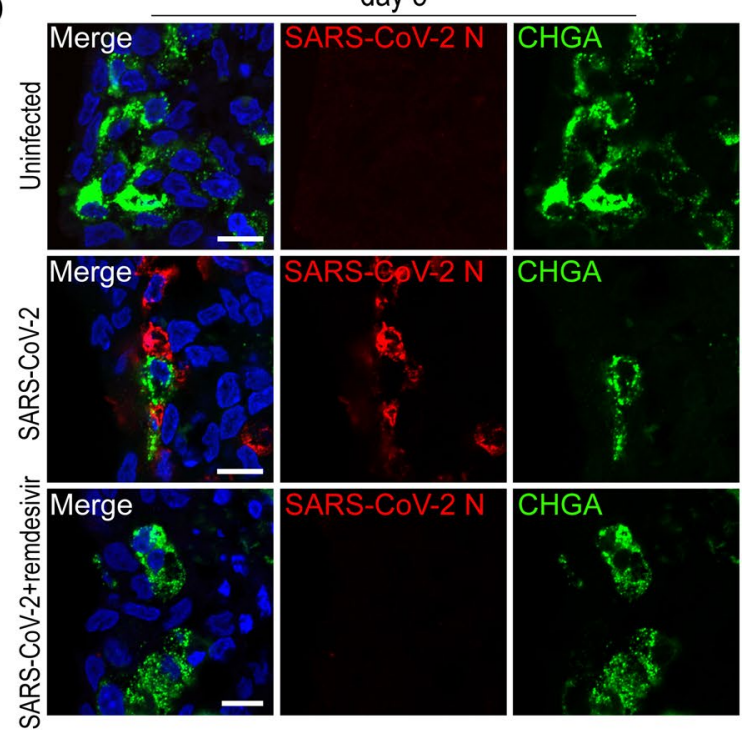

d

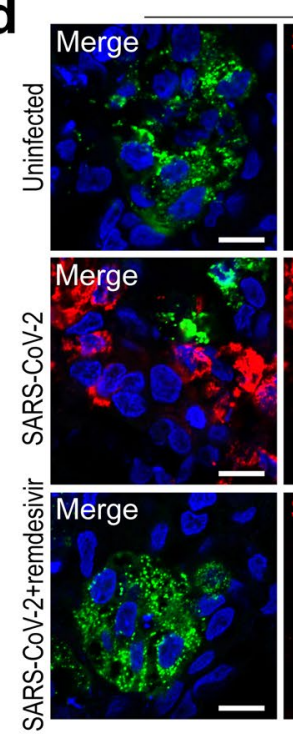

day 5

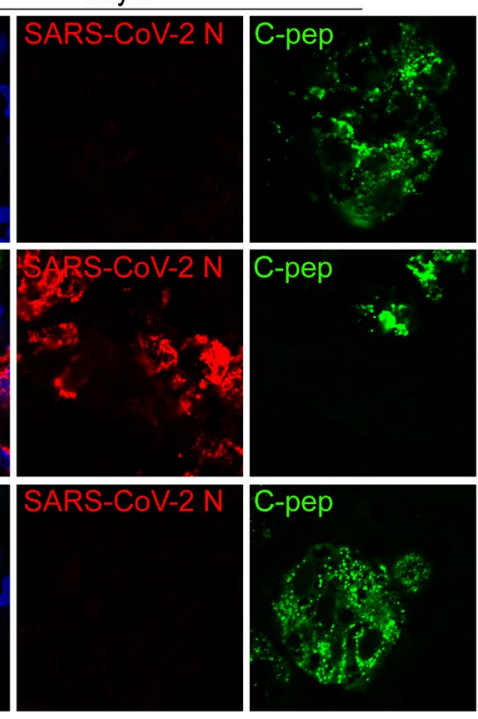

day 3

f

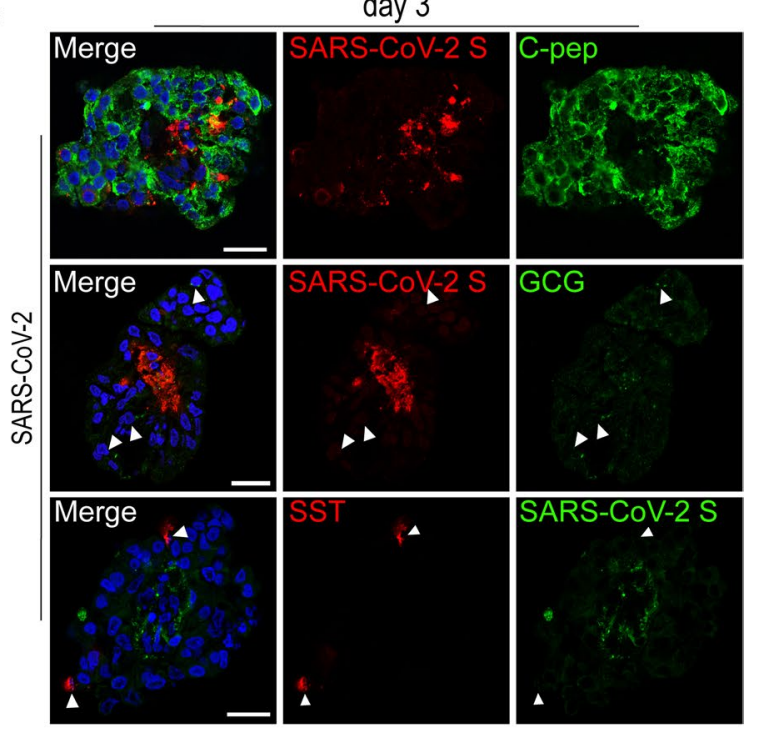


Extended Data Fig. $\mathbf{5}$ | SARS-CoV-2 infects $\boldsymbol{\beta}$-cells of pancreatic islets. Human pancreatic islets were inoculated with SARS-CoV-2 and cultivated with or without $5 \mu \mathrm{M}$ remdesivir. Mock-infected islets served as control. (a,b) At day $3($ a) and 5 (b), islets of donor 3 were histologically analyzed for chromogranin A (CHGA, green), SARS-CoV-2 N protein (red) and cell nuclei (DAPI, blue). Representative images are shown, scale bars depict $10 \mu \mathrm{m}$. (c,d) Islets of donor 3 fixed after 3 (c) and 5 (d) days post infection were additionally stained for C-peptide (C-pep, green) and SARS-CoV-2 N protein (red). Representative images are shown, scale bars depict $10 \mu \mathrm{m}$. (e,f) Islets of donor 1 (day 3 post infection) were stained for chromogranin A (CHGA, red), C-peptide (C-pep, green), glucagon (GCG, green) or somatostatin (SST, green), and SARS-CoV-2 S protein (green/red). Arrows indicate $\alpha$ - and $\delta$-cells; scale bars represent $20 \mu \mathrm{m}$. Representative images in a-f were selected from at least 4 pancreatic islets. 
a
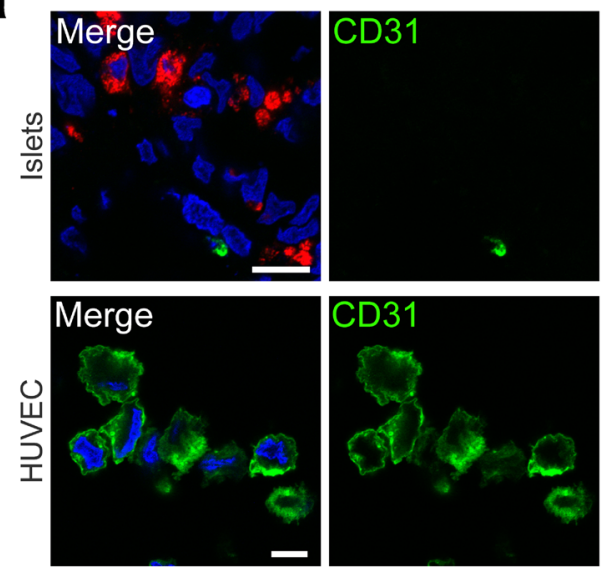

b

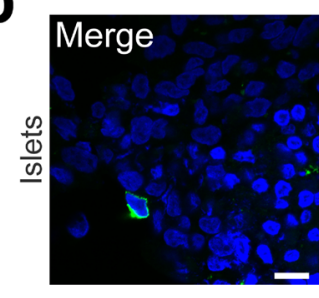

C

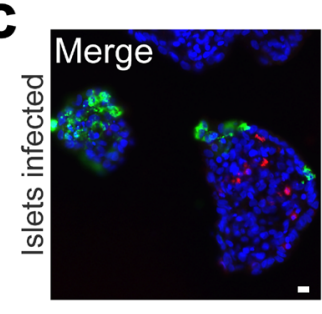

d
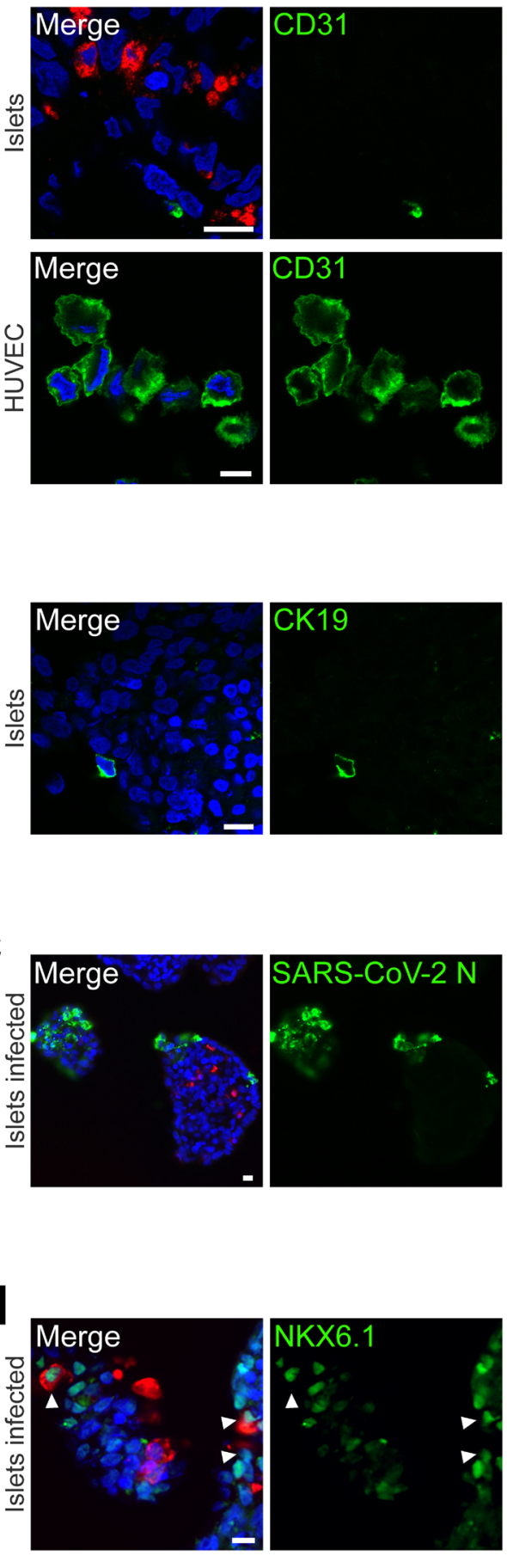

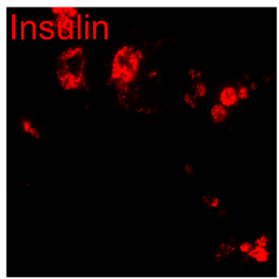

Insulin
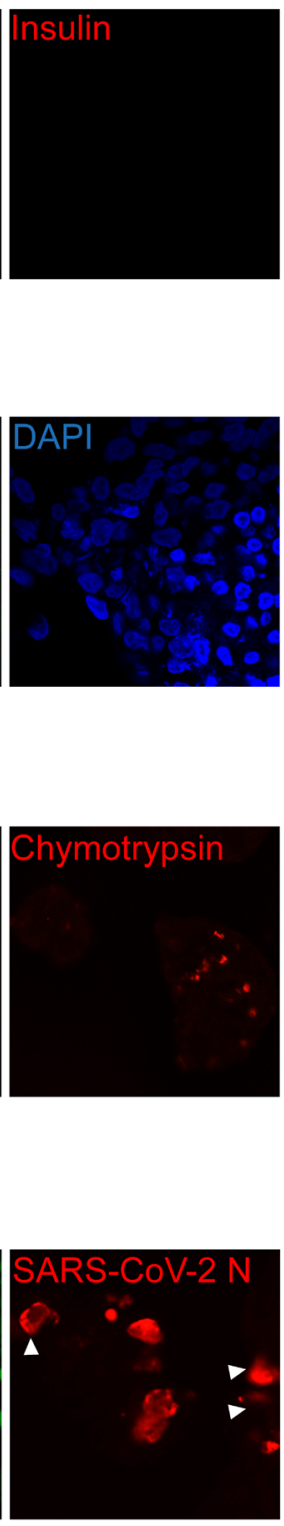

e

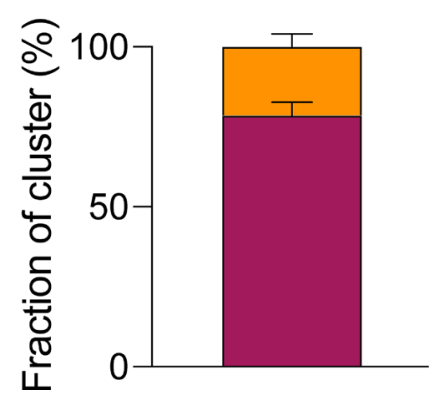

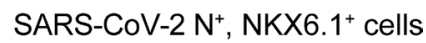

SARS-CoV-2 N-, NKX6.1+ cells 
Extended Data Fig. 6 | Islet preparations contain only few non-endocrine cells. (a) Infected pancreatic islets of donor 3 were stained for endothelial marker CD31 (green) and insulin (red) and compared to primary human umbilical vein endothelial cells (HUVEC) cells as positive control. Cell nuclei were visualized by DAPI (blue). (b) Pancreatic islets were stained for pancreatic ductal marker cytokeratin 19 (CK19, green) and cell nuclei were visualized by DAPI (blue). (c) Infected pancreatic islets were co-stained for pancreatic acinar cell marker chymotrypsin (red) and viral N protein (green). Representative laser-scanning confocal images selected from at least 4 pancreatic islets are shown, scale bars depict $10 \mu \mathrm{m}$ (a-c). (d) Infected pancreatic islets of donor 3 (day 5) were co-stained for pancreatic $\beta$-cell marker NKX6.1 (green) and viral SARS-CoV-2 N protein (red). Cell nuclei were stained with DAPI (blue). Representative fluorescence images selected from 11 pancreatic islets are shown, scale bars depict $10 \mu \mathrm{m}$. (e) Fraction of NKX6.1 and N protein double-positive cells were quantified in infected islet clusters of donor 3 . Data are presented as mean values \pm s.e.m. from 11 individual islet clusters positive for $\mathrm{N}$ protein. 

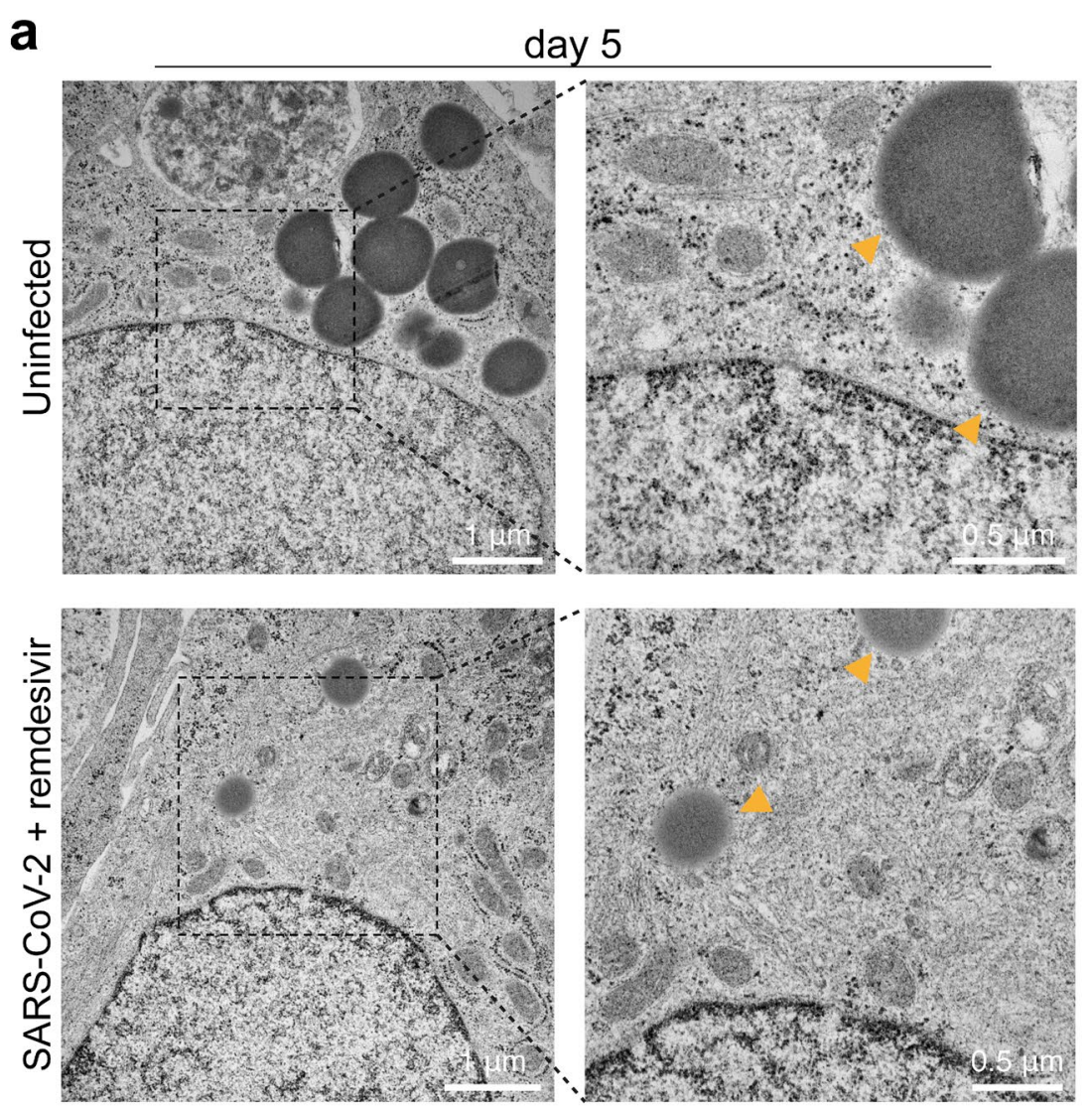

\section{b}

day 5
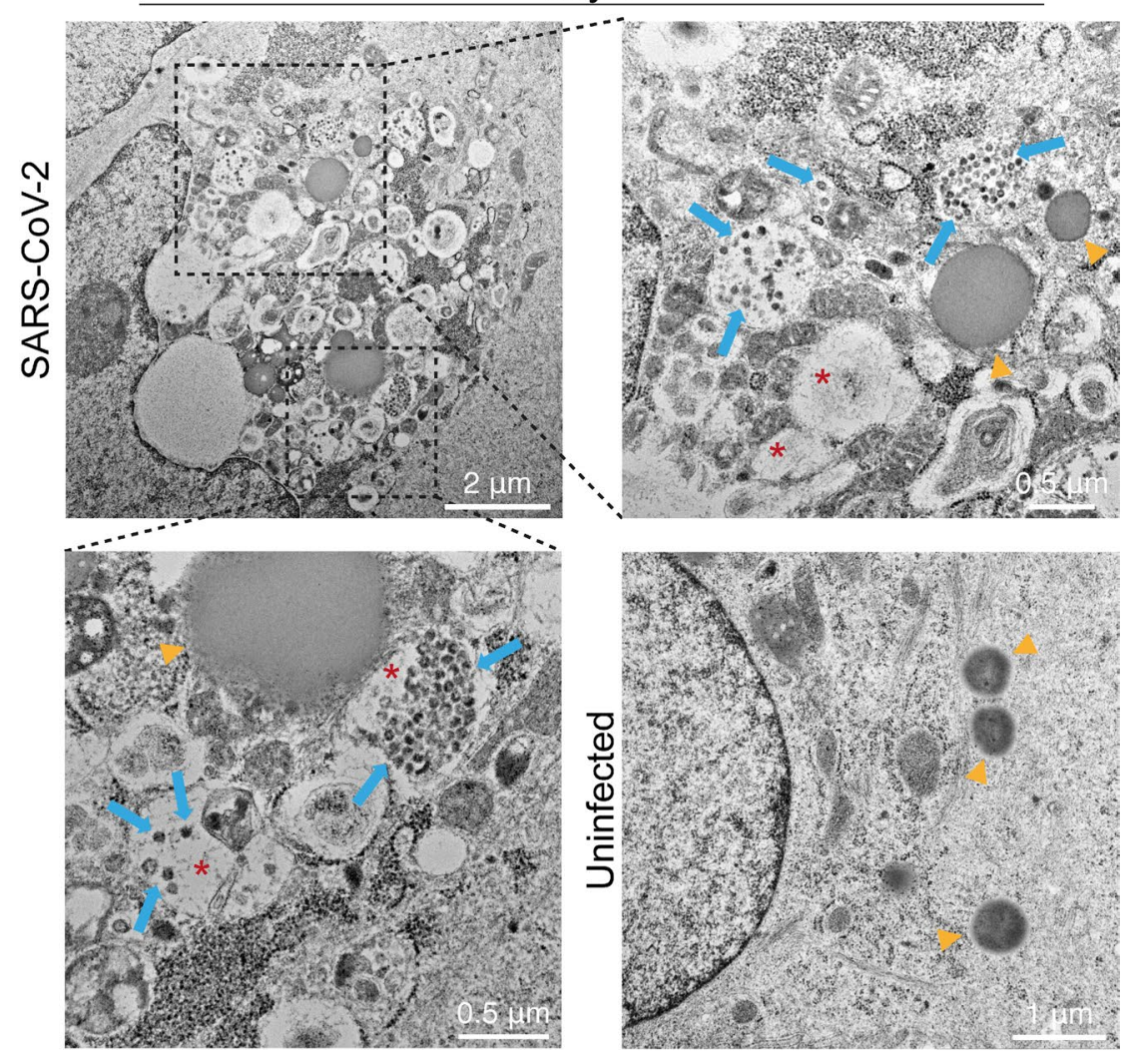

Extended Data Fig. 7 | See next page for caption. 
Extended Data Fig. 7 I Transmission electron microscopy images of SARS-CoV-2 infected human islets. Human pancreatic islets of donors 2 and 3 were infected with SARS-CoV-2 and cultivated with or without $5 \mu \mathrm{M}$ of remdesivir, or left uninfected, and prepared for electron microscopy 5 days post infection. (a) Uninfected or remdesivir treated donor 3 islets at similar magnification as shown for SARS-CoV-2-infected cells (see Fig. 3a). Electron micrographs and magnified inlets show cytoplasmic structures containing secretory vesicles (orange arrowheads). (b) SARS-CoV-2 exposed islets from donor 2 show cells with endocrine secretory vesicles (orange arrowheads) and vacuoles (red asterisks) containing viral particles (blue arrows). Vacuoles and viral particles were absent in the uninfected sample. Representative electron micrographs were selected from at least 5 images. 
a

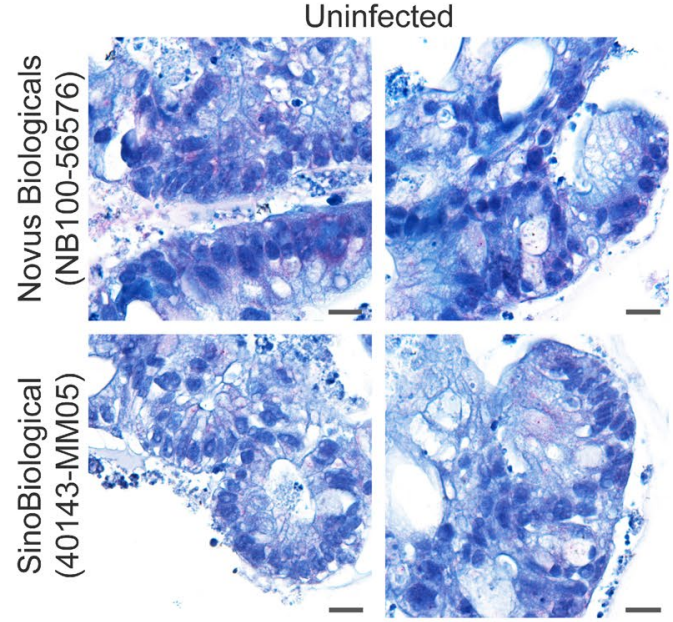

SARS-CoV-2

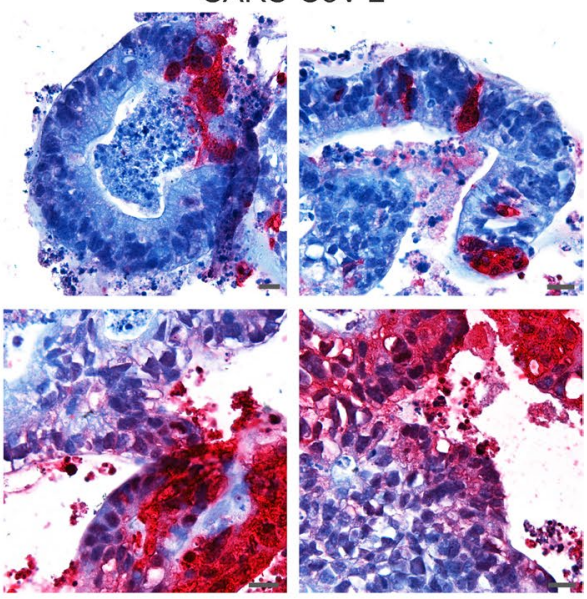

b Novus Biologicals (NB100-56576)
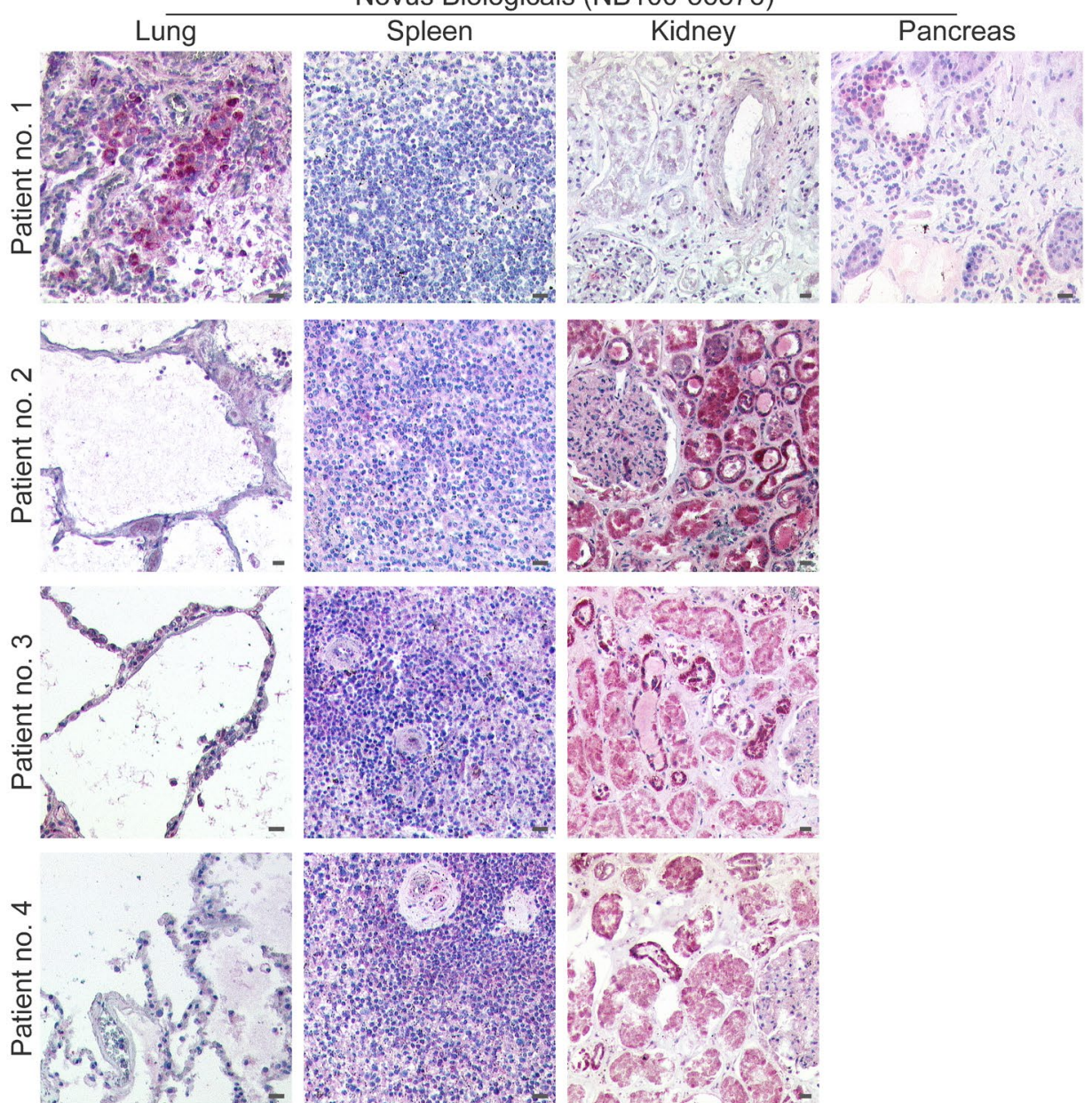

C

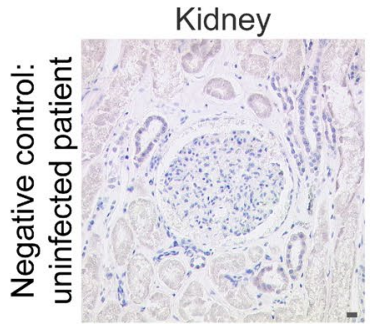

Extended Data Fig. 8 | See next page for caption. 
Extended Data Fig. 8 | Validation of antibodies for IHC stainings. (a) Uninfected or SARS-CoV-2 infected human pluripotent stem cell derived intestinal organoids were immunohistochemically stained for N protein using both the SinoBiological (40143-MM05) and the Novus Biologicals (NB100-56576) anti-N protein antibodies. (b) Tissue sections from infected patients 1 - 4 were stained for SARS-CoV-2 N protein using an antibody from Novus Biologicals (NB100-56576). (c) Kidney tissue sections from an uninfected patient were stained for SARS-CoV-2 N protein (NB100-56576) serving as negative control. Representative images were selected from at least 4 regions per tissue section and patient, scale bars represent $20 \mu \mathrm{m}$. 

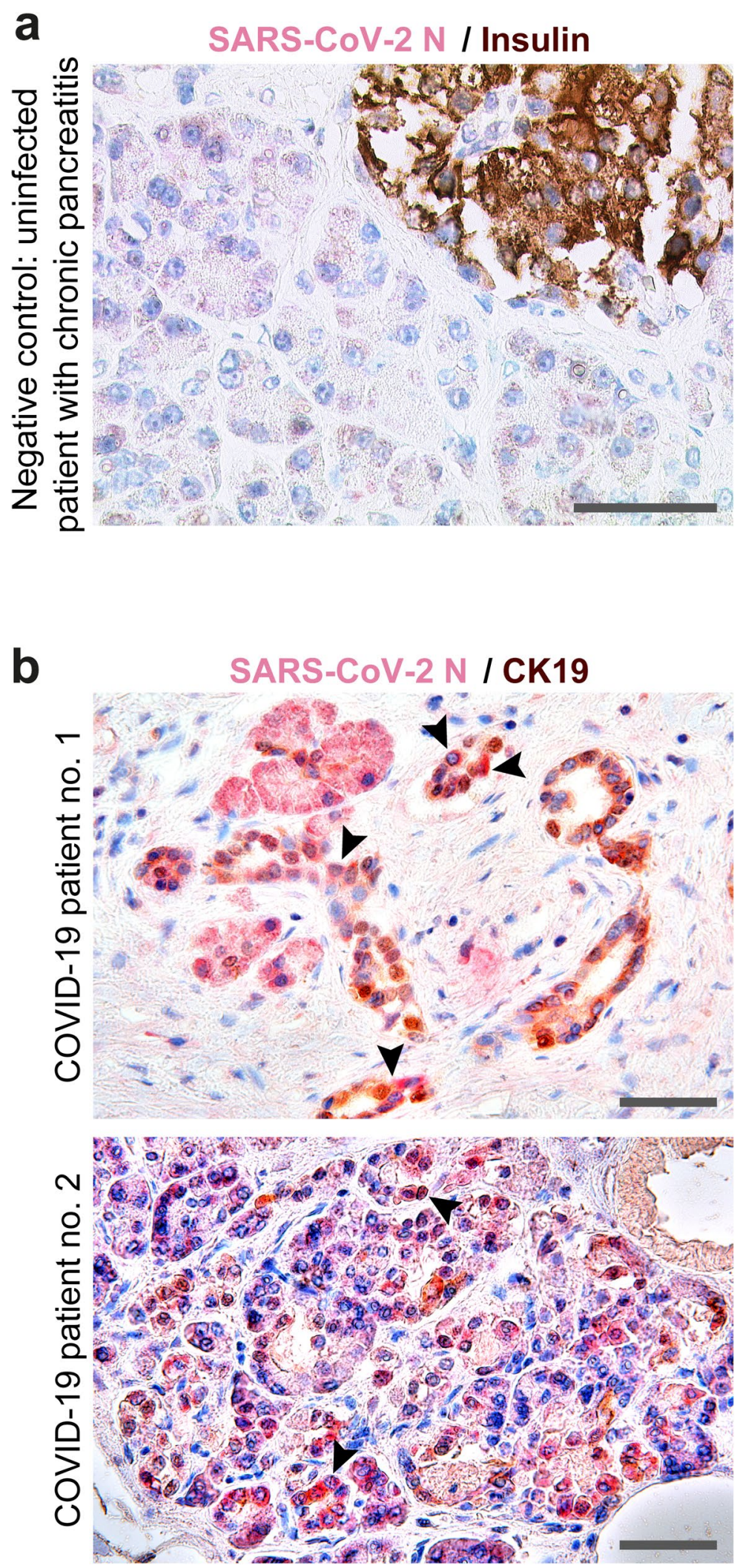

Extended Data Fig. 9 | SARS-CoV-2 infects pancreatic ductal cells. (a) Pancreatic tissue of a non-infected patient with chronic pancreatitis was immunohistochemically co-stained for insulin (brown) and viral $\mathrm{N}$ protein (red). (b) Tissue sections of pancreata from patient 1 and 2 were co-stained for SARS-CoV-2 N protein (red) and ductal marker cytokeratin 19 (CK19, brown). Representative images were selected from at least 4 regions of tissue section per patient, scale bars represent $50 \mu \mathrm{m}$. 
a SARS-CoV=2 N / NKX6.1
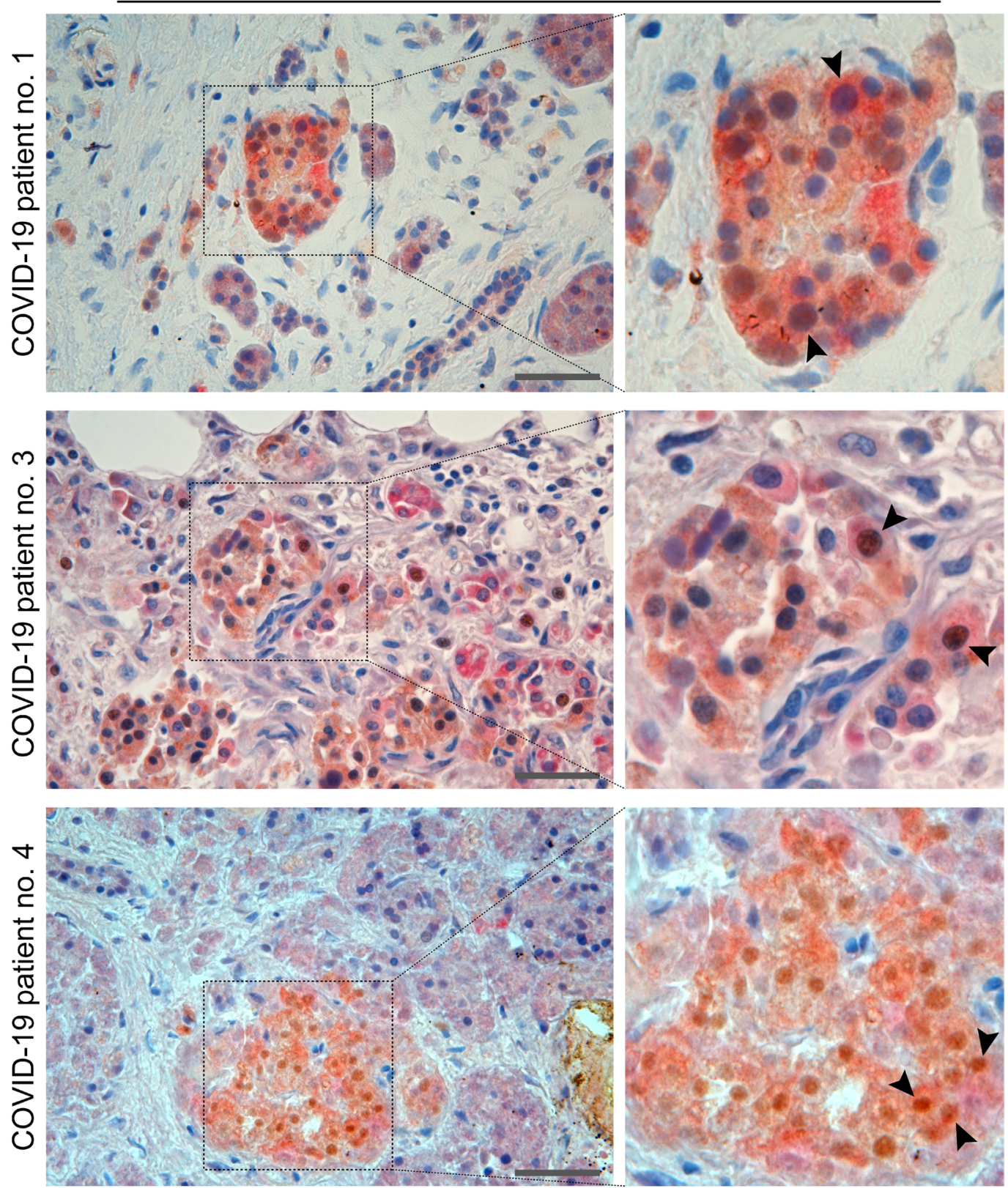

b

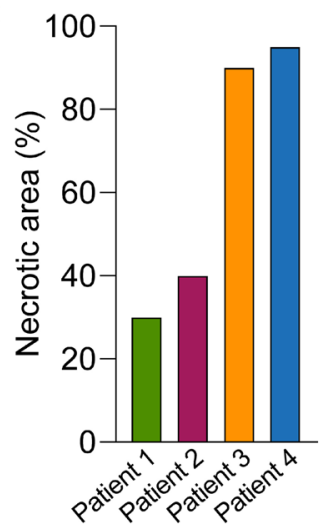

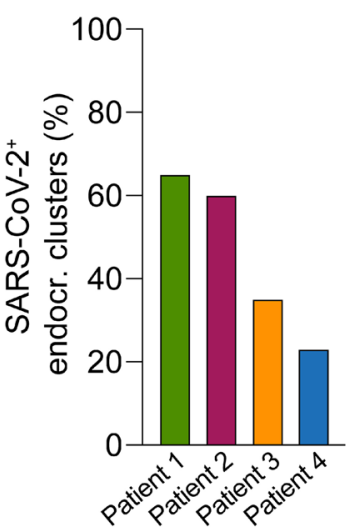


Extended Data Fig. 10 | NKX6.1- and N protein double-positive cells in COVID-19 deceased patients. (a) Pancreatic tissue sections from three different COVID-19 deceased patients $(1,3,4)$ were stained for SARS-CoV-2 N protein (red), and NKX6.1 (brown). Left columns represent overview images. Rectangles mark areas of higher magnification in the next column. N-positive cells frequently display nuclear NKX6.1 staining marked with arrow heads in areas representing metaplastic islets. Representative images were selected from at least 4 pancreatic islets per patient, scale bars depict $50 \mu \mathrm{m}$.

(b) Pancreatic tissue sections stained for SARS-CoV-2 N and NKX6.1 were evaluated for percentage of necrotic area and infected clusters in non-necrotic areas. 


\section{Reporting Summary}

Nature Research wishes to improve the reproducibility of the work that we publish. This form provides structure for consistency and transparency in reporting. For further information on Nature Research policies, see our Editorial Policies and the Editorial Policy Checklist.

\section{Statistics}

For all statistical analyses, confirm that the following items are present in the figure legend, table legend, main text, or Methods section.

n/a Confirmed

\The exact sample size $(n)$ for each experimental group/condition, given as a discrete number and unit of measurement

\ A statement on whether measurements were taken from distinct samples or whether the same sample was measured repeatedly

The statistical test(s) used AND whether they are one- or two-sided

Only common tests should be described solely by name; describe more complex techniques in the Methods section.

$\bigotimes$ A description of all covariates tested

$\bigotimes$ A description of any assumptions or corrections, such as tests of normality and adjustment for multiple comparisons

A full description of the statistical parameters including central tendency (e.g. means) or other basic estimates (e.g. regression coefficient)

AND variation (e.g. standard deviation) or associated estimates of uncertainty (e.g. confidence intervals)

区

For null hypothesis testing, the test statistic (e.g. $F, t, r)$ with confidence intervals, effect sizes, degrees of freedom and $P$ value noted Give $P$ values as exact values whenever suitable.

For Bayesian analysis, information on the choice of priors and Markov chain Monte Carlo settings

$\bigotimes$ For hierarchical and complex designs, identification of the appropriate level for tests and full reporting of outcomes

$\bigotimes$ Estimates of effect sizes (e.g. Cohen's $d$, Pearson's $r$ ), indicating how they were calculated

Our web collection on statistics for biologists contains articles on many of the points above.

\section{Software and code}

Policy information about availability of computer code

Data collection Expression profiling libraries were sequenced on HiSeq 3000/4000 instruments (Illumina, San Diego, CA, USA) following 50-base-pair, singleend recipe. Raw data acquisition (HiSeq Control Software, HCS, HD 3.4.0.38) and base calling (Real-Time Analysis Software, RTA, 2.7.7) was performed on-instrument.

Data analysis Sequencing and Raw Data Processing

For raw data processing off the instruments, code for two custom programs based on Picard tools (2.19.2) is available at https://github.com/ DanieleBarreca/picard/ and https://broadinstitute.github.io/picard/.

Transcriptome Analysis

NGS reads were mapped to the Genome Reference Consortium GRCh38 assembly via "Spliced Transcripts Alignment to a Reference" (STAR, 2.7.5a) utilising the "basic" Ensembl transcript annotation from version e100 (April 2020) as reference transcriptome. Ensembl transcript annotation had to be adjusted to UCSC Genome Browser sequence region names. Aligned NGS reads overlapping Ensembl transcript features were counted with the Bioconductor (3.11) GenomicAlignments::summarizeOverlaps() function (1.24.0). Bioconductor DESeq2 package

(1.28.1) was used to test for differential expression based on a model using the negative binomial distribution.

An initial exploratory analysis included CRAN ggplot2 3.3.2, Bioconductor ComplexHeatmap 2.4.3 as well as Bioconductor EnhancedVolcano 1.6.0. Sample distance heatmaps were obtained via the CRAN pheatmap package. Biologically meaningful results were extracted from the model, log2-fold values where shrunk with the CRAN ashr package (2.2-47) and p-values were adjusted with the Bioconductor Independent Hypothesis Weighting (IHW, 1.16.0) package. g:Profiler [version: e100_eg47_p14 7733820] was applied to test enrichment of significantly differentiated genes against gene sets in common databases, EnrichR allowed expansion to COVID-19 related disease terms (Enrichr). For gene set enrichment analysis gsea desktop tool was used (GSEA version 4.0.3). Enrichment was tested against hallmark gene sets from MSigDB 7.2. 
If not stated otherwise, statistical analyses were performed using GraphPad Prism version 8.4.2, GraphPad Software, San Diego, California USA, www.graphpad.com.

For manuscripts utilizing custom algorithms or software that are central to the research but not yet described in published literature, software must be made available to editors and reviewers. We strongly encourage code deposition in a community repository (e.g. GitHub). See the Nature Research guidelines for submitting code \& software for further information.

\section{Data}

Policy information about availability of data

All manuscripts must include a data availability statement. This statement should provide the following information, where applicable:

- Accession codes, unique identifiers, or web links for publicly available datasets

- A list of figures that have associated raw data

- A description of any restrictions on data availability

RNA-Seq data (Fig.4) have been deposited in NCBI's Gene Expression Omnibus under GEO Series accession number GSE159717 (https://www.ncbi.nlm.nih.gov/geo/ query/acc.cgi?acc=GSE159717) and will be accessible upon publication.

For gene set enrichment, an additional beta cell gene cluster was derived from: Ackermann, A. M., Wang, Z., Schug, J., Naji, A. \& Kaestner, K. H. Integration of ATACseq and RNA-seq identifies human alpha cell and beta cell signature genes. Mol Metab 5, 233-244, doi:10.1016/j.molmet.2016.01.002 (2016)

Additional data that support the findings of this study are available from the corresponding authors upon request. Furthermore, source data are provided with this paper.

\section{Field-specific reporting}

Please select the one below that is the best fit for your research. If you are not sure, read the appropriate sections before making your selection. $\bigotimes$ Life sciences $\quad \square$ Behavioural \& social sciences $\quad \square$ Ecological, evolutionary \& environmental sciences

For a reference copy of the document with all sections, see nature.com/documents/nr-reporting-summary-flat.pdf

\section{Life sciences study design}

All studies must disclose on these points even when the disclosure is negative.

Sample size No statistical methods were used to calculate sample size for our biological experiments. Sample size was limited through availability (e.g. number of islet donors or deceased COVID patients) and respective statements on limited sample size is discussed in the manuscript.

Data exclusions We did not exclude data from analysis.

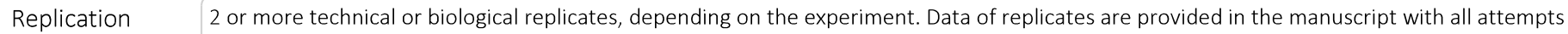
being successful.

Randomization Donor-derived pancreatic islet preparations of each donor containing a suspension of individual islets were equally divided into treatment groups (uninfected, infected, remdesivir) not requiring randomization. Additional biopsy samples of COVID-19 and uninfected patients were not devided into study groups and therefore, not requiring randomization.

Blinding Data analyses were not blinded since data analysis was based on quantitative measurements.

Endocrine secretory vesicles were manually identified by two independent individuals and quantified blinded using Fiji (Fig.3).

\section{Reporting for specific materials, systems and methods}

We require information from authors about some types of materials, experimental systems and methods used in many studies. Here, indicate whether each material, system or method listed is relevant to your study. If you are not sure if a list item applies to your research, read the appropriate section before selecting a response.

Materials \& experimental systems

$\mathrm{n} / \mathrm{a}$ Involved in the study

$\bigotimes$ Antibodies

Eukaryotic cell lines

Х Palaeontology and archaeology

Х $\square$ Animals and other organisms

$\square$ Human research participants

Х $\square$ Clinical data

$\triangle \square$ Dual use research of concern

\begin{tabular}{l|l} 
Methods \\
\hline n/a & Involved in the study \\
$\searrow$ & $\square$ ChIP-seq \\
$\searrow$ & $\square$ Flow cytometry \\
$\searrow$ & $\square$ MRI-based neuroimaging
\end{tabular}


C-peptide Guinea-pig ; Abcam; ab30477; 1:200; IF

Glucagon; mouse; Sigma; G2654; 1:500; FC, IF

ACE2; rabbit; Abcam; ab15348; 1:1,500; IF, 1:1000 WB, 1:750 (HAECS)

ACE2 blocking peptide; synthetic; Abcam; ab15352

SARS-CoV-2 Spike; rabbit; Abcam; ab252690; 1:500; IF

SARS-CoV-2 Spike; mouse; Biozol; GTX632604; 1:500; IF

SARS-CoV-2 nucleocapsid; rabbit; Novus Biologicals; NB100-56576; 1:1000 IF, 1:100 IHC

SARS-CoV-2 nucleocapsid; mouse; Sinobiological; 40143-MM05; 1:500 IF, 1:100 IHC

TMPRSS2; rabbit; Abcam; ab92323; 1:250; IF

CASP3; rabbit; Cell Signaling; \#9664; 1:1,000; IF, FC

CHGA; rabbit; DAKO; A0430; 1:500; IF

Somatostatin; mouse; Santa Cruz; sc-74556; ; 1:100 IF

CK19; mouse; DAKO; RCK108; 1:100

CD31; mouse; DAKO; M0823; 1:35

Chymotrypsin; mouse; Millipore; MAB1476; 1:1000

GATA4; mouse; BD Bioscience; 560327; 1:50

Insulin; rabbit; Abcam; ab181547; 1:5000

NKX6.1; mouse; DSHB; F55A12 conc. ; 1:125

PDX1; goat; R\&D; AF2419; 1:100

alpha-tubulin; rat; Thermo Fisher; MA1-80017; 1:500

GAPDH; rat; Biolegend; 607902; 1:5000

GAPDH; human; Biorad; 12004168; 1:5000

Secondary antibodies:

Alexa Fluor donkey anti-rat/mouse/goat/rabbit 488/468/647; Invitrogen; 1:500

The Primary antibodies against ACE2 and TMPRSS2 were validated by overexpression of the protein in HEK293T cells followed by IF staining and Western Blot. Furthermore, ACE2 signal was efficiently inhibited by using a specific blocking peptide.

Antibodies against SARS-CoV-2 spike and SARS-CoV-2 N protein were validated in a SARS-CoV-2 gut organoid model. Infected and uninfected organoids embedded in paraffin served as positive and negative controls for IHC stainings.

Other Primary antibodies used for this study were recommended for the applications by the manufacturer (see manufacturer statements) and used in previous publications. Relevant articles are:

C-peptide: Lee et al. (2020) Beta Cell Dedifferentiation Induced by IRE1 $\alpha$ Deletion Prevents Type 1 Diabetes Cell Metab 7;31(4):822-836.e5

C-Peptide: Wang X et al. Point mutations in the PDX1 transactivation domain impair human B-cell development and function. Mol Metab 24:80-97 (2019)

Glucagon: Habegger K M, et al. (2010) The metabolic actions of glucagon revisited. Nature reviews. Endocrinology 6(1), 689-689 Nicin L et al. (2020)

ACE2: Cell type-specific expression of the putative SARS-CoV-2 receptor ACE2 in human hearts. Eur Heart J 41:1804-1806 Benjamin T Bradley et al. Lancet 2020; S0140-6736 (20):31305-2

SARS-CoV-2 nucleoprotein: Leist SR, Dinnon KH, SchAfer A et al. A Mouse-Adapted SARS-CoV-2 Induces Acute Lung Injury and Mortality in Standard Laboratory Mice Cell Sep 232020 [PMID: 33031744]

SARS-CoV-2 nucleoprotein: Molecular Detection of SARS-CoV-2 in Formalin Fixed Paraffin Embedded Specimens Zeng, X;Liu, J;Babka, A; Kearney, B;Radoshitzky, 2020; bioRxiv

TMPRSS2: Ubuka T et al. (2018) Identification of Transmembrane Protease Serine 2 and Forkhead Box A1 As the Potential Bisphenol CASP3: Allison S Cohen, et. al. Combined blockade of EGFR and glutamine metabolism in preclinical models of colorectal cancer. Transl Oncol, 2020

CHGA: Shinji, S., Sasaki, N., et al. (2019) Establishment and characterization of a novel neuroendocrine carcinoma cell line derived from a human ascending colon tumor. Cancer Science

Somatostatin: Saxena P, Heng BC, Bai P, Folcher M, Zulewski H, Fussenegger M. A programmable synthetic lineage-control network that differentiates human IPSCs into glucose-sensitive insulin-secreting beta-like cells. Nat Commun. 2016 Apr 11;7:11247. doi: 10.1038/ncomms11247.

CK19: Dalal P, Shousha S. Keratin 19 in paraffin sections of medullary carcinoma and other benign and malignant breast lesions. Mod Pathol 1995,8:413-6.

CD31: Parums DV, Cordell JL, Micklem K, Heryet AR, Gatter KC, Mason DY. JC70: a monoclonal antibody that detects vascular endothelium associated antigen on routinely processed tissue sections. J Clin Pathol 1990,43:572-7. 
Chymotrypsin: Pancreatic serous microcystic adenoma with extensive oncocytic change.

Takashi Akiyama, Yoshito Sadahira,Isao Irei,Hirotake Nishimura,Akira I Hida,Kenji Notohara,Shuji Hamazaki Pathology international

GATA4: Viger RS, Guittot SM, Anttonen M, Wilson DB, Heikinheimo M. Role of the GATA family of transcription factors in endocrine development, function, and disease. Mol Endocrinol. 2008; 22(4):781-789.

Insulin: Liu Q et al. Zwitterionically modified alginates mitigate cellular overgrowth for cell encapsulation. Nat Commun 10:5262 (2019).

NKX6.1: Generation and characterization of monoclonal antibodies against the transcription factor Nkx6.1.

Jorgensen MC The journal of histochemistry and cytochemistry : official journal of the Histochemistry Society 54.5 (2006 May): 567-74.

Pdx1: Circadian Entrainment Triggers Maturation of Human In Vitro Islets, JR Alvarez-Do, J Donaghey, N Rasouli, JHR Kenty, A Helman, J Charlton, JR Straubhaar, A Meissner, DA Melton, Cell Stem Cell, 2019;26(1):108-122.e10.

alpha-tubulin: Jiang K, Faltova L, Hua S, Capitani G, Prota AE, Landgraf C, Volkmer R, Kammerer RA, Steinmetz MO, Akhmanova A. Structural Basis of Formation of the Microtubule Minus-End-Regulating CAMSAP-Katanin Complex. Structure. 2018 Mar 6;26(3):375-382.e4. doi: 10.1016/j.str.2017.12.017.

\section{Eukaryotic cell lines}

Policy information about cell lines

Cell line source(s)

Caco-2 (Cell Lines Services (CLS) \# 300137), Vero E6 (ATCC ${ }^{\circledR}$ CRL-1586 ${ }^{\mathrm{TM}}$ ), HEK293T (ATCC), HUES8 (Harvard university) with permission from the Robert Koch Institute according to the "79. Genehmigung nach dem Stammzellgesetz, AZ

3.04.02/0084" , HUVEC (ATCC), Endo-beta-H1 cell line acquired from Scharfmann lab, Calu-3 (ATCC); HAECs (generated from primary basal epithelial cells obtained from several donors, all experiments were performed with approval of the ethics committee of Hannover Medical school; Project no. 2701-2015)

Authentication

Cell lines were recently purchased from the indicated companies, expanded and aliquoted for experimental use. No further authentication was performed.

For HUES8, a DNA profile generated at 8 STR regions using nonaplex PCR was compared to the parental profile (reference databases) and confirmed the authenticity of the cell line. Pluripotency of human embryonic stem cells and human induced pluripotent stem cells was tested through the expression of pluripotency-associated markers.

Mycoplasma contamination

All cell lines are regularly tested for mycoplasma contamination. For cell lines used within this manuscript, test results were negative for contamination.

Commonly misidentified lines

(See ICLAC register)

No commonly misidentified cell lines were used.

\section{Human research participants}

Policy information about studies involving human research participants

Population characteristics

Four preparations of human pancreatic islets were obtained from the Alberta Diabetes Institute IsletCore at University of Alberta. Islet material is derived from excess donor organs used for clinical transplantation and with the written informed consent for research.

The first donor ( $95 \%$ purity), female, 31 years old, had a BMI of 20.3 and had no history of diabetes (HbA1C: $4.8 \%$ ). The second donor ( $50 \%$ purity), female, 55 years old, had a BMI of 29.1 and no history of diabetes (HbA1C: not given). The third donor (45\% purity), male, 58 years old, had a BMI of 31 and no history of diabetes (HbA1C: $5.6 \%$ ). The fourth donor (90\% purity), female, 53 years old, had a BMI of 33.2 and no history of diabetes (HbA1C: $6.1 \%$ ).

Sections of human pancreas were provided by the pathology department of Ulm University. Non-neoplastic pancreatic tissue integrity was approved by a board-certified pathologist. Patient tissue samples were provided by the tissue bank of the German Center for Infection Research and of the Institute of Pathology, UIm University. Patient characteristics are provided in Table 1 of the manuscript.

Recruitment

Islet material is derived from excess donor organs used for clinical transplantation and highly depends on donor availability. Only non-diabetic donors were selected for this study. Islet preparation purity determines amount of endocrine vs exocrine tissue. Contamination with exocrine tissue might influence testing of beta cell function (GSIS) as well as infectability with virus.

Ethics oversight

Islet material is derived from excess donor organs used for clinical transplantation and with the written informed consent for research (Alberta Diabetes Institute IsletCore at University of Alberta, approval \#Pro00013094). This study was also approved by "Ethikkommission TUM" (\#394/20 S).

Experiments were conducted in accordance with guidelines of the Ethics Committee of the Federal General Medical Council and approved by the Ethics Committee of the University of Ulm (vote for usage of archived human material 03/2014) and DZIF, Heidelberg, Germany (approval S242/2020) 